
of Engineers ${ }_{\circledast}$

Engineer Research and

Development Center

\title{
West Closure Complex Pump Intake Model, New Orleans, Louisiana
}

Stephen T. Maynord

February 2013

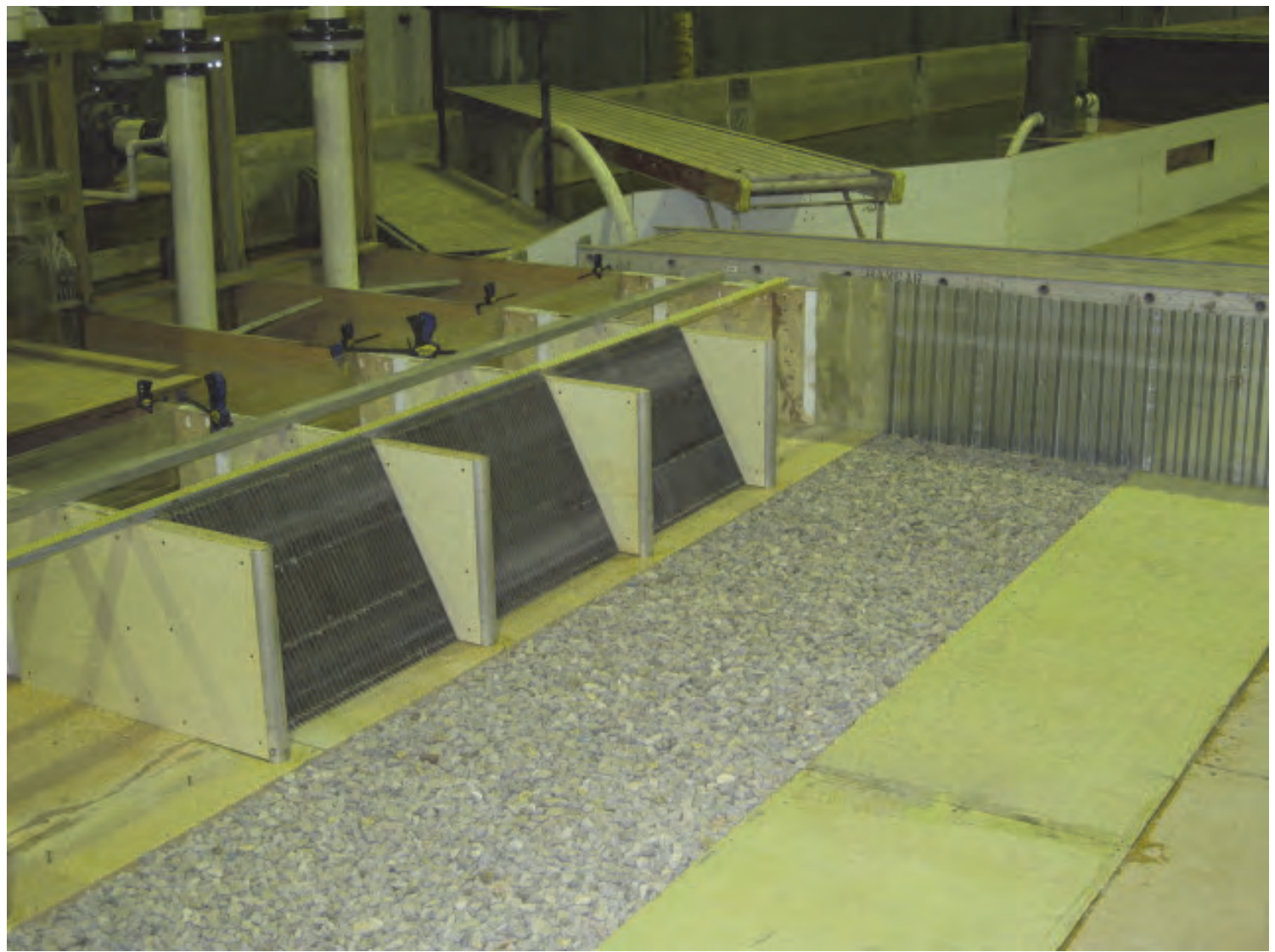


The US Army Engineer Research and Development Center (ERDC) solves the nation's toughest engineering and environmental challenges. ERDC develops innovative solutions in civil and military engineering, geospatial sciences, water resources, and environmental sciences for the Army, the Department of Defense, civilian agencies, and our nation's public good. Find out more at www.erdc.usace.army.mil.

To search for other technical reports published by ERDC, visit the ERDC online library at http://acwc.sdp.sirsi.net/client/default. 


\section{West Closure Complex Pump Intake Model, New Orleans, Louisiana}

Stephen T. Maynord

Coastal and Hydraulics Laboratory

3909 Halls Ferry Road

Vicksburg, MS 39180-6199

Final report

Approved for public release; distribution is unlimited.

Prepared for U.S. Army Corps of Engineers

441 G Street, NW

Washington, DC 20314-1000 


\section{Abstract}

The WCC pump station intake was evaluated for intake performance using a 1:20-scale model of the approach channel, intake bays, contracted section, FSI, and pump column. Across the 11 different pump intakes, approach flow ranged from almost straight in to highly skewed. The original design of the contracted section was shown to have unacceptable submerged vortices. A fillet was added to eliminate a zone of low velocity and the submerged vortices were eliminated.

The recommended design consists of no flow divider wall, longer dividing walls, and contracted sections with fillet added to low velocity zone. Tests were conducted with various pump operating combinations ranging from all pumps to single pumps to pumps on each end to odd versus even pumps. Tests were conducted for a range of approach flow skew ranging from large to straight in. Intake water level was varied from the minimum of EL 0.0 to the maximum of EL 7.0. Swirl in the pump intake was always less than the $\mathrm{HI}$ Standard of five degrees and was a maximum of three degrees when 50 percent of the trash rack on one side of the pump bay was completely blocked. Submerged vortices were acceptable with the fillet added to the contracted section. Time averaged velocity distribution in the pump throat met the HI Standard of \pm 10 percent for all conditions including tests with 50 percent of the trash rack blocked on one side of the pump bay. Most measured velocity distributions met, and all but the trash rack blockage tests were within 1.0 percent of meeting, the more stringent velocity distribution requirement of \pm five percent used in some pump intake studies. Testing showed that the combination of the contracted section and the FSI were effective in limiting swirl and producing an acceptable velocity for highly skewed approach flow conditions.

DISCLAIMER: The contents of this report are not to be used for advertising, publication, or promotional purposes. Citation of trade names does not constitute an official endorsement or approval of the use of such commercial products. All product names and trademarks cited are the property of their respective owners. The findings of this report are not to be construed as an official Department of the Army position unless so designated by other authorized documents. 


\section{Contents}

Abstract................................................................................................................................. if

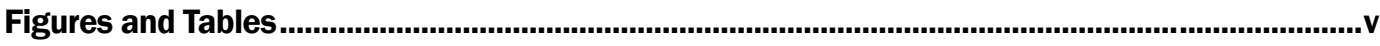

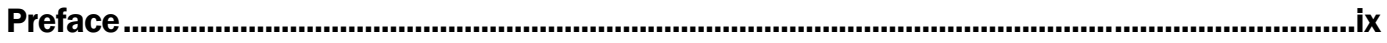

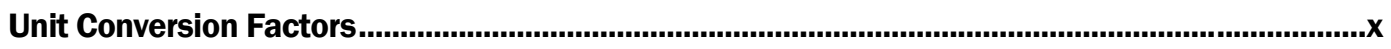

1 Introduction.................................................................................................................... 1

1.1 Background .................................................................................................. 1

1.2 Past formed suction intake pump stations ........................................................ 4

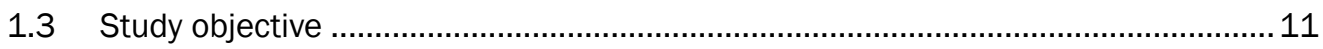

2 Physical Model: Design, Scaling Requirements, Description, and Inflow Calibration ........................................................................................................................12

2.1 Design of the pump station model ........................................................................ 12

2.2 Hydraulic Institute Standards for pump intake models ........................................ 13

2.3 Description of the 13-pump design ...................................................................... 18

2.4 Description of the 11-pump design ...................................................................... 23

2.5 Selection of flow divider wall length for initial model tests ...................................2 27

2.6 Calibration of Inflow Distribution in the Model ..................................................29

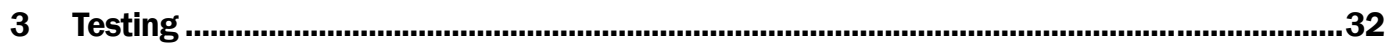

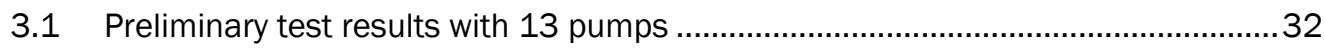

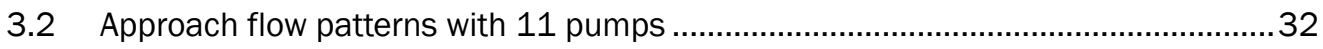

3.3 Flow divider wall between pumps and sluice gates ........................................... 41

3.4 Revision to contracted section to address submerged vortices............................42

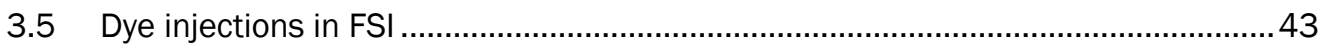

3.6 HI test results with short dividing walls ............................................................ 44

$3.7 \mathrm{HI}$ test results with correct dividing wall length ...............................................46

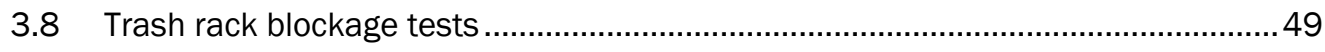

3.9 Water level difference across flow divider wall....................................................60

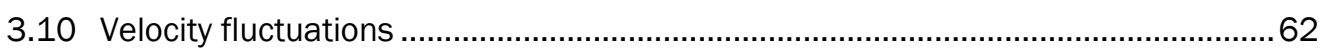

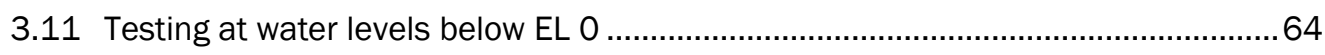

3.12 Testing with reduced flow divider wall length between sector gate and

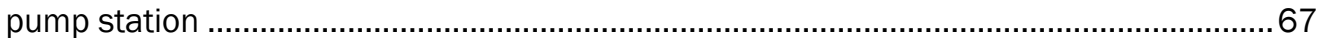

3.13 Testing at increased velocity to evaluate scale effects .......................................... 70

3.14 Keel coolers in intakes ....................................................................................... 71

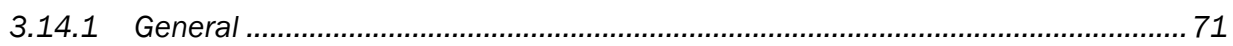

3.14.2 Intake bay velocity........................................................................................ 71

3.15 Intake performance with all keel coolers on floor ............................................... 75

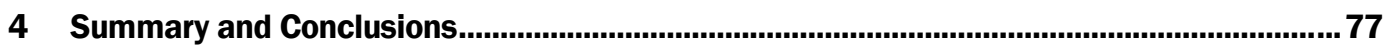




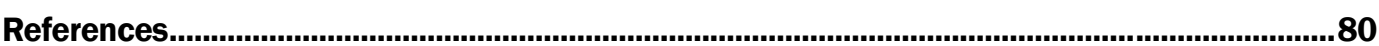

Report Documentation Page 


\section{Figures and Tables}

\section{Figures}

Figure 1. Location of WCC.

Figure 2. Project Layout of initial design. ....................................................................................... 2

Figure 3. Intake details showing dividing walls, contracted section, and Formed Suction

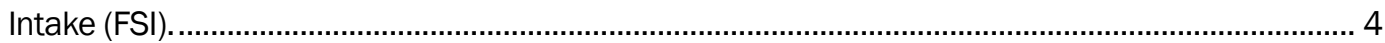

Figure 4. Type $10 \mathrm{FSI}$ design guidance from EM 1110-2-3105..................................................... 5

Figure 5. 17th Street Canal. Velocities in pump intake with FSI for Type 7 intake design, Type 1 grate, all 29 pumps operating, canal EL 2, pump W11-8. Flow approaches from

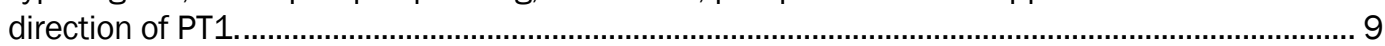

Figure 6. Isovels from Yazoo Pump Station Model....................................................................... 10

Figure 7. The HI standards for surface and ub-surface vortices (1998).......................................... 14

Figure 8. Swirl meter in 6-in. inside diameter acrylic pipe. ............................................................. 15

Figure 9. Schematic of Pitot tube locations.................................................................................. 17

Figure 10. Model Pitot tube array at top of FSI........................................................................... 17

Figure 11. Areas represented by each Pitot tube........................................................................... 18

Figure 12. View of original 13-pumps design looking downstream from upstream end of model.

Figure 13. View of original design station with 13 pumps looking downstream............................... 19

Figure 14. View looking downstream of contracted section and FSI in original design model. 20

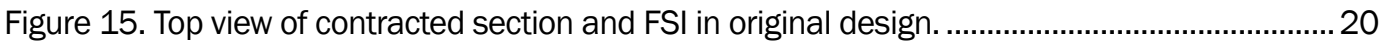

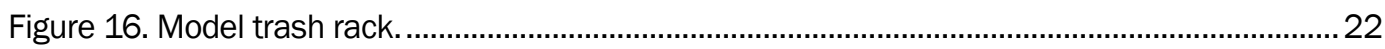

Figure 17. Approach walls used to guide flow from Algiers and Harvey Canals. ................................2

Figure 18. Revisions to approach channel and reduction from 13 to 11 pumps. Includes $300-\mathrm{ft}$ long flow dividing wall between sector gates and pump station and sluices between pump station and east bank....................................................................................... 24

Figure 19. View of revised approach channel looking downstream................................................. 24

Figure 20. View looking downstream of east bank at two unused pump bays, which are in the location of the sluices.

Figure 21. View looking west of east bank at two unused pump bays, which are in the location of the sluices.

Figure 22. Schematic of east bank area and potential wrap around of flow at the east dividing wall of the easternmost pump bay.

Figure 23. View showing model sheet pile wall used to form 300-ft long flow divider wall between the pump station and the sector gate.

Figure 24. 300-ft long flow divider wall. Velocity vectors and velocity magnitude with original design having 13 pumps. Water surface at EL 2.0, normal flow split of 65 percent Algiers/35 percent Harvey Canal. All pumps operating. 
Figure 25.500 -ft long flow divider wall. Velocity vectors and velocity magnitude with original design having 13 pumps. Water surface at EL 2.0, normal flow split of 65 percent Algiers/35 percent Harvey Canal. All pumps operating.

Figure 26. Numerical and physical model velocities $300 \mathrm{ft}$ upstream of pump station with 500 -ft long flow divider wall.

Figure 27. Location of dye injection and observed path of dye in evaluating dividing wall contraction. Applies to surface currents only.

Figure 28. Dividing wall contraction with Pumps 4-6 operating. Water level at EL 2.0 and discharge $=1,740 \mathrm{cfs} /$ pump.

Figure 29. Dividing wall contraction with single pump operation. All pumps are shown but this plot was for only one pump in operation. Water level at EL 2.0. .... 35

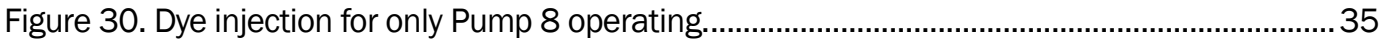

Figure 31. Dividing wall contraction with all pumps operating. Water level at EL 2.0......................35

Figure 32. Dye injection at Pump 3 with all pumps operating........................................................36

Figure 33. Dye injection at Pump 8 with all pumps operating........................................................36

Figure 34. Dye injection at Pump 12 with all pumps operating. …………………………….........36

Figure 35. Dye injection at Pump 13 with all pumps operating. ……………………………........ 37

Figure 36. Dividing wall contraction with all six odd numbered pumps operating. Water level at EL 2.0.

Figure 37. Dividing wall contraction with all five even numbered pumps operating. Water level at EL 2.0.

Figure 38. Dividing wall contraction with three pumps on each end operating. Water level at EL 2.0.

Figure 39. Dividing wall contraction with four pumps on each end operating. Water level at EL 2.0.

Figure 40. Dividing wall contraction with Pumps 9-11 operating. Water level at EL 2.0.

Figure 41. Dividing wall contraction with Pumps 10-12 operating. Water level at EL 2.0.

Figure 42. Velocity distribution at pump impeller for Pump 3, with correct dividing wall, water level at EL 0.0, only Pump 3 operating, flow non-uniformity for single pump operation at entrance to pump bay. Based on 4 velocity position measurements at 90 degrees.

Figure 43. Velocity distribution at pump impeller for Pump 3, with correct dividing wall, water level at EL 0.0, only Pump 3 operating, flow non-uniformity for single pump operation at entrance to pump bay. Based on eight velocity position measurements at 45 degrees.

Figure 44. Velocity distribution at pump impeller for Pump 3, with correct dividing wall, water level at EL 2.0, only Pump 3 operating, flow non-uniformity for single pump operation at entrance to pump bay. Based on four velocity position measurements at 90 degrees.

Figure 45. Velocity distribution at pump impeller for Pump 3, with correct dividing wall, water level at EL 2.0, only Pump 3 operating, flow non-uniformity for single pump operation at entrance to pump bay. Based on eight velocity position measurements at 45 degrees.

Figure 46. Velocity distribution at pump impeller for Pump 3, with correct dividing wall, water level at EL 7.0, only Pump 3 operating, flow non-uniformity for single pump operation at entrance to pump bay. Based on four velocity position measurements at 90 degrees.

Figure 47. Velocity distribution at pump impeller for Pump 3, with correct dividing wall, water level at EL 7.0, only Pump 3 operating, flow non-uniformity for single pump operation at entrance to pump bay. Based on eight velocity position measurements at 45 degrees.. 
Figure 48. Velocity distribution at pump impeller for Pump 3, with correct dividing wall, water level at EL 2.0, all 11 pumps operating, flow non-uniformity for single pump operation at entrance to pump bay. Based on four velocity position measurements at 90 degrees.

Figure 49. Velocity distribution at pump impeller for Pump 3, with correct dividing wall, water level at EL 2.0, all 11 pumps operating, flow non-uniformity for single pump operation at entrance to pump bay. Based on eight velocity position measurements at 45 degrees.

Figure 50. Velocity distribution at pump impeller for Pump 8, with correct dividing wall, water level at EL 0.0, all 11 pumps operating, almost no flow non-uniformity at entrance to pump bay.

Figure 51. Velocity distribution at pump impeller for Pump 8, with correct dividing wall, water level at EL 0.0, Pumps 8-13 operating, large flow non-uniformity at entrance to pump bay.

Figure 52. Velocity distribution at pump impeller for Pump 8, with correct dividing wall, water level at EL 2.0, all 11 pumps operating, almost no flow non-uniformity at entrance to pump bay.

Figure 53. Velocity distribution at pump impeller for Pump 8, with correct dividing wall, water level at EL 2.0, Pumps 8-13 operating, large flow non-uniformity at entrance to pump bay.

Figure 54. Velocity distribution at pump impeller for Pump 8, with correct dividing wall, water level at EL 7.0, all pumps operating, almost no flow non-uniformity at entrance to pump bay.

Figure 55. Velocity distribution at pump impeller for Pump 11, with correct dividing wall, water level at EL 0.0, all pumps operating, significant flow non-uniformity at entrance to pump bay.

Figure 56. Velocity distribution at pump impeller for Pump 11, with correct dividing wall, water level at EL 0.0, odd number pumps operating, large flow non-uniformity at entrance to pump bay.

Figure 57. Velocity distribution at pump impeller for Pump 11, with correct dividing wall, water level at EL 0.0, Pumps 11-13 operating, large flow non-uniformity at entrance to pump bay.

Figure 58. Velocity distribution at pump impeller for Pump 13, with correct dividing wall, water level at EL 0.0, all 11 pumps operating, large flow non-uniformity at entrance to pump bay

Figure 59. Velocity distribution at pump impeller for Pump 13, with correct dividing wall, water level at EL 0.0, 6 odd number pumps operating, large flow non-uniformity at entrance to pump bay.

Figure 60. Velocity distribution at pump impeller for Pump 13, with correct dividing wall, water level at EL 2.0, all 11 pumps operating, large flow non-uniformity at entrance to pump bay.

Figure 61. Velocity distribution at pump impeller for Pump 13, with correct dividing wall, water level at EL 2.0, 6 odd number pumps operating, large flow non-uniformity at entrance to pump bay.

Figure 62. Velocity distribution at pump impeller for Pump 13, with correct dividing wall, water level at EL 7.0, all 11 pumps operating, large flow non-uniformity at entrance to pump bay.

Figure 63. Velocity distribution at pump impeller for Pump 3, with correct dividing wall, water level at EL 2.0, Pump 3 operating, and trash rack blocked on right one-half of pump bay (looking downstream). 
Figure 64. Velocity distribution at pump impeller for Pump 3, with correct dividing wall, water level at EL 2.0, Pump 3 operating, and trash rack blocked on left one-half of pump bay (looking downstream).

Figure 65. Differential pressure transducer used to measure velocity fluctuations. Although some soft tubing was used to purge air from the system, rigid tubing was used between the pressure transducer and the Pitot tube.

Figure 66. Velocity fluctuations. Pump 3, with correct dividing wall, water level at EL 2.0, all 11 pumps operating, large flow non-uniformity at entrance to pump bay.

Figure 67. Velocity fluctuations. Pump 3, with correct dividing wall, water level at EL 2.0, only Pump 3 operating, single pump flow non-uniformity at entrance to pump bay.

Figure 68. Velocity distribution at pump impeller for Pump 3, with correct dividing wall, water level at EL-1.5, Pump 3 operating.

Figure 69. Velocity distribution at pump impeller for Pump 3, with correct dividing wall, water level at EL -1.5, all 11 pumps operating.

Figure 70. Location of velocity measurement transect for keel coolers.

Figure 71. Velocities in Pump 12 intake, intake level $=2.0$, only Pump 12 operating. Cross section looking downstream. Discharge $=1,740 \mathrm{cfs}$.

Figure 72. Velocities in Pump 12 intake, intake level = 2.0, Pumps 11-13 operating. Cross-section looking downstream. Discharge $=1,740 \mathrm{cfs}$.

Figure 73. Velocities in Pump 12 intake, intake level $=2.0$, all 11 pumps operating. Crosssection looking downstream. Discharge $=1,740 \mathrm{cfs}$.

Figure 74. Velocities in Pump 12 intake, intake level $=7.0$, all 11 pumps operating. Crosssection looking downstream. Discharge $=1,800 \mathrm{cfs}$.

Figure 75. Velocities in Pump 6 intake, intake level $=7.0$, Pumps 4-6 operating. Crosssection looking downstream. Discharge $=1,800 \mathrm{cfs}$.

Figure 76. Layout of floor coolers and piping along floor and up walls 75

Figure 77. Keel coolers and pipes on floor of pump intake model and 6-in. diameter vertical pipes on west wall.

\section{Tables}

Table 1. Kinematic viscosity of water.

Table 2. Tests conducted with design having 11 pumps, short dividing walls, revised approach channel, 300-ft long flow divider wall. Swirl angle in degrees shown in parenthesis was the maximum value of twenty 30 -sec readings.

Table 3. Tests conducted with design having 11 pumps, correct dividing wall length, revised approach channel, 300-ft long flow divider wall. Swirl angle in degrees shown in parenthesis was maximum value of twenty $30-\mathrm{sec}$ readings.

Table 4. Swirl angle for trash rack blockage tests conducted with Pump 3, only Pump 3 operating, water level at EL 2, with correct dividing wall length, revised approach channel, 300 -ft long flow divider wall.

Table 5. Water level difference across the 300-ft long flow divider wall measured in physical model. All pumps operating.

Table 6. Tests with 150-ft flow divider wall. Swirl in degrees was the highest value of twenty 30-sec (model duration) readings.

Table 7. Intake elevation, pump discharge, and average channel velocity in pump intake channel. 


\section{Preface}

This study was conducted for the US Army Engineer Districts, Rock Island and New Orleans

The work was performed by the Navigation Branch of the Navigation Division, U.S. Army Engineer Research and Development Center, - Coastal and Hydraulics Laboratory. At the time of publication, Dr. Richard Styles was Chief, Navigation Branch and Dr. Rose Kress was Chief, Navigation Division. The Deputy Director of ERDC-CHL was J ose Sanchez and the Director was Dr. William Martin.

COL Kevin J . Wilson was the Commander and Executive Director of ERDC, and Dr. J effery P. Holland was the Director. 


\section{Unit Conversion Factors}

\begin{tabular}{|l|l|l|}
\hline Multiply & By & To Obtain \\
\hline cubic feet & 0.02831685 & cubic meters \\
\hline feet & 0.3048 & meters \\
\hline inches & 0.0254 & meters \\
\hline
\end{tabular}




\section{Introduction}

\subsection{Background}

At the request of the US Army Engineer Districts, New Orleans and Rock Island, the US Army Engineer Research and Development Center (ERDC) conducted a physical model study of the pump intakes for the pump station at the West Closure Complex (WCC). The WCC is located just downstream of the confluence of the Harvey and Algiers Canals, as shown in Figure 1. The WCC consists of levees, navigation channels, storm surge gates, and a pumping station. The pump station was initially configured with 16 vertical axial pumps at 1,250 cfs per pump for a total station capacity of 20,000 cfs. The station was modified to 13 pumps at 1,540 cfs per pump for a total station capacity of $20,000 \mathrm{cfs}$. The station was finalized to 11 pumps at 1,740 cfs per pump for a total station capacity of 19,140 cfs. These discharges are based on the design intake elevation of two (EL 2). All elevations are in feet relative to the vertical datum of NAVD88 (2004.65). At the minimum intake EL 0, discharge per pump will be 1,710 cfs for a total capacity of 18,810 cfs. At the maximum intake EL 7, discharge per pump will be 1,815 cfs for a total capacity of 19,965 cfs.

During non-storm surge conditions, navigation passes through the sector gates (Figure 2). The sector gates will be closed during storm surge coming from the south. When the gates are closed, the new pump station is required to evacuate interior drainage from the area protected by the levees.

Under typical inflow distribution and peak discharge, 65 percent of the flow comes from Algiers Canal and 35 percent comes from Harvey Canal. For the condition of Algiers providing its highest discharge, Algiers can provide up to 75 percent with 25 percent from Harvey Canal. For the condition of Harvey providing its highest discharge, Harvey and Algiers Canal provide 50 percent of the flow each.

When the station consisted of 13 pumps, pumps were numbered 1-13 from left to right looking downstream. The number of pumps was reduced to 11 but the numbering system was retained and the 11 pumps were numbered $3-13$. This report focuses on results with testing of 11 pumps. Some information was presented with the 13 pump configuration if it was used in decision making. 


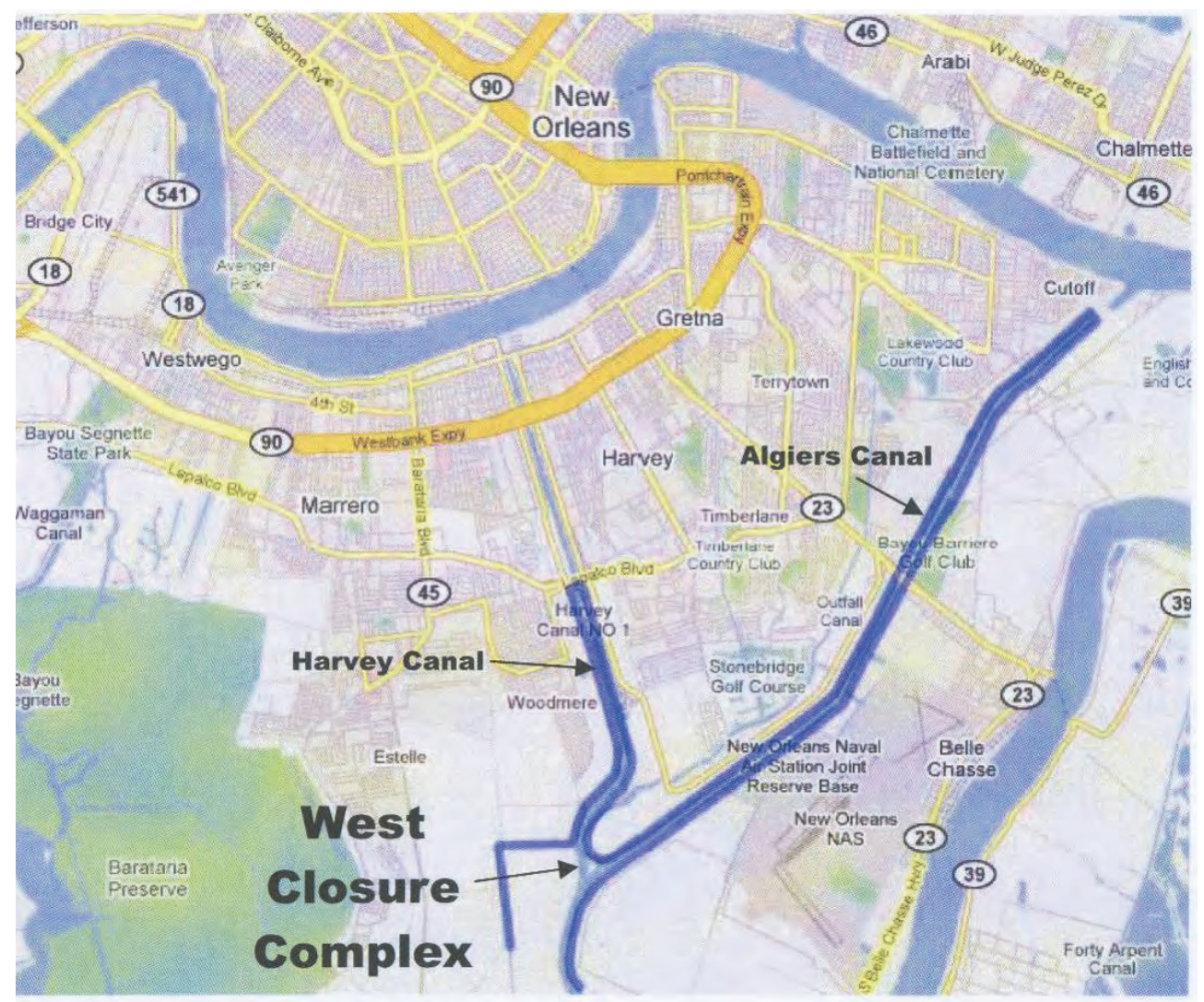

Figure 1. Location of WCC.

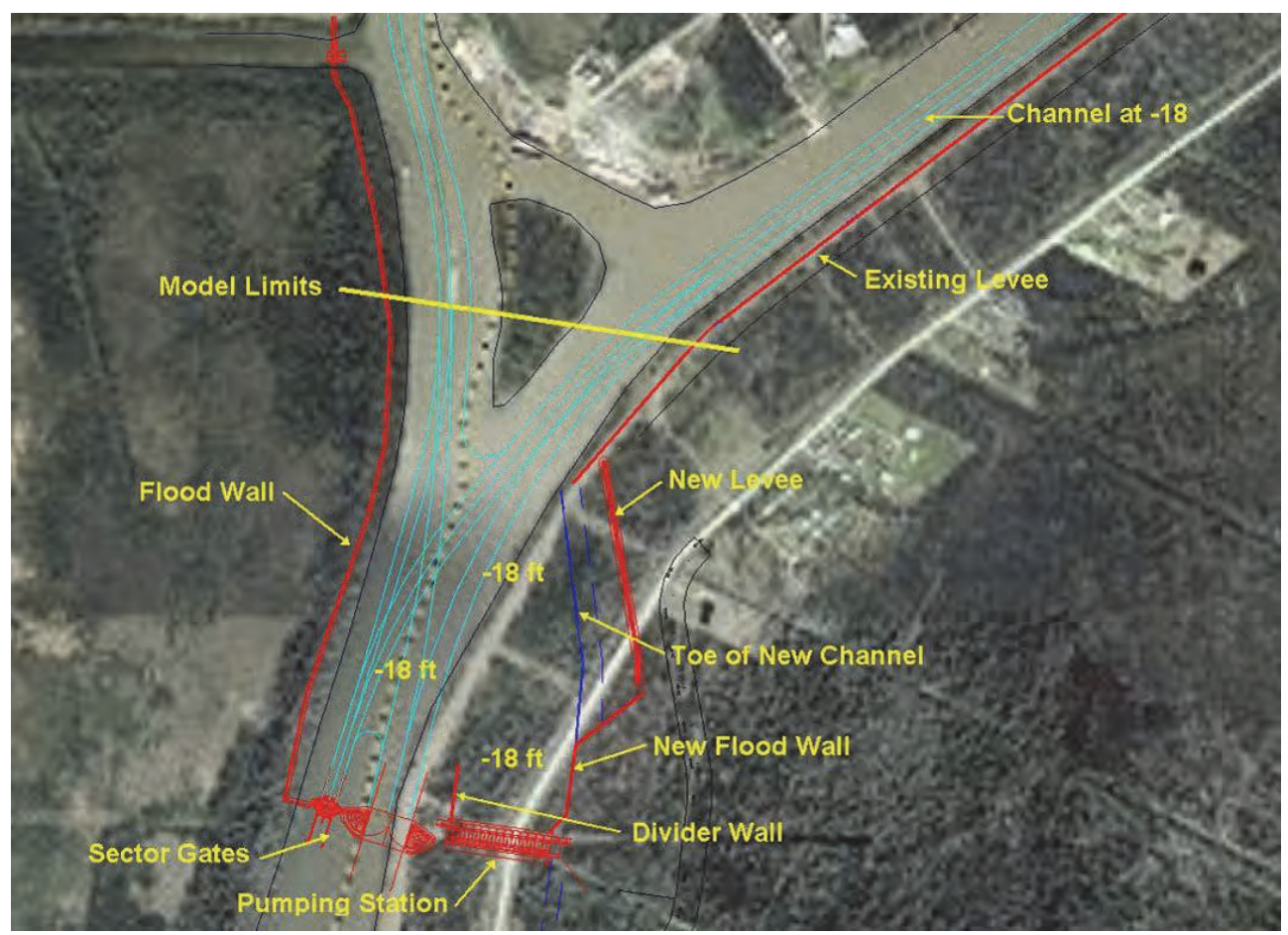

Figure 2. Project Layout of initial design. 
Flow from the pumps is discharged into a flowerpot discharge outlet which exits above the downstream maximum tailwater, so there is no variation of flow with downstream conditions. The flowerpot was tested in a separate model and results presented in a separate report (Maynord 2011).

The details of the pump intake are shown in Figure 3. Each pump is fitted with a USACE Type 10 Formed Suction Intake (FSI). The pumps have a discharge column diameter, $\mathrm{d}$, of $10.0 \mathrm{ft}$ that was used to size all dimensions of the FSI. This intake also has a unique feature referred to in the design build documents as a "contracted section" upstream of the FSI. The FSI works because it provides a gradual contraction of the flow toward the pump. The contracted section is an additional contraction of the flow before it gets to the FSI and should reduce adverse conditions reaching the entrance to the FSI. Figure 3 shows the variation of cross section flow area throughout the pump column, FSI, contracted section, and inside the pump bay. The contracted section should assist the FSI in minimizing any effects of adverse approach flow on the pump. Because of the use of the contracted section immediately upstream of the FSI, the Type 10 used herein does not have the rounding of the roof and sides of the upstream entrance of the FSI used in some recent applications of the Type 10 FSI (Werth and Demlow 1998, 1999).

The Hydraulic Institute (HI) standards (1998) refer to the walls between pump bays as "dividing walls" and that terminology was used herein. The WCC also has a wall upstream of the pump station that is between the pump station and sector gate and is referred to herein as the "flow divider wall".

Figure 3 shows two lengths of the dividing walls between the pumps. The model was built and a full set of tests were conducted with 11 pumps and the shorter dividing walls. Subsequently, it was determined that the dividing walls had been lengthened to accommodate a climber screen cleaner as opposed to the original arm screen cleaner. Results from both wall lengths were presented because the shorter wall may be of use in future pump station studies.

Each pump bay contains a trash rack having $1 / 2$-in. thick by 9 -in. deep bars placed on 4.5-in. centers. The trash rack is inclined at 60 degrees. The rack uses a climber screen cleaner that was not simulated in the model. 


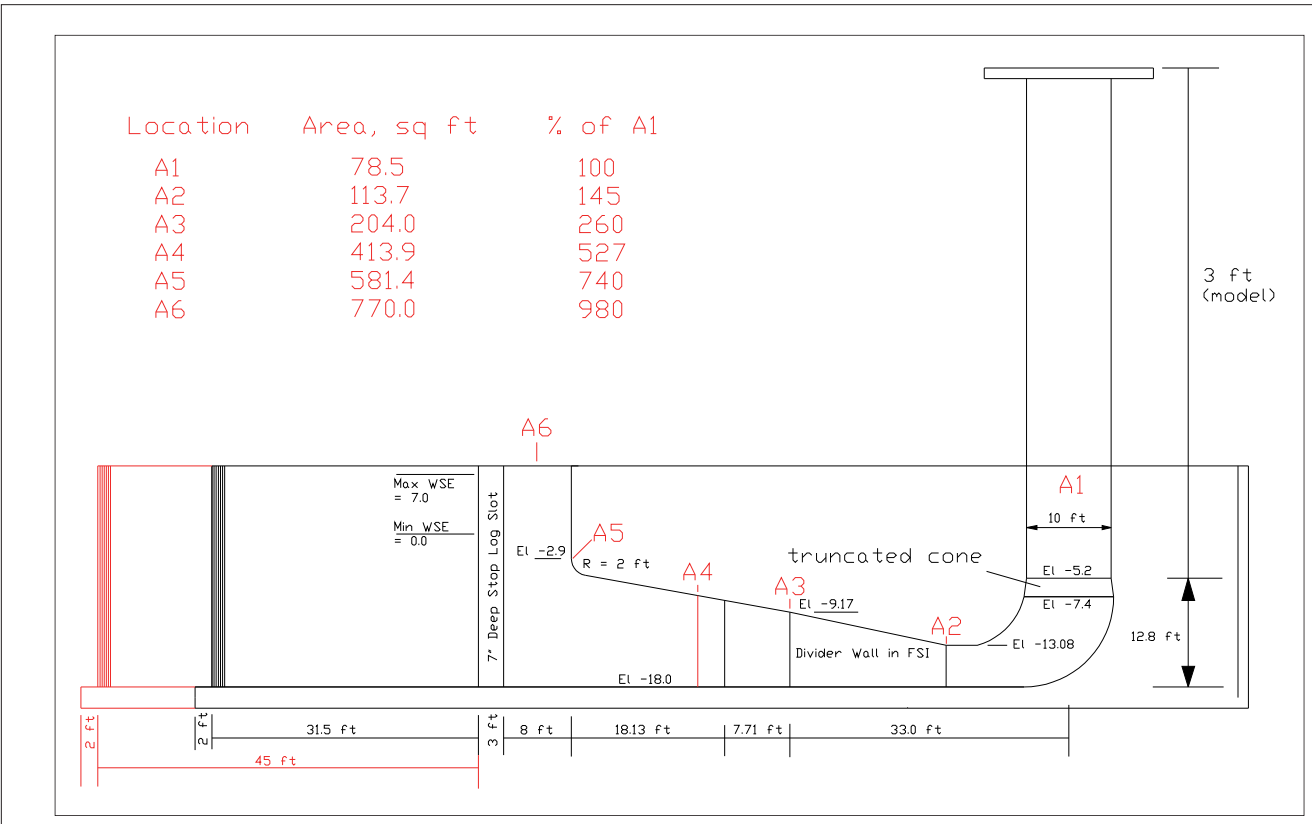

3a. Elevation view showing shorter dividing wall length (in black) and corrected dividing wall length (in red). Also shown is the area comparison through pump column, $\mathrm{FSI}$, contracted section, and inside pump bay. Area A6 is based on the design intake EL 2.0.

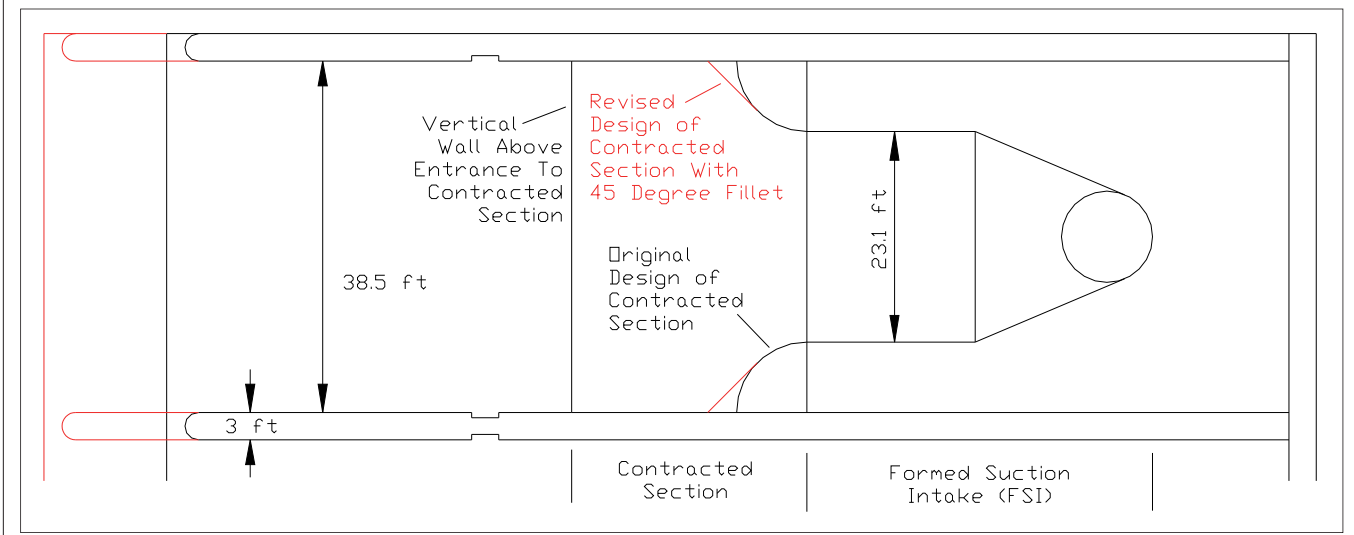

3b. Plan view showing shorter dividing wall length (in black) and corrected dividing wall length (in red). Also shows revision of contracted section with fillet added to address submerged vortices.

Figure 3. Intake details showing dividing walls, contracted section, and Formed Suction Intake (FSI).

\subsection{Past formed suction intake pump stations}

Since the WCC proposes to use large pumps initially having a capacity of 1250 cfs per pump, which was later increased to 1,740 cfs, an evaluation was conducted of past use of FSI on large pumps. None of the previous FSI pump stations used a contracted section as used at the WCC. The Type 10 FSI is shown in Figure 4. 


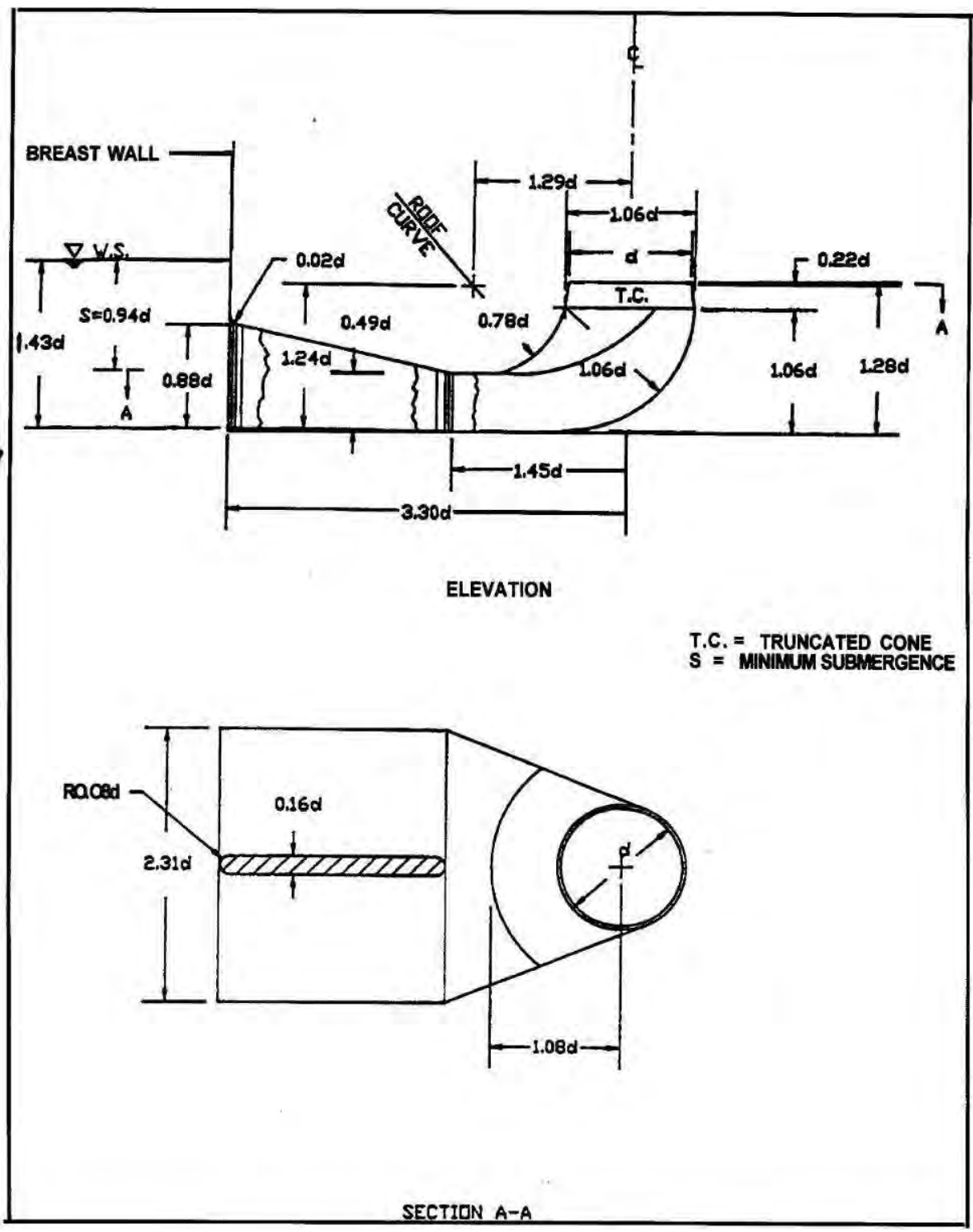

Figure 4. Type $10 \mathrm{FSI}$ design guidance from EM 1110-2-3105.

One parameter used to describe an FSI is the discharge intensity $Q /\left(d^{5} g\right)^{1 / 2}$. This parameter differs from the pipe Froude number used in the HI standards by only a constant. In this parameter, $d$ is the diameter of the FSI where it connects to the pump and is the dimension that determines all geometric characteristics of the FSI. For the WCC, $d=10 \mathrm{ft}$. The discharge intensity parameter was tested up to 1.99 in the development of the FSI and the Engineer Manual 1110-2-3105 on FSI gives this as a usable upper limit.

This parameter is rarely below about 0.6 and typically 0.7 to 1.2 . A concern of using large values of FSI discharge intensity is separation of flow along the roof of the FSI as it makes a 90 degree turn into the pump. If the flow 
separates, the velocity will not be uniform at the pump intake, possibly not meeting HI standards. In addition, excessive turbulence from flow separation may enter the pump and cause poor pump performance.

The following paragraphs summarize past studies and applications of FSIs and give pertinent values of discharge intensity $\mathrm{Q} /\left(\mathrm{d}^{5} \mathrm{~g}\right)^{1 / 2}$, submergence $\mathrm{S} / \mathrm{d}$, approach bay average velocity, and dividing wall length upstream of the FSI. Submergence S is measured from the minimum forebay water level to the lowest elevation of the roof of the FSI. The lowest elevation of the roof is $0.49 \mathrm{~d}$ above the floor of the FSI. Submergence and approach bay velocity were based on the minimum water level measured just upstream of the FSI. As part of this effort, HQUSACE helped ERDC contact USACE districts to see how existing FSIs were performing. Reports received to date from that process are presented below along with other previous studies on FSIs. The information was broken into FSIs that have been built and apparently successfully operating (some with a model test) and those that were only model tested.

Projects built and apparently operating successfully (some with a model test):

1. A large physical model of 470 and $950 \mathrm{cfs}$ pumps having a Type $10 \mathrm{FSI}$ was conducted by Lehr et al. (1999 and Werth and Demlow (1998). The study was conducted by ENSR for Ingersoll-Dresser Pump (IDP) Company. The pump stations using these pumps were G-310 and G-335 and are part of the South Florida Water Management District (SFWMD). This study showed that the roof, sidewalls, and floor entrance of the FSI need to be rounded to about $0.25 \mathrm{~d}$ to prevent flow separation. The Type 10 in the USACE Engineer Manual has a roof entrance radius of $0.02 \mathrm{~d}$. This was possibly a typographical error because some earlier designs showed radius $=0.2 \mathrm{~d}$ and a radius of $0.02 \mathrm{~d}$ would not be expected to have any significant effect. These pumps had $\mathrm{Q} /\left(\mathrm{d}^{5} \mathrm{~g}\right)^{1 / 2}=0.71$ for the $470 \mathrm{cfs}$ pumps and 0.62 for the $950 \mathrm{cfs}$ pumps. Approach bay velocity was $1.8 \mathrm{ft} / \mathrm{sec}$ and submergence S/ d was 1.16 for the $950 \mathrm{cfs}$ pumps at the rated water surface. Dividing walls extended $4 \mathrm{~d}$ upstream of the face of the opening of the FSI. The Lehr et al. (1999) study did not measure velocities at the location of the pump impeller, but used dye to determine if separation was occurring along the roof curve and tested the FSI with a scaled pump. Vortex breaker pipes were added above the inlet of the FSI at top elevation 1-ft below the minimum intake level to eliminate surface vortices. The pumps and FSIs have been in successful operation for about five years. 
2. In a subsequent study, Werth and Demlow (1999) conducted a similar study of Type 10 FSIs for Station S-319, which had 550 cfs and 960 cfs pumps. This station was built by the USACE J acksonville District and turned over to the SFWMD for operation. The $0.25 \mathrm{~d}$ rounding of the roof and side entrances of the FSI was used in this study. The original design did not have a vertical wall above the FSI entranœe. This wall was added in the recommended design to reduce separation of flow entering the intake as well as to reduce surface vortices. This study also found that submerged vortices at the sides of the intake attributed to the dead zones in the corners just upstream of the FSI entrance. Corner fillets at 45 degrees were added to the entrance of the FSI to eliminate the submerged vortices. Vortex breaker pipes were added above the inlet at top elevation 1-ft below the minimum intake level to eliminate surface vortices. For the $550 \mathrm{cfs}$ pumps, $\mathrm{Q} /\left(\mathrm{gd}^{5}\right)^{1 / 2}=0.84$, approach velocity was $1.43 \mathrm{ft} / \mathrm{sec}$ at minimum intake, and $\mathrm{S} / \mathrm{d}=1.9$. For the $960 \mathrm{cfs}$ pumps, $\mathrm{Q} /\left(\mathrm{gd}^{5}\right)^{1 / 2}=0.63$, approach velocity was $194 \mathrm{ft} /$ sec at minimum intake, and S/ $d=121$. Length of dividing walls upstream of the face of the opening of the FSI was $4.5 \mathrm{~d}$ for the $960 \mathrm{cfs}$ pumps.

3. A third study by Werth and Demlow (2000) conducted a similar study of Type 10 FSIs for Station S-362, which had 550 cfs and 960 cfs pumps. This station was built by the USACE J acksonville District and turned over to the SFWMD for operation. The $0.25 \mathrm{~d}$ rounding of the roof and side entrances of the FSI was used in this study. The same modifications were used in this study as in station S-319. For the $550 \mathrm{cfs}$ pumps, Q/ $\left(\mathrm{gd}^{5}\right)^{1 / 2}=0.84$, approach velocity was $1.48 \mathrm{ft} / \mathrm{sec}$ at minimum intake, and $\mathrm{S} / \mathrm{d}=1.8$. For the $960 \mathrm{cfs}$ pumps, Q/ (gd5) $)^{1 / 2}=0.63$, approach velocity was $2.00 \mathrm{ft} / \mathrm{sec}$ at minimum intake, and $\mathrm{S} / \mathrm{d}=1$ 1.16. Length of dividing walls upstream of the face of the opening of the FSI was $4.5 \mathrm{~d}$ for the $960 \mathrm{cfs}$ pumps.

4. In a Type 1FSI (similar to Type 10) at the River Styx pump station, $d=$ $3.43 \mathrm{ft}$ and $\mathrm{Q}=167 \mathrm{cfs}$, resulting in $\mathrm{Q} /\left(\mathrm{d}^{5} \mathrm{~g}\right)^{1 / 2}=1.35 . \mathrm{S} / \mathrm{d}=2.7$, and no information was available on approach velocity. This station is in operation with no problems but no data was available on velocity uniformity at the pump impeller.

5. The Clover Fork pumping station in the Nashville District of USACE had three axial flow pumps with FSI having $d=3.67 \mathrm{ft}$ and $\mathrm{Q}=98 \mathrm{cfs}$ at max head and $127 \mathrm{cfs}$ at minimum head. Values of $\mathrm{Q} /\left(\mathrm{d}^{5} \mathrm{~g}\right)^{1 / 2}$ are 0.67 and 0.87 for the two heads, respectively. $\mathrm{S} / \mathrm{d}=1.55$ at minimum intake and approach velocity was not defined for the wide open configuration at Clover Fork. The pumps run smoothly without vortices or vibration. No information on velocity uniformity at the pump impeller was available. 
6. The Mt Kennedy pump station in J efferson Parish, New Orleans had $\mathrm{d}=$ $3.93 \mathrm{ft}$, Q of $174 \mathrm{cfs}$ at low intake water level, resulting in $\mathrm{Q} /\left(\mathrm{d}^{5} \mathrm{~g}\right)^{1 / 2}$ of 1.0 . $\mathrm{S} / \mathrm{d}=1$.3. No information on velocity uniformity at the pump impeller was available.

7. The Davis Pond pump station in New Orleans had three $190 \mathrm{cfs}$ pumps with $\mathrm{d}=3.66 \mathrm{ft}$, resulting in $\mathrm{Q} /\left(\mathrm{d}^{5} \mathrm{~g}\right)^{1 / 2}$ of $1.3 \mathrm{~S} / \mathrm{d}=1.4$ and approach velocity is $2.2 \mathrm{ft} / \mathrm{sec}$. No information on velocity uniformity was available.

8. A Type $10 \mathrm{FSI}$ was used on the interim pumping stations on the outfall canals of New Orleans. The 17th Street canal FSI had d $=5.0 \mathrm{ft}$ and $\mathrm{Q}=$ $380 \mathrm{cfs}$, resulting in $\mathrm{Q} /\left(\mathrm{d}^{5} \mathrm{~g}\right)^{1 / 2}=1.2$. The 17 th Street approach velocity was $1.9 \mathrm{ft} / \mathrm{sec}$ and $\mathrm{S} / \mathrm{d}$ was 1.9. The London Avenue canal FSI had d $=5.0 \mathrm{ft}$ and $\mathrm{Q}=336 \mathrm{cfs}$, resulting in $\mathrm{Q} /\left(\mathrm{d}^{5} \mathrm{~g}\right)^{1 / 2}=1.06$. The London Avenue approach velocity was $1.8 \mathrm{ft} / \mathrm{sec}$ and $\mathrm{S} / \mathrm{d}$ was 1.6 . The upstream ends of dividing walls were 2.6d upstream of the face of the opening of the FSI. The New Orleans FSI used on the interim pump stations were built with the $0.25 \mathrm{~d}$ rounding of the roof and side entrances. A difference between the model FSI in the Maynord tests was that the FSI was built using a 3-D printer that uses ABS plastic to form the shape of the FSI. The 3-D printer is an extremely accurate method of forming the model FSI but the resulting finish was rougher than smooth Plexiglas used in other FSI model studies. Consideration was given to coating the surface of the ABS plastic to produce a smooth finish similar to Plexiglas. The surface of pumps placed in the London outfall canal, which had been removed for maintenance, was found coated with deposits after only a short period of installation. These deposits produced a relatively rough surface, which would likely occur inside the FSIs. The uncoated ABS surface was used in the model because it was felt to better replicate roughness conditions in the prototype. The difference between the two surfaces regarding flow separation along the roof was not certain. The velocity measurements from the recommended design from Maynord are shown in Figure 5 for 17th street. Note that at the side toward the roof curve (PT1), the velocities were just barely above the HI standard of \pm 10 percent.

Projects only model tested:

1. Leech (1989) evaluated the New Madrid pump station, which had 500 cfs pumps with FSIs. The d of the proposed pumps was $7.35 \mathrm{ft}$, resulting in $\mathrm{Q} /\left(\mathrm{d}^{5} \mathrm{~g}\right)^{1 / 2}=0.60$. Velocity measurements at the pump impeller met the uniformity criteria of the HI of \pm 10 percent. Leech used an FSI having width of 2.7d as opposed to 2.31d for the Type 10. The FSI roof entrance had a radius of $0.33 \mathrm{~d}$. Approach bay velocity was $2.3 \mathrm{ft} / \mathrm{sec}$ and $\mathrm{S} / \mathrm{d}$ was 0.94 . 


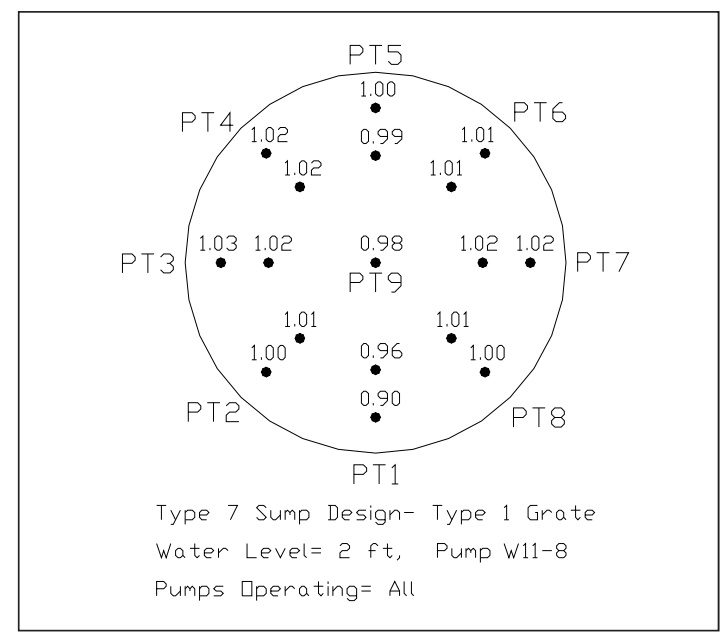

Figure 5.17th Street Canal. Velocities in pump intake with FSI for Type 7 intake design, Type 1 grate, all 29 pumps operating, canal EL 2, pump W11-8. Flow approaches from direction of PT1.

2. Kirkpatrick and Fletcher (1991) in a study of the Alton pump station used an FSI that was different from the Type 10 and found a uniform velocity distribution, which met $\mathrm{HI}$ standards for $\mathrm{Q} /\left(\mathrm{d}^{5} \mathrm{~g}\right)^{1 / 2}=0.80$. The FSI had a width at the entrance of 3.2d compared to a width of 2.31d for the Type 10 . The FSI roof entrance had a radius of $0.21 \mathrm{~d}$. Approach bay velocity was 1.1 $\mathrm{ft} / \mathrm{sec}$ and S/ d was 1.9. Upstream ends of dividing walls were $13 \mathrm{~d}$ upstream of the face of the opening of the FSI.

3. Fletcher (1990) evaluated an FSI for the proposed Yazoo pumping station, which had pumps with maximum discharge of $1460 \mathrm{cfs}$ and $\mathrm{d}$ of $9.38 \mathrm{ft}$, resulting in $\mathrm{Q} /\left(\mathrm{d}^{5} \mathrm{~g}\right)^{1 / 2}=0.96$. This FSI was closer to the Type 1 FSI than the Type 10 but the two are similar. The velocity measurements were outside the HI standards for velocity uniformity and showed about +10 percent and - 15 percent deviations from the average based on an average value of 0.82 . Figure 6 shows the plot of the velocities. A low velocity zone was seen on the side toward the FSI opening and was similar to the low velocity location in the 17th Street velocities in Figure 5.

4. The Cypress Avenue pump station (Fletcher 1994) used an FSI with $\mathrm{d}=$ $3.94 \mathrm{ft}$ and $\mathrm{Q}=134 \mathrm{cfs}$, resulting in a $\mathrm{Q} /\left(\mathrm{d}^{5} \mathrm{~g}\right)^{1 / 2}=0.77$. No velocities were taken. Cypress Avenue used a rounding of $0.02 \mathrm{~d}$ at the roof entrance. The approach was so unusual at Cypress Avenue that an approach velocity was not well defined. Submergence S/ d was 2.6.

5. Fletcher (1991) in a study of the St J ohn Pump Station used an FSI with d $=5.2 \mathrm{ft}$ and $\mathrm{Q}=333 \mathrm{cfs}$ for $\mathrm{Q} /\left(\mathrm{d}^{5} \mathrm{~g}\right)^{1 / 2}=0.95$. The FSI had length of $5.8 \mathrm{~d}$ compared to 3.3d for the Type 10 and entrance width of $3.1 \mathrm{~d}$ versus $2.31 \mathrm{~d}$ for the Type 10. Velocity measurements met the HI standards for 
uniformity but this FSI differs too much from a Type 10 to use this data. Approach velocity was $2.3 \mathrm{ft} / \mathrm{sec}$ and $\mathrm{S} / \mathrm{d}$ was 0.96 . Upstream ends of dividing walls were $8 \mathrm{~d}$ upstream of the face of the opening of the FSI.

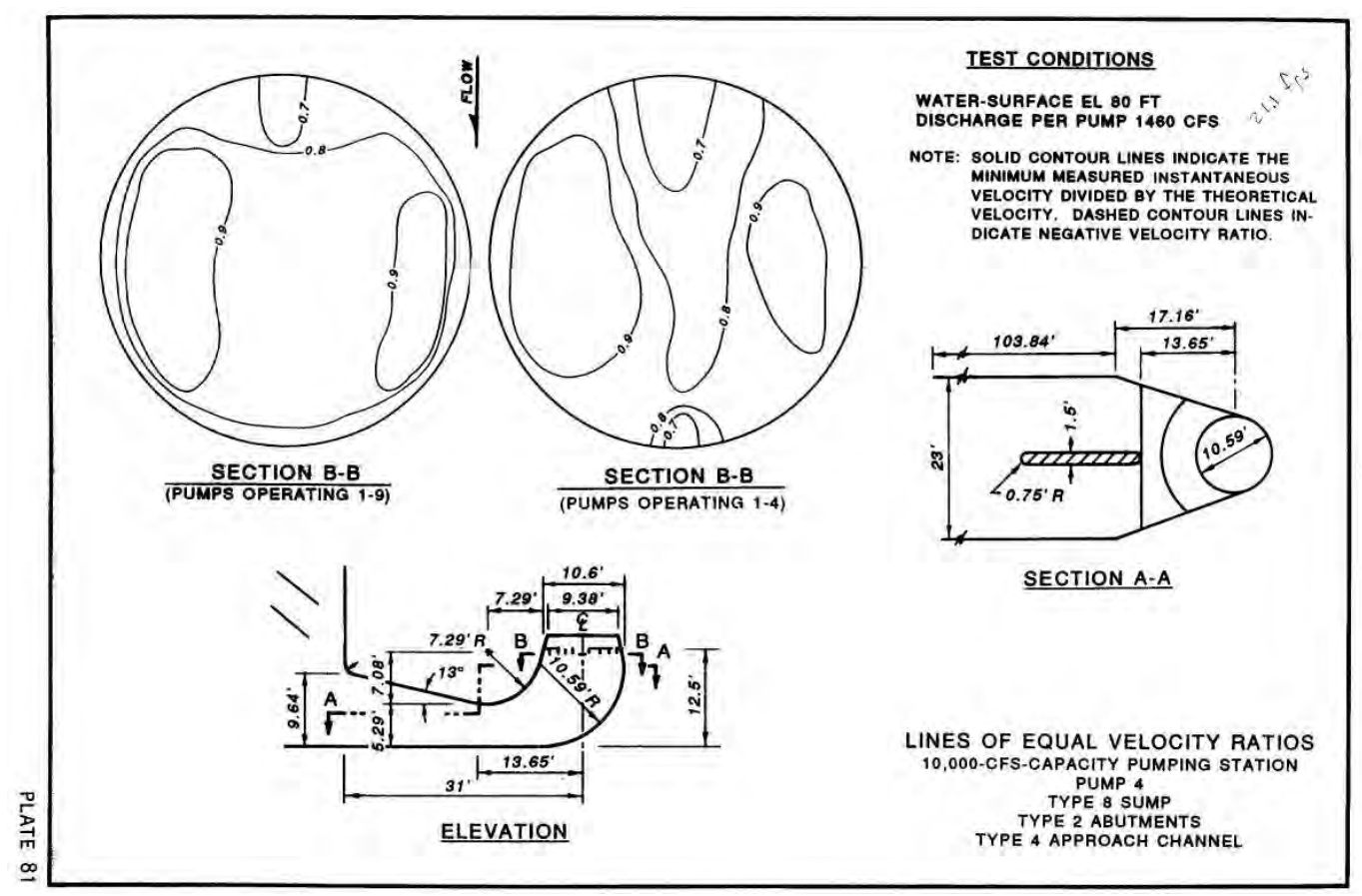

Figure 6. Isovels from Yazoo Pump Station Model

In summary, for FSIs reasonably similar to Type 10 USACE FSI, acceptable performance regarding flow separation at the roof based on velocity measurements or dye studies was found for $\mathrm{Q} /\left(\mathrm{d}^{5} \mathrm{~g}\right)^{1 / 2}$ of 0.60 (Leech 1989), 0.62 and 0.71 (Lehr et al. 1999), and 1.06 (Maynord, London). Borderline but acceptable performance was found for Q/ $\left(d^{5} g\right)^{1 / 2}$ of 1.2 (Maynord, 17th Street). Unacceptable performance was found for Q/ $\left(\mathrm{d}^{5} \mathrm{~g}\right)^{1 / 2}$ of 0.96 (Fletcher 1990). River Styx, Clover Fork, Mt Kennedy, and Davis Pond have successful operation at Q/ $\left(\mathrm{d}^{5} \mathrm{~g}\right)^{1 / 2}$ of 1.35, $0.87,1.0$, and 1.3, respectively, but no velocity information at the pump impeller was available and pumps were medium size.

Submergence effects appear to also depend on $\mathrm{Q} /\left(\mathrm{d}^{5} \mathrm{~g}\right)^{1 / 2}$. Submergence at New Madrid was low at 0.95, but discharge intensity was also low at 0.6. At Yazoo, submergence was high at $\mathrm{S} / \mathrm{d}=1.7$, but the pump did not meet $\mathrm{HI}$ velocity uniformity criteria, possibility due to the high approach velocity. Minimum submergence for an FSI can be expressed as a constant value of $\mathrm{S} / \mathrm{d}=0.94$ based on EM 1110-2-3105. In the HI standards, submergence depends on discharge intensity. The HI standards equation for submer- 
gence gives relatively large values of submergence, but these apply to intakes without devices like vortex breaker pipes to eliminate surface vortices.

For approach velocity, values of $2.3 \mathrm{ft} / \mathrm{sec}$ and less resulted in successful installations. The proposed Yazoo Pump Station had approach velocity of $3.0 \mathrm{ft} / \mathrm{sec}$ and did not meet HI velocity criteria but the reason is unknown.

For bay length, the lowest distance from the face of the FSI to the upstream end of the dividing walls was $2.6 \mathrm{~d}$ and the largest was $13 \mathrm{~d}$. The three Werth and Demlow (1998, 1999 and 2000) studies were 4.0 to 4.5d.

Design parameters for the WCC with 11 pumps were compared with those for the past FSIs described above. The discharge intensity Q/ $\left(\mathrm{gd}^{5}\right)^{1 / 2}$ is 0.95 at $\mathrm{Q}=1,710 \mathrm{cfs}$ (intake water level at EL 0) and 0.97 at Q =1,740 cfs (intake water level at EL 2). These values are within the typical range for all pumps but on the upper end for large pumps. At minimum intake EL 0.0 and the floor EL -18, the available submergence on the FSI will be $18-0.49 \times 10=$ $13.1 \mathrm{ft}$ or available $\mathrm{S} / \mathrm{d}=1.31$. At the minimum intake EL 0.0 and floor EL -18 , approach velocity is $1,710 /(18 \times 38.5)=2.47 \mathrm{ft} / \mathrm{sec}$. This is slightly greater than the maximum velocity of $2.3 \mathrm{ft} / \mathrm{sec}$ that was found in the past stations described previously. At intake EL 2, the approach velocity is $1,740 /(20 \times 38.5)=2.26 \mathrm{ft} / \mathrm{sec}$ and within past studies. Approach bay wall length upstream of the entrance to the contracted section with the correct dividing wall length is $56 \mathrm{ft}$ or 5.6d, which is in the middle of the range of past studies and greater than the values in the large pumps studied by Werth and Demlow (1998, 1999 and 2000).

\subsection{Study objective}

The objective of this physical model study was to insure adequate performance of the intakes of the pumps at the WCC. This study will follow the requirements for modeling pump intakes set forth in the HI standards (1998). The HI standards set forth requirements for model size, model operation, and allowable vortices, swirl, and velocity distribution uniformity in the pump column. Meeting pump intake standards is of primary importance because the WCC pumps are extremely large. 


\section{Physical Model: Design, Scaling Requirements, Description, and Inflow Calibration}

\subsection{Design of the pump station model}

Pump intake design requirements are addressed by the HI. Almost all pump manufacturers want or require a pump intake that meets HI standards. The latest HI standards were published in 1998 and were used in the WCC pump station physical model in design and testing of the physical model. The HI standards require that a physical model should be conducted for large pump stations like the WCC.

Pump intake models are studied with Froude similarity, which means the ratio of inertial force to gravity force is the same value in the model and the prototype. In addition to achieving equality of Froude number in model and prototype, pump intake models must be built and operated such that viscous and surface tension forces are not significant in the model. Stated otherwise, the model must not be too small. The HI standards require the Reynolds number $\left(\mathrm{R}_{\mathrm{b}}\right)$ based on bell diameter $\left(\mathrm{D}_{\mathrm{b}}\right)$ and inlet velocity at the bell $\left(\mathrm{V}_{\mathrm{b}}\right)$ is:

$$
\mathrm{R}_{\mathrm{b}}=\frac{\mathrm{V}_{\mathrm{b}} \mathrm{D}_{\mathrm{b}}}{v} \geq 3(10)^{4}
$$

where $v$ is the kinematic viscosity of water, which varies with temperature. Table 1 shows the kinematic viscosity of water for different temperatures. The HI standards suggest that a factor of two should be applied to this model size, resulting in a required $\mathrm{R}_{b}$ of $6 \times 10^{4}$. The WCC uses an FSI instead of a pump bell. Had a pump bell been used, the bell diameter would be $20.1 \mathrm{ft}$ for the HI recommended bell velocity of $5.5 \mathrm{ft} / \mathrm{sec}$ for the 1,740 cfs pumps.

One of the HI requirements for a satisfactory intake is uniformity of velocity in the throat of the pump. This requires placing velocity probes inside the throat of the model pump intake. While smaller diameters can be used and meet the minimum Reynolds number criteria, a 6-in. diameter model pump intake provides room to place multiple velocity 
Table 1. Kinematic viscosity of water.

\begin{tabular}{|l|l|}
\hline Temperature & $\mathrm{v}, \mathrm{ft}^{2} / \mathrm{sec}$ \\
\hline 45 & 0.0000153 \\
\hline 50 & 0.0000141 \\
\hline 55 & 0.0000131 \\
\hline 60 & 0.0000122 \\
\hline 65 & 0.0000114 \\
\hline 70 & 0.0000106 \\
\hline 75 & 0.0000099 \\
\hline 80 & 0.0000093 \\
\hline 85 & 0.0000087 \\
\hline 90 & 0.0000083 \\
\hline 95 & 0.0000078 \\
\hline 100 & 0.0000074 \\
\hline
\end{tabular}

probes in the throat of the model pump. The 6-in. diameter results in a model scale ratio of 1:20 based on the 10-ft diameter pumps used at WCC. The 1:20 scale also allows adequate approach channel length in the flume used in the WCC study. Using a scale ratio of $1: 20, Q=1,740 \mathrm{cfs}(0.97 \mathrm{cfs}$ in the model), hypothetical bell diameter of $20.1 / 20=1.005 \mathrm{ft}$, and a water temperature of $50^{\circ} \mathrm{F}$, the resulting model $\mathrm{R}_{\mathrm{b}}$ was $9 \times 10^{4}$, which was above the required $R_{b}$ of $6 \times 10^{4}$. Past pump station intake model studies at ERDC have required a minimum Reynolds number at the pump throat of $1 \mathrm{x} 10^{5}$. At a flow rate of $1,740 \mathrm{cfs}$ and water temperature of $50^{\circ} \mathrm{F}$, the throat model Reynolds number was $1.8 \times 10^{5}$ and met the ERDC criteria.

\subsection{Hydraulic Institute Standards for pump intake models}

The HI standards provide acceptance criteria for intakes regarding surface and subsurface vortices, swirl, and velocity distribution in Section 9.8.5.6 as follows:

1 "Free surface and sub-surface vortices entering the pump must be less severe than vortices with coherent (dye) cores (free surface vortices of Type 3 and sub-surface vortices of Type 2 in HI standards Figure 9.8.23). Dyecore vortices may be acceptable only if they occur for less than 10 percent of the time or only for infrequent pump operating conditions." Figure 7 shows HI standards Figure 9.8.23. During a visit by the design builder HNTB, 


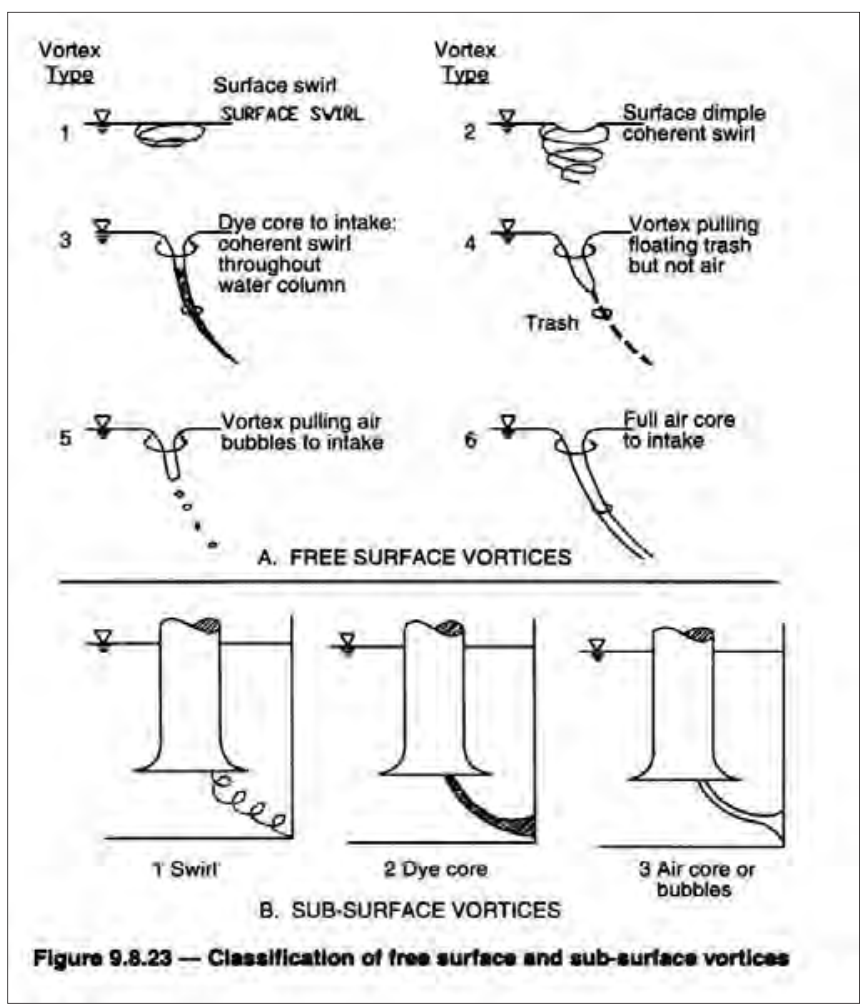

Figure 7. The $\mathrm{HI}$ standards for surface and ub-surface vortices (1998).

they raised the important issue of where is the intake of the pump defined to meet HI standards regarding vortices "entering the pump". HNTB stated that consideration should be given to defining the intake as the opening of the FSI and not the opening of the contracted section. The reason behind this statement was that vortices forming at the intake to the contracted section not meeting $\mathrm{HI}$ standards could be reduced to acceptable levels by the contracted section. Because of the large number of pumps, large number of pump operating combinations, and variable water levels yielding a large number of test conditions, surface vortex characterization was limited to defining if Type 3 dye-core surface vortices form, whether their frequency of occurrence was greater than 10 percent of the time, and if they make it into the pump intake. Since the contracted section is a new type of intake appurtenance and the WCC pumps are large pumps, the HI standards for evaluation of surface vortices will be applied conservatively. The location defined herein as "entering the pump" will be halfway through the contracted section. If a coherent dye-core vortex makes it past halfway through the contracted section, it was considered to have entered the pump. This definition is considered conservative because the flowstill must pass through the contraction at the downstream end of the contracted section and through the FSI before it reaches the pump impeller. 
2. Uneven approach flow distribution can cause flow entering the pump intake to have a swirling motion that is detrimental to pump performance and can lead to formation of submerged vortices and pump vibration. Swirl was measured with a swirl meter, which is a four bladed rotor with zero angle of attack, which can be seen in Figure 8. The vertical position and dimensions of the rotor were based on $\mathrm{HI}$ standards. Revolutions of the swirl meter were counted over 30 sec intervals for 20 readings. Revolutions were converted to a swirl angle $\theta$ according to $\theta=\tan ^{-1}\left(\frac{\pi n D_{p}}{V_{p}}\right)$ where $n$ is the rev/ sec. Based on HI standards, swirl angles, both short-term (10 to 30 seconds in model) maximum and thelong term (10 minutes in model) average indicated by the swirl meter rotation, must be less than 5.0 degrees. Maximum short-term (10 to 30 seconds in model) swirl angles up to 7.0 degrees may be acceptable, only if they occur less than 10 percent of the time or for infrequent pump operating conditions. The swirl meter rotation should be reasonably steady, with no abrupt changes in direction when rotating near the maximum allowable rate (angle).

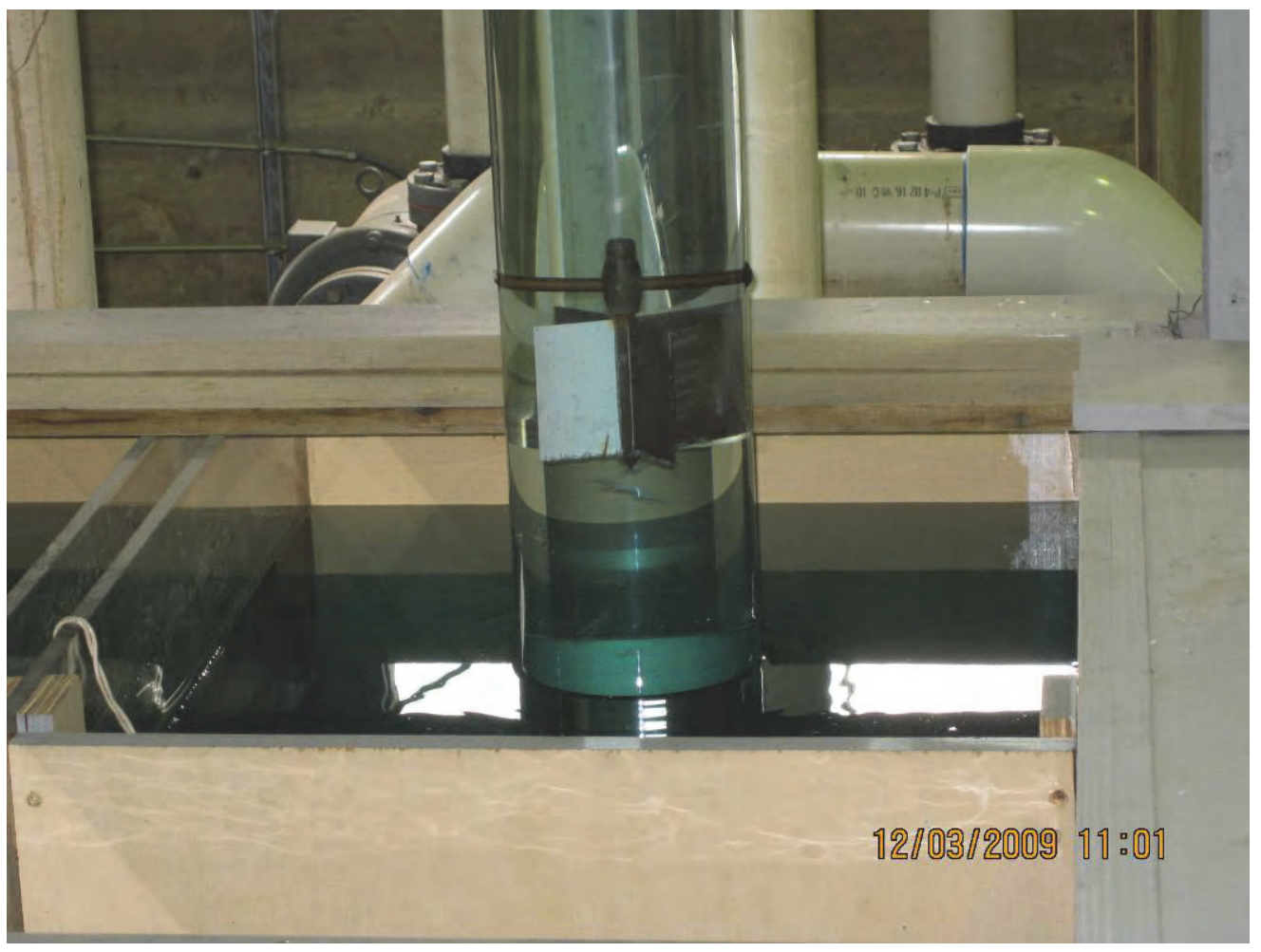

Figure 8. Swirl meter in 6-in. inside diameter acrylic pipe.

3. Time averaged velocities at points in the throat of the bell or at the pump suction shall be within 10 percent of the cross-sectional area averaged velocity. Time varying fluctuations of velocity at a point shall produce a 
standard deviation from the time averaged signal of less than 10 percent. Figure 9 shows the locations of the five Pitot static tubes used to determine the velocity distribution. Figure 10 shows the model intake with the five Pitot tubes. The Pitot tubes could be easily rotated to measure any position around the pump intake. Velocity was determined from:

$$
\mathrm{V}=\mathrm{C}_{\mathrm{v}} \sqrt{2 \mathrm{~g} \Delta \mathrm{H}}
$$

where $C_{v}$ is a coefficient equal to 1.0 for the Pitot tubes used herein, $g$ is gravitational constant, and $\Delta \mathrm{H}$ is the difference between the total head and the static head. Ratios of point velocity/ average pipe velocity greater than or equal to 0.9 and less than or equal to 1.1 are within the HIS for velocity distribution. The HI requires velocity traverses along two perpendicular axes.

Nakato (2000) presents analysis addressing the best practices concerning velocity acceptance criteria for pump intake studies. Nakato presents a variety of criteria, which have been proposed in addition to the HI standards and points out that there was no consensus. The allowable variation from the cross section average velocity is either \pm 5 percent or \pm 10 percent. Some of the criteria do not define if the allowable variation is over the entire cross section or only along a circle of constant radius. Only two of the criteria specify the number of traverses. The HI specifies at least two perpendicular axes. The Iowa Institute of Hydraulic Research (IIHR) specifies eight radii separated by 45 degrees. IIHR is the only criterion to specify three points per radius plus one at the centerline.

Nakato also addresses the issue of what details should be modeled near the impeller of the pump. The pumps used at WCC are axial flow pumps with configuration as shown in Figure 9. The top of the truncated cone of the FSI is at EL -5.2. The impeller eye is at EL -5.0. J ust above the truncated cone, the pump throat has a uniform diameter of $10 \mathrm{ft}$ up to EL -2.0. Above the pump throat, the vane section of the pump flares out at a 4.0 degree angle up to EL 4.5. Above EL 4.5, the pump column flares out at a 6.1 degree angle to EL 10.6 where it begins the flowerpot section of the pump discharge outlet. Because of the uniform throat diameter and the mild 4.0 degree flare above the pump throat, the WCC model used a uniform diameter pipe above the top of the truncated cone. As in other studies, the hub and vanes were not included because they affect the measurement of swirl. The tip of the Pitot tube array in the 1:20 scale model was near the middle of the pump throat section at EL -3.5 . 


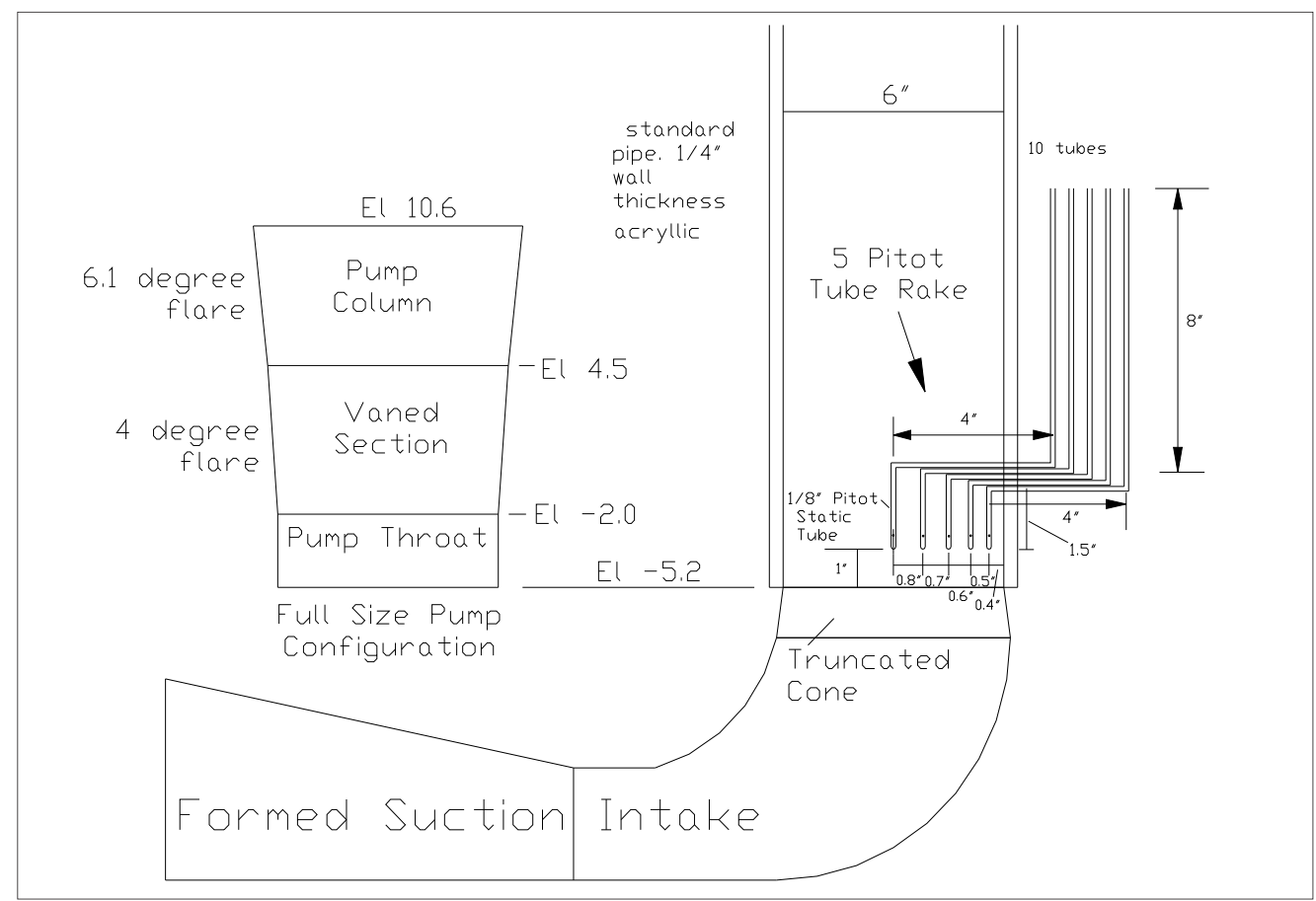

Figure 9. Schematic of Pitot tube locations.

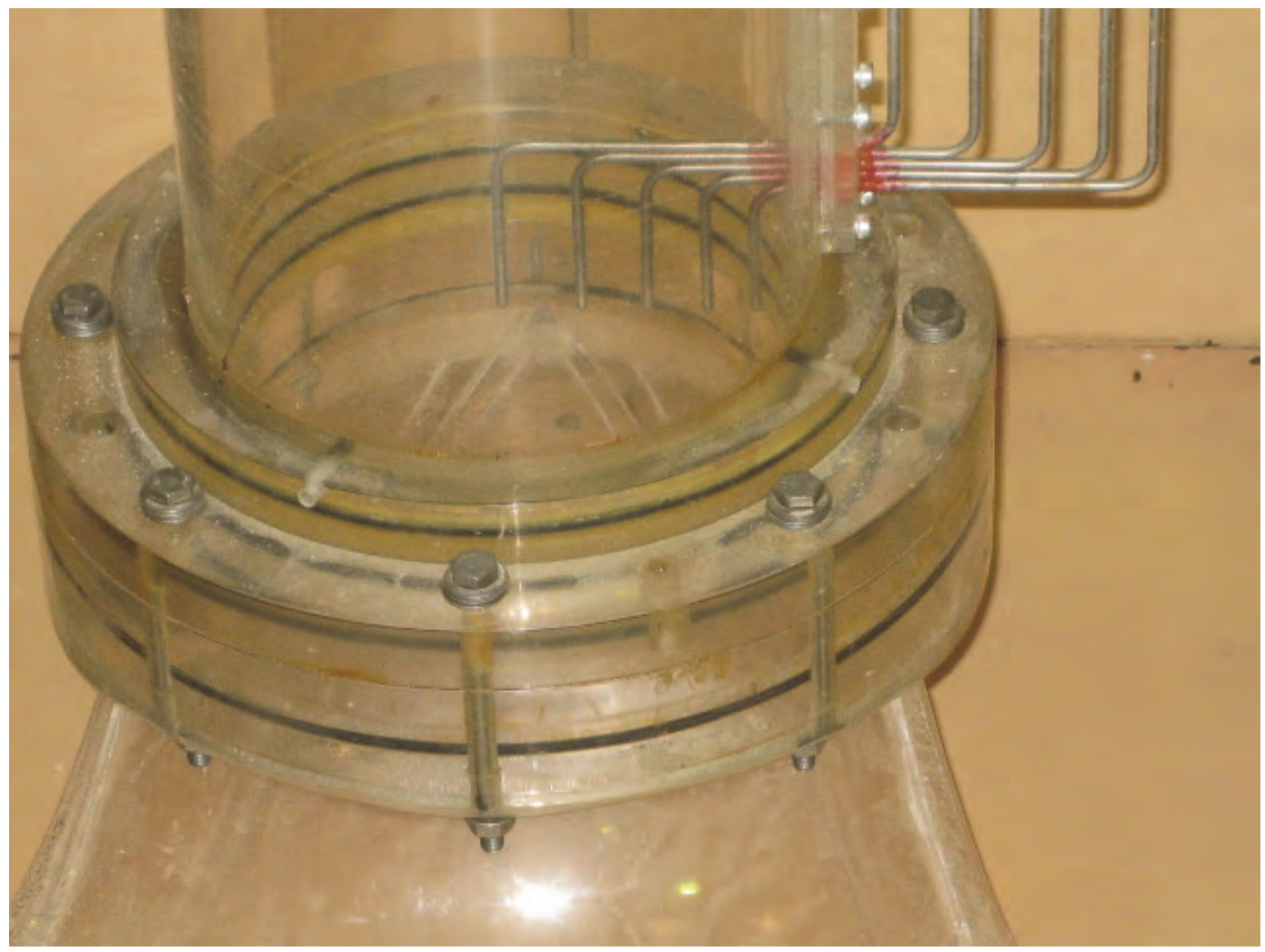

Figure 10. Model Pitot tube array at top of FSI. 
Nakato also recommended calculation of cross section average velocity in the throat based on a weighted average of the areas represented by each Pitot tube. The weighted area approach was used herein and areas represented by each Pitot tube are shown in Figure 11. The boundary between two sub areas was based on halfway between the two Pitot tube locations. Note that the Pitot tube at the centerline has a small representative area and thus small impact on the average velocity.

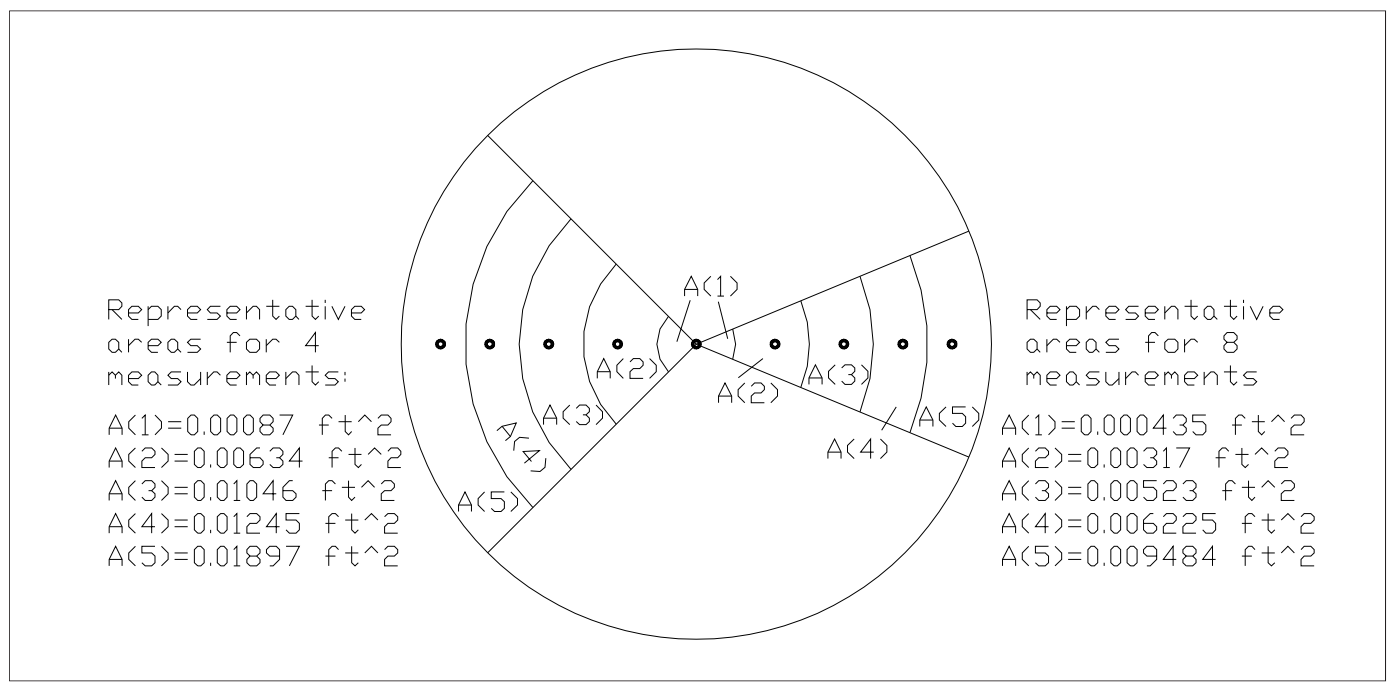

Figure 11. Areas represented by each Pitot tube.

The HI standards require velocity measurements along 4 radii. Because of the large number of pumps and pump operating combinations, most tests were measured with the 4.0 radii. However, some of the measurements were conducted with 8.0 radii as used by the IIHR to gain a full understanding of the velocity distributions based on the 4.0 radii measurements. The 8.0 radii measurements versus the 4.0 radii measurements will be discussed subsequently under the HI test results.

\subsection{Description of the 13-pump design}

At the 1:20 scale, the model reproduced approximately 2,500 ft upstream from the pump station and a portion of both the Harvey and Algiers Canals. The upstream model limits are shown in Figure 2. The initial model bathymetry was constructed using concrete molded to metal templates except for the area immediately upstream of the intake, which had riprap for $100 \mathrm{ft}$ (full scale) and a plywood bottom for $800 \mathrm{ft}$ (full scale) upstream. The plywood on the approach channel invert extended from the east bank over to the location of the flow divider wall. The 
plywood was used to allow ease of modifications in the approach to the intake. Pictures of the model are shown in Figures 12-15. Only limited testing was done with the configuration shown in Figures 12-15.

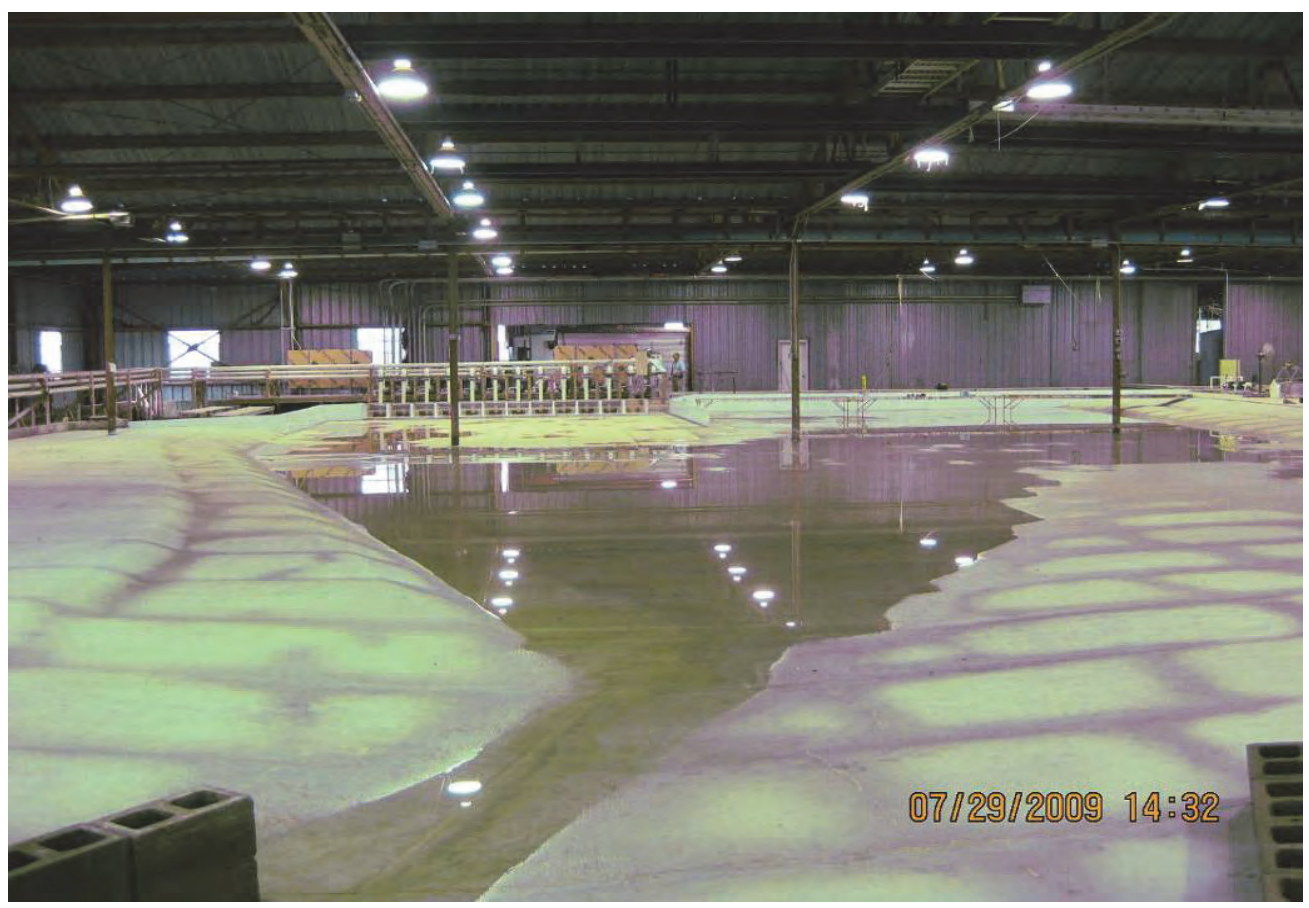

Figure 12. View of original 13-pumps design looking downstream from upstream end of model.

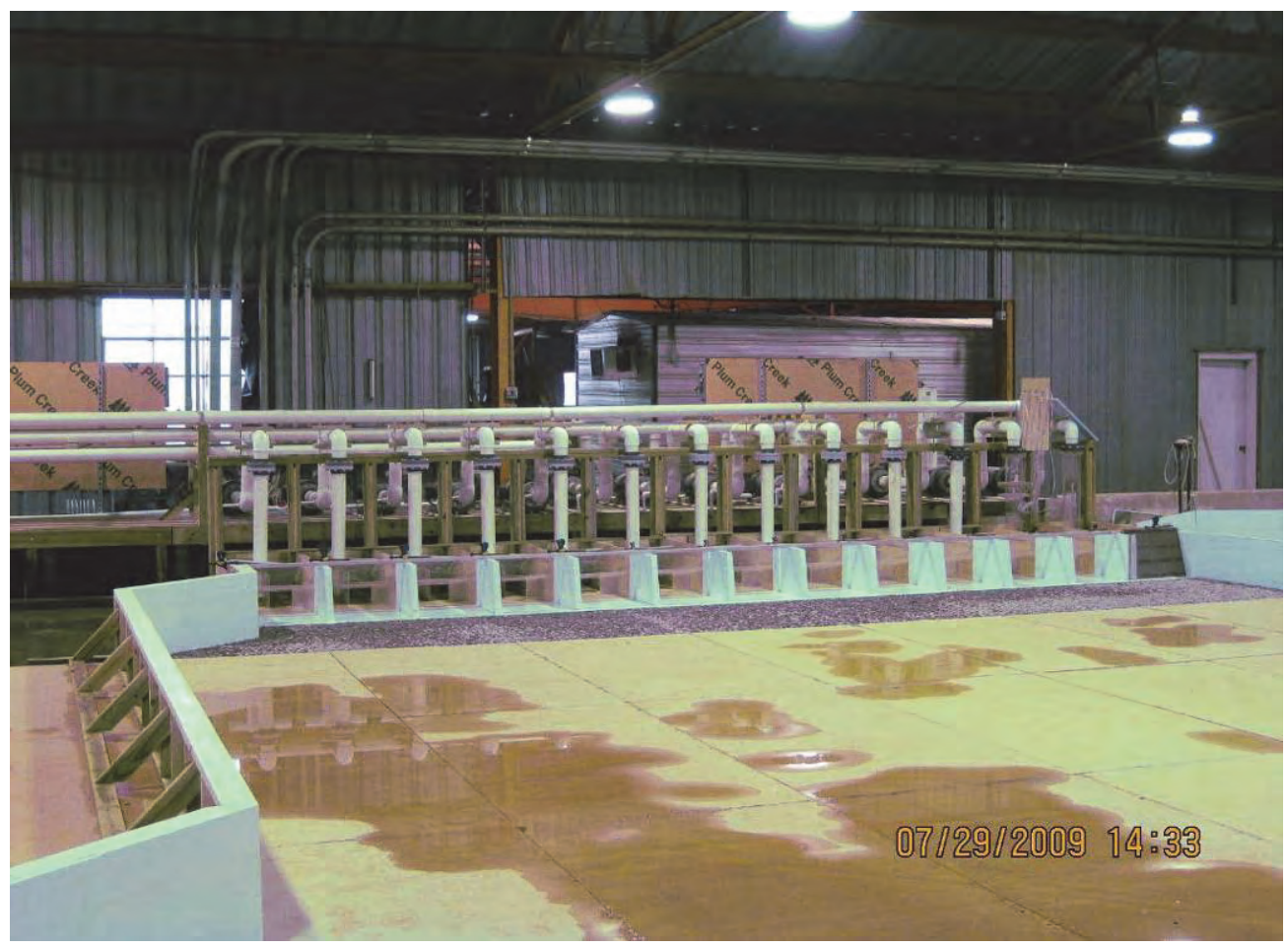

Figure 13. View of original design station with 13 pumps looking downstream. 


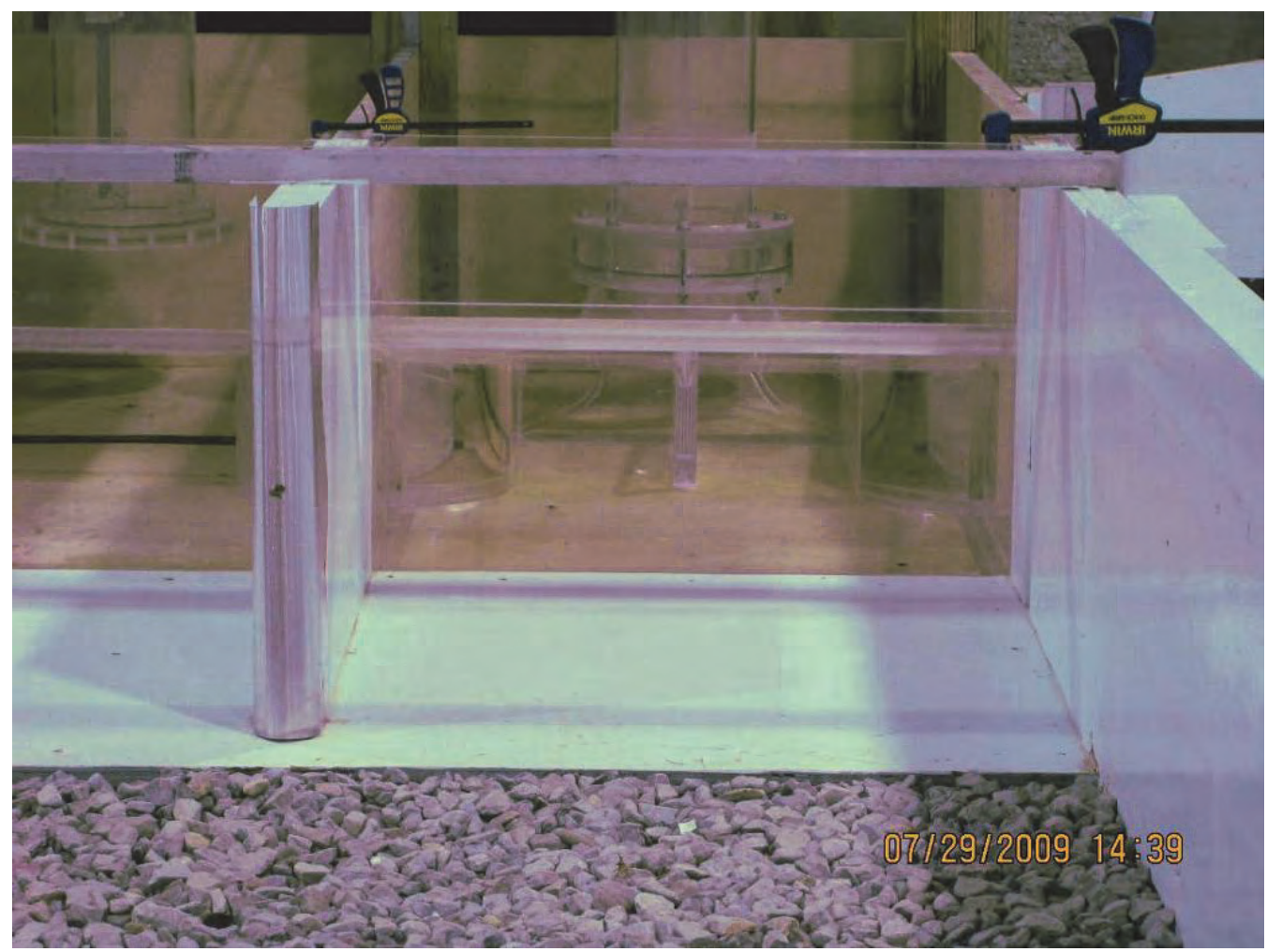

Figure 14. View looking downstream of contracted section and FSI in original design model.

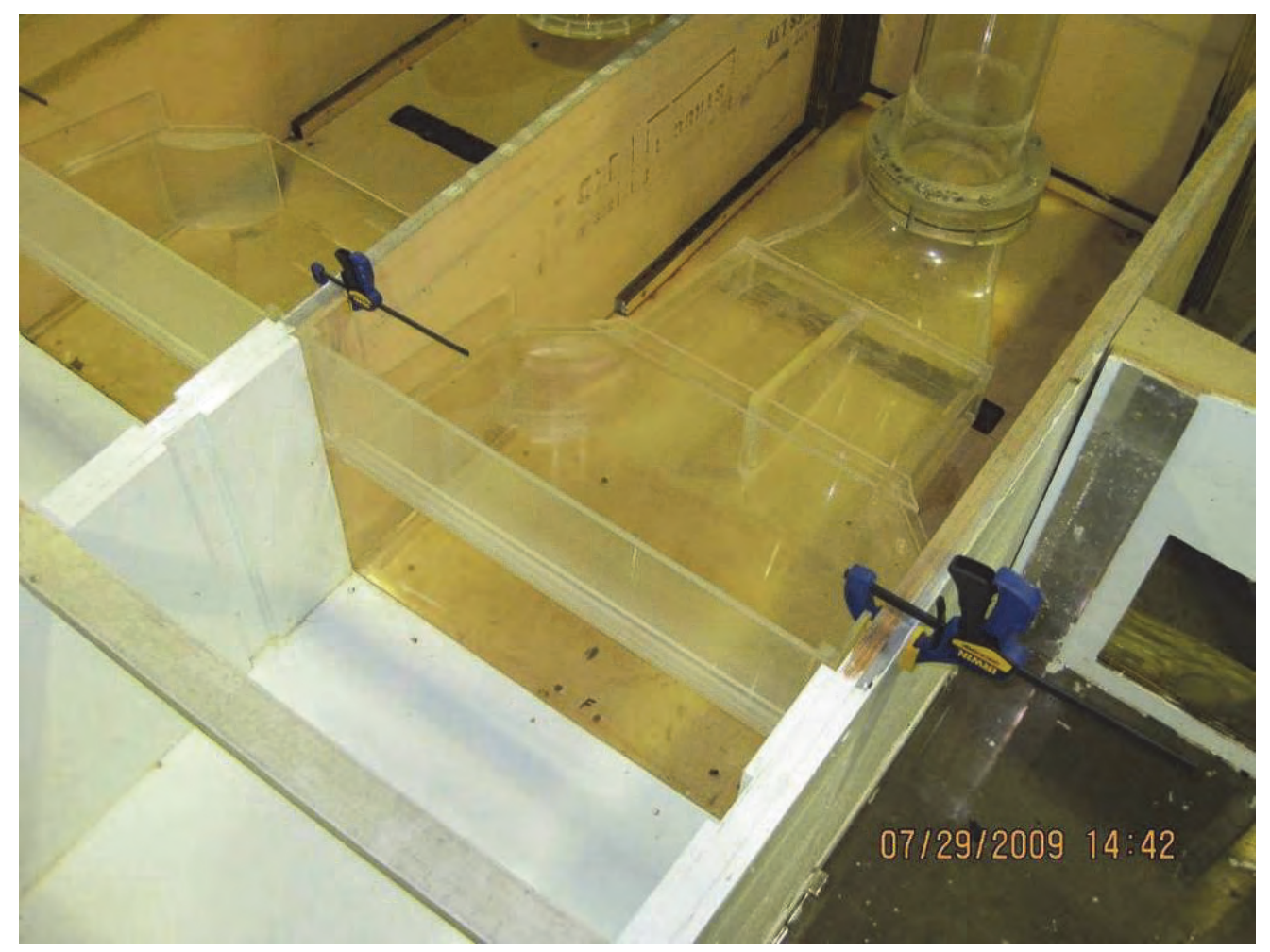

Figure 15. Top view of contracted section and FSI in original design. 
The invert and dividing walls of the pump intake were fabricated from plastic coated plywood. The plywood was initially painted white; however, when placed underwater, the painted surface gradually formed a bumpy surface, which was too rough for valid testing. The paint was sanded off as shown in subsequent pictures, such as Figures 20 and 21. The model pump intakes were constructed from commercially available 6-in. inside diameter acrylic tubes. The FSI and contracted section were constructed using acrylic molded to wooden forms. Only one complete FSI and contracted section unit was fabricated. The model contracted section and FSI are shown in Figures 14 and 15. This unit was moved to test each of the pump bays. The other 12 pump bays were fitted with only the contracted section to insure that flow entering the pump bay was similar to the actual contracted section and FSI.

In some hydraulic structure modeling, trash racks are not modeled with the assumption that they either do not affect the flow significantly or they improve the flow and, therefore, their omission is conservative. Pump intake performance is somewhat difficult to predict and this author used model trash racks. The model trash racks were designed based on keeping the same solidity ratio or percentage of blockage as the full scale intake and the same flow straightening characteristics. At a 1:20 scale, geometric scaling of the trash rack results in bars $1 / 40$-in. thick by 0.45 -in. deep separated by 0.225 -in. on center. Model bars cannot be fabricated that thin (1/40-in.) and remain stable in the model. The thinnest reasonable size in the model is about 1/ 16-in. In addition, bars and their spacing, that are too small, result in loss coefficients through the rack greater than the full scale. The solidity ratio or bar area/gross area must be maintained in model and prototype. The solidity ratio in the full scale system is $0.5 / 4.5=0.111$. The resulting center-to-center spacing in the model with $1 / 16$-in. thick bars was 0.5625 -in. to maintain the same solidity ratio. This results in 41 model bars in the $38.5 \mathrm{ft} / 20=1.925 \mathrm{ft}$ wide pump bay. The depth of the bars must be set to maintain the same flow straightening effect as in the prototype. This was achieved by keeping the depth to spacing ratio the same in model and prototype. The full size depth to spacing ratio was $9 / 4.5=2.0$. The resulting bar depth in the model was $2 \times 0.5625=1.125$-in. Velocities in the full size pump bay are $2.3 \mathrm{ft} / \mathrm{sec}$ and $0.51 \mathrm{ft} / \mathrm{sec}$ in the 1:20-scale model at intake water level at EL 2.0 and Q =1,740 cfs. The model Reynolds number based on bar thickness was $0.51 \times$ (1/ 16)/ 12/ $0.00001=263$. Papworth (1972) shows negligible scale effects for solidity ratio of 0.111 at Reynolds number above about 200-300. Summarizing, the 41 bars in each model trash rack 
will be 1/ 16-in. thick by 1.125-in. deep by 0.5625 -in. center-to-center spacing. The model trash rack is shown in Figure 16 . Three racks were made for the model. The racks were placed on the pump being tested and on each side of the test pump.

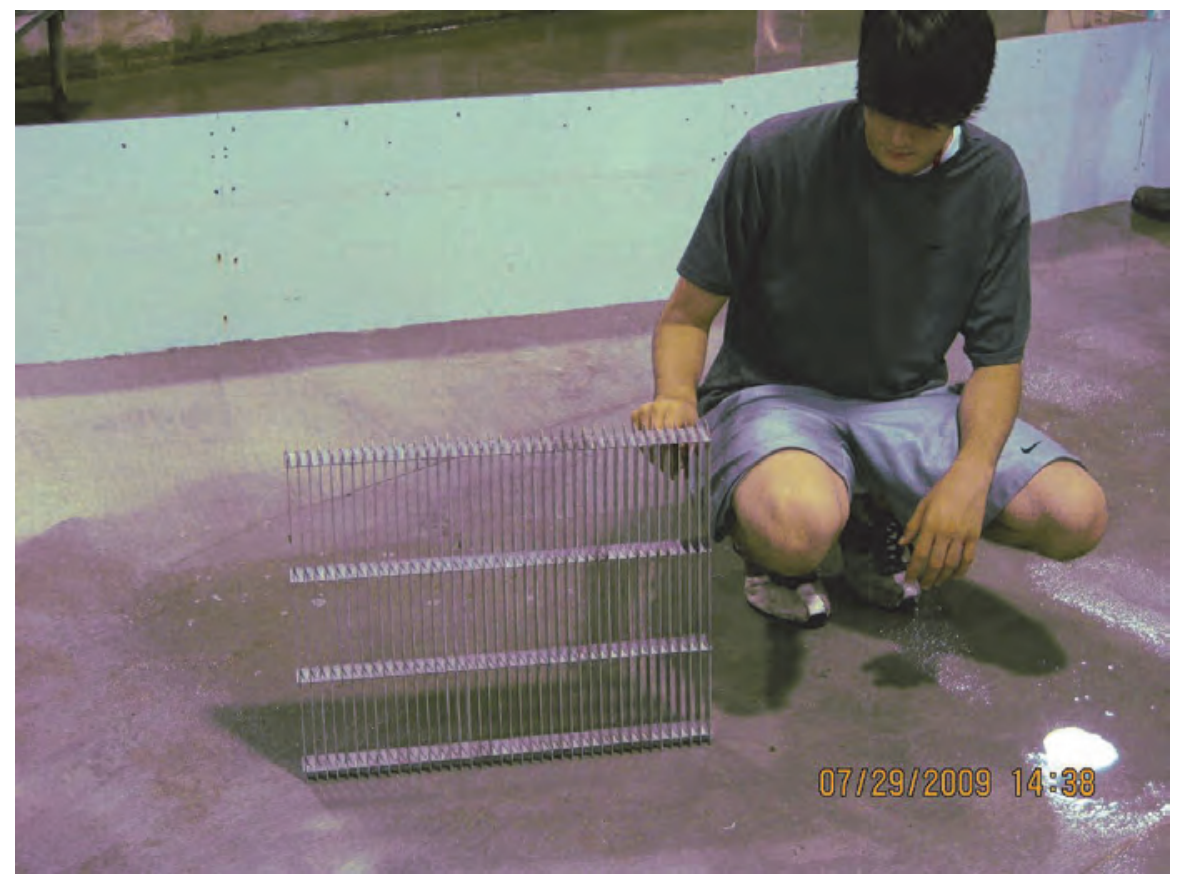

Figure 16. Model trash rack.

The WCC pump station model used the suction side of 13 centrifugal pumps to provide the correct intake flow conditions. The pumps discharged into the upstream (north) end of the model and re-circulated flow in the canal. The overflow weir at the upstream end was configured such that the length of overflow corresponded to the percentage of flow from each canal. Concrete block walls shown in Figure 17 were used to orient the flow leaving the overflow weir in the proper direction. Development of the location of these walls will be addressed subsequently.

Discharge in the 4-in. diameter pipe was measured using a Pitot-static tube. The Pitot tubes were used because they have minimal head loss and allow the maximum flow capacity from the model pumps, which was needed because maximum pump discharge was increased during the study. As a result of converting from 16 pumps to 11 pumps to reduce pump station cost, discharge to be simulated in the model increased from 1250 cfs to 1,740 cfs. To accommodate the increased discharge using the model pumps originally purchased for the 1,250 cfs simulation, it was necessary to minimize head loss in the model discharge lines. The WCC model had long 


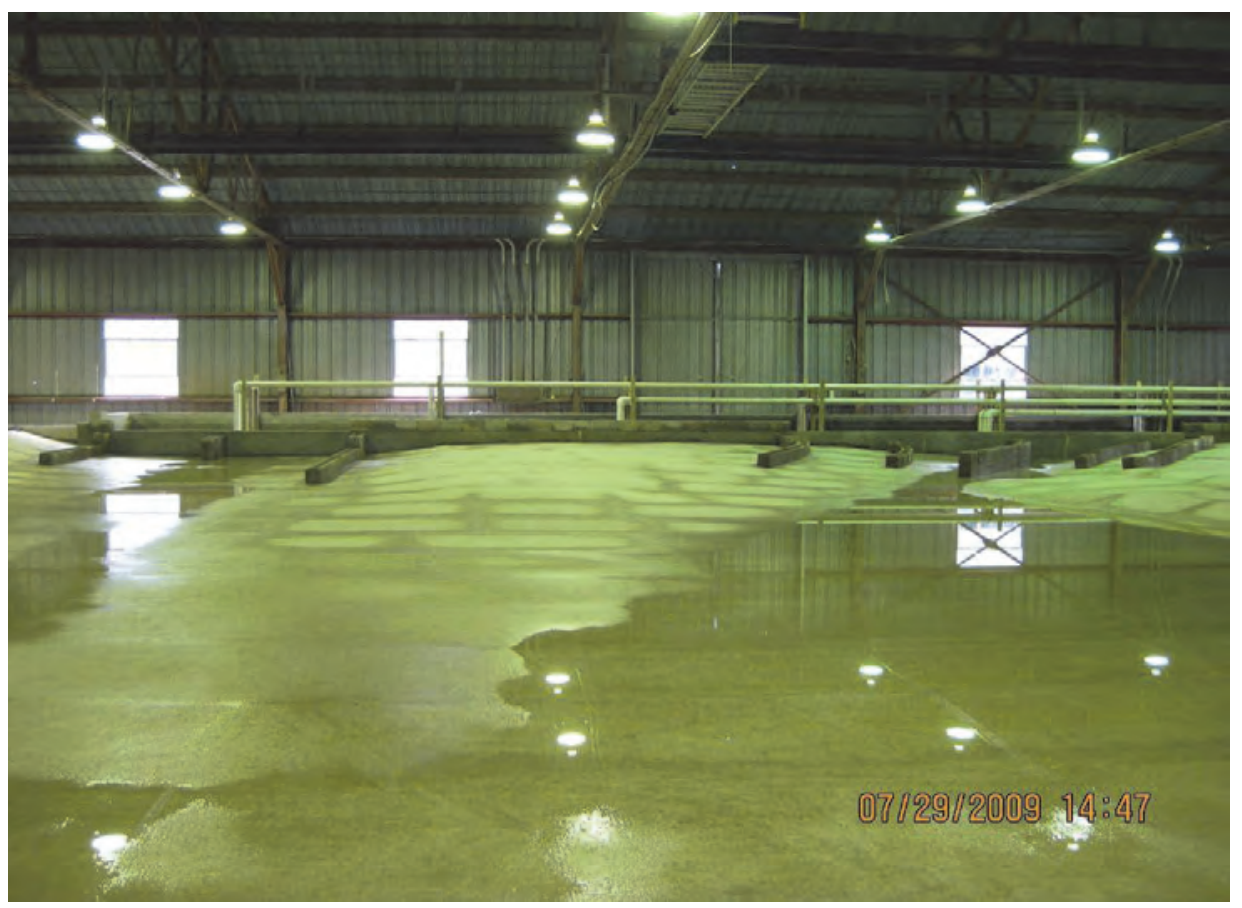

Figure 17. Approach walls used to guide flow from Algiers and Harvey Canals.

straight reaches of 4-in. diameter pipe on the discharge side of the pump (see Figures 12 and 17) in which velocity can be measured with a Pitot tube. The long pipe lengths available downstream of bends and valves in the WCC piping should result in almost no swirl and symmetrical velocity profiles in the pipe. A 1/8-in. diameter Pitot tube at the centerline of a 4-in. diameter PVC pipe was calibrated against flow measured using a 60 degree v-notch weir and a venturi meter. The ratio of centerline velocity measured with the Pitot tube to average pipe velocity determined from the v-notch weir and the venturi meter was 1.11 for flows typical of the WCC pump intakes. This ratio was used to convert centerline velocity to average pipe velocity to determine pump discharge. All 11 pumps were fitted with the Pitot tube flow meter. Subsequent tests with 1/8-in. diameter Pitot tubes placed at 20 different positions at the location of the pump impeller resulted in discharge within three percent of the discharge from the single Pitot tube reading in the 4-in. discharge pipe.

\subsection{Description of the 11-pump design}

The pump station was revised to an 11-pump configuration and the approach channel was changed as shown in Figures 18 and 19. The invert upstream of the pump station was raised and the east bank alignment of the pump station intake channel was modified. The changes were molded using "pea rock", which was $1 / 4$-in. diameter rounded stone. 


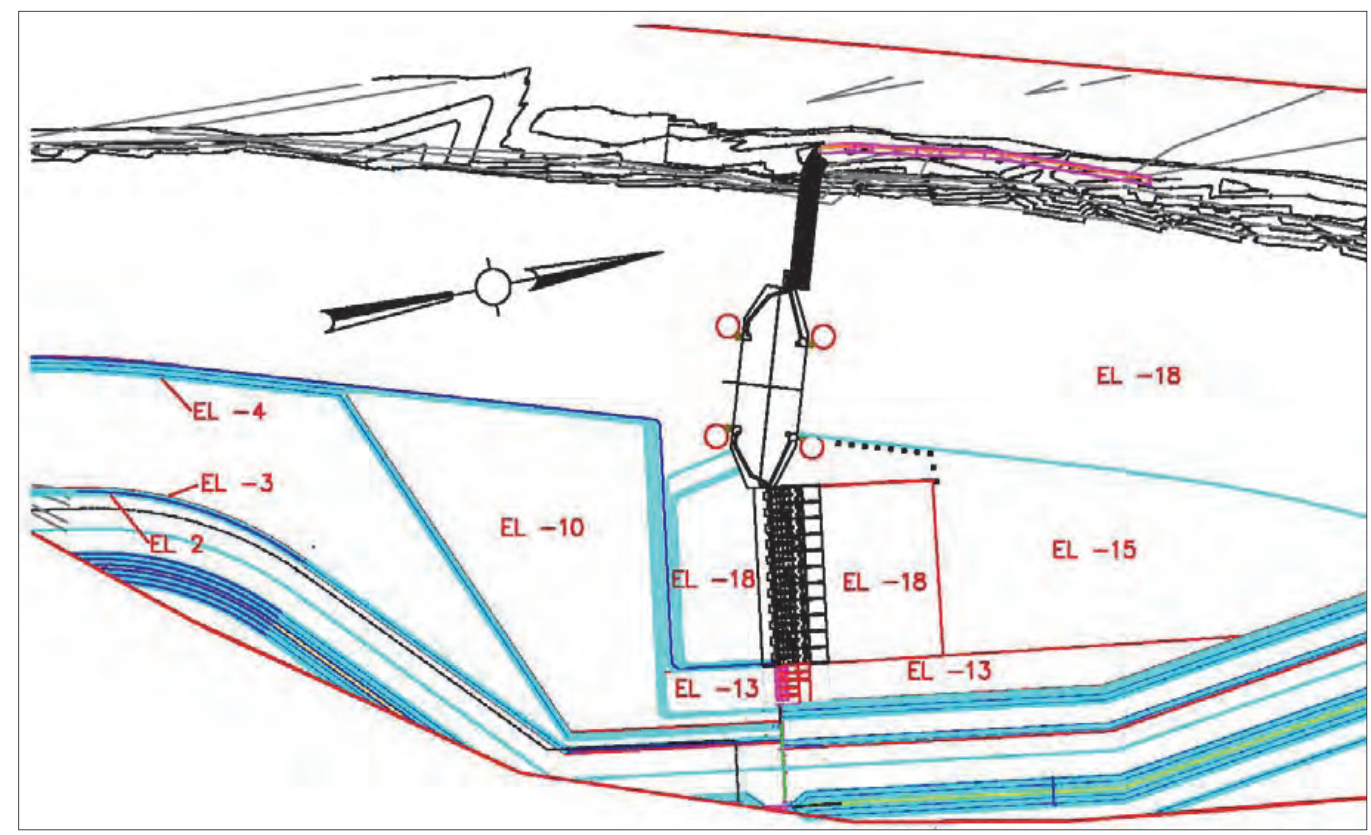

Figure 18. Revisions to approach channel and reduction from 13 to 11 pumps. Includes $300-\mathrm{ft}$ long flow dividing wall between sector gates and pump station and sluices between pump station and east bank.

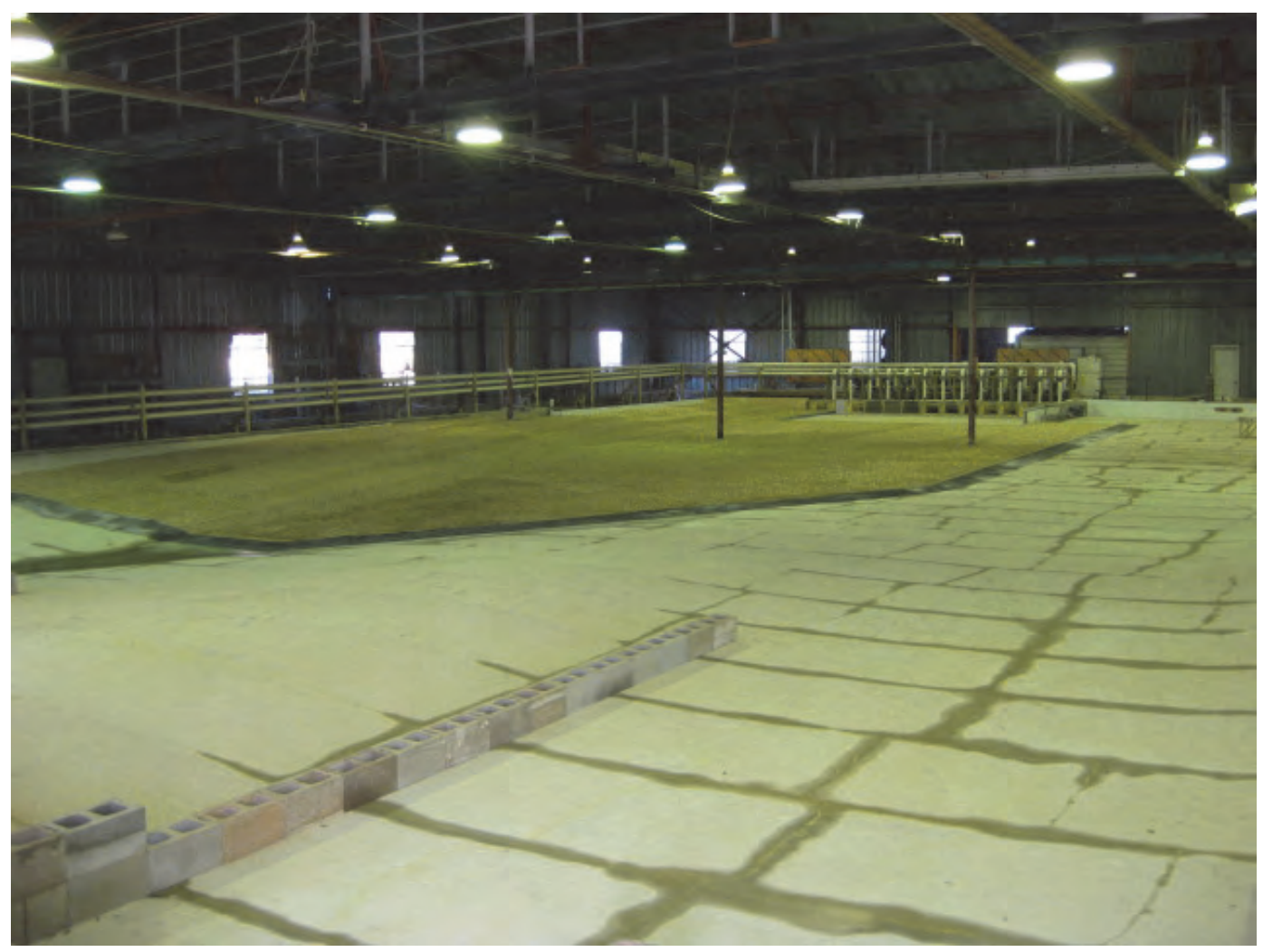

Figure 19. View of revised approach channel looking downstream. 
Figures 20 and 21 show the east bank where the two unused pump bays were located from the original 13 pump design. These two bays on the east side are in the location of the sluice gates in the revised design. The upstream ends of the dividing walls of the sluices are about $60 \mathrm{ft}$ downstream of the upstream ends of the dividing walls of the pump station. This allows a portion of the flow along the east bank to travel downstream of the upstream ends of the pump station dividing walls which wrap around the first pump station dividing wall as shown in the schematic in Figure 22. The vertical wall to the left or east of the two unused pumps (see Figures 20 and 21) was positioned downstream of the pump bay walls to allow the flow in the model to wrap around the pump bay dividing wall and model the contraction of flow properly at the east dividing wall of the first pump on the east side. Also note in Figures 20 and 21 that the riprap distance upstream of the pump station has been reduced to a distance of $50 \mathrm{ft}$ upstream. The 300 -ft long flow divider wall between the pump station and the sector gates was revised from a smooth concrete wall to sheet pile configuration modeled as shown in Figure 23.

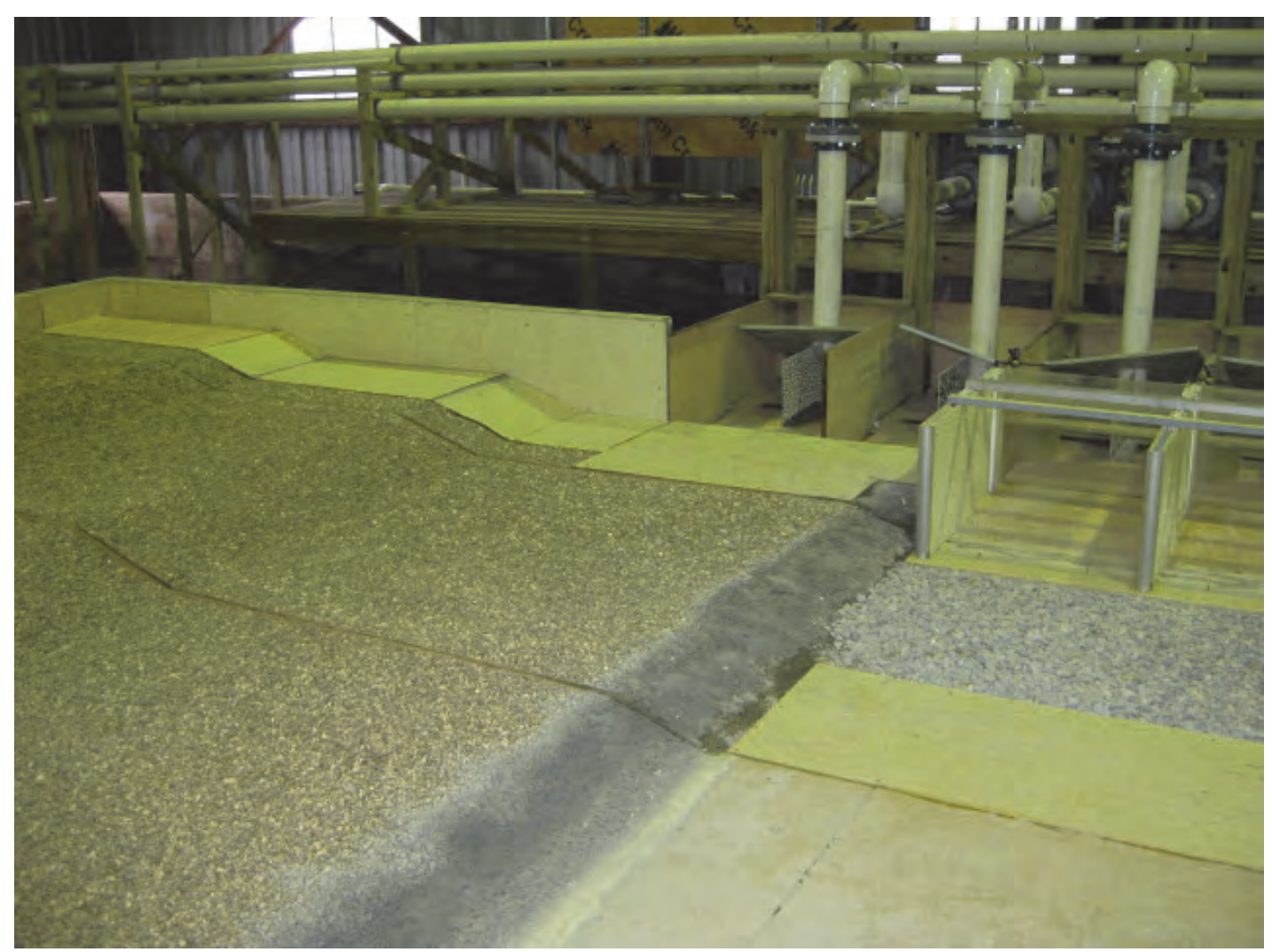

Figure 20. View looking downstream of east bank at two unused pump bays, which are in the location of the sluices. 


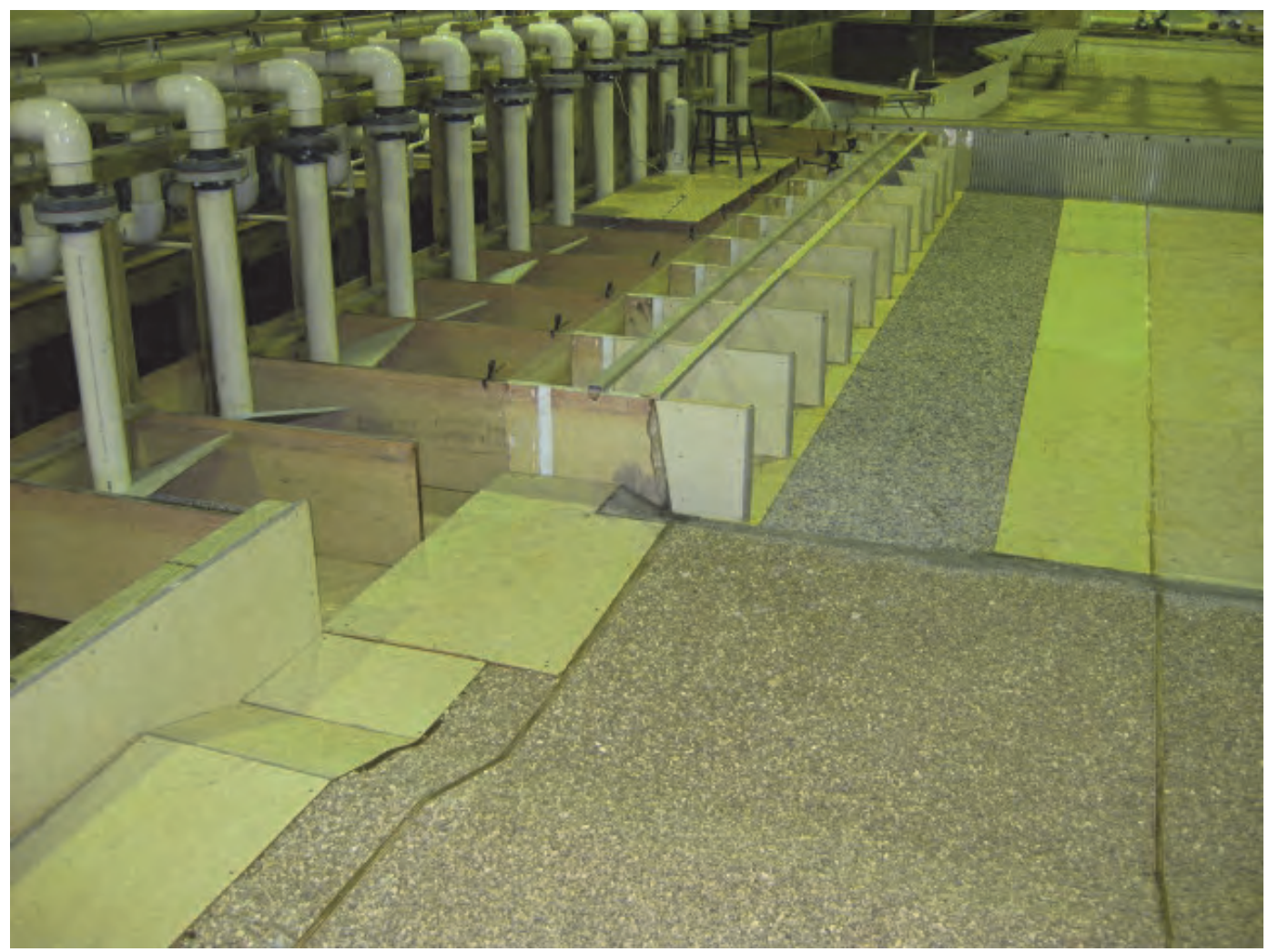

Figure 21. View looking west of east bank at two unused pump bays, which are in the location of the sluices.

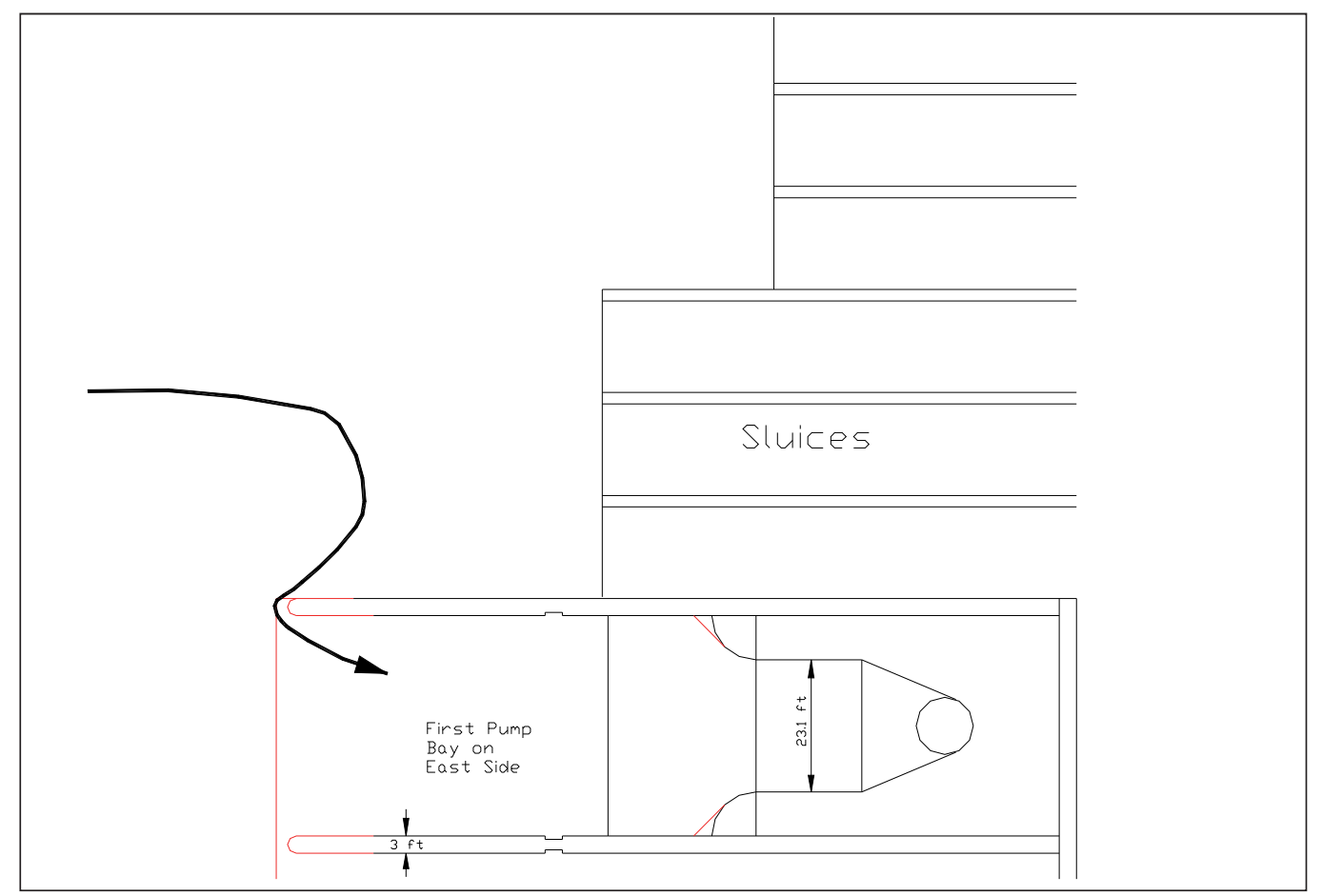

Figure 22. Schematic of east bank area and potential wrap around of flow at the east dividing wall of the easternmost pump bay. 


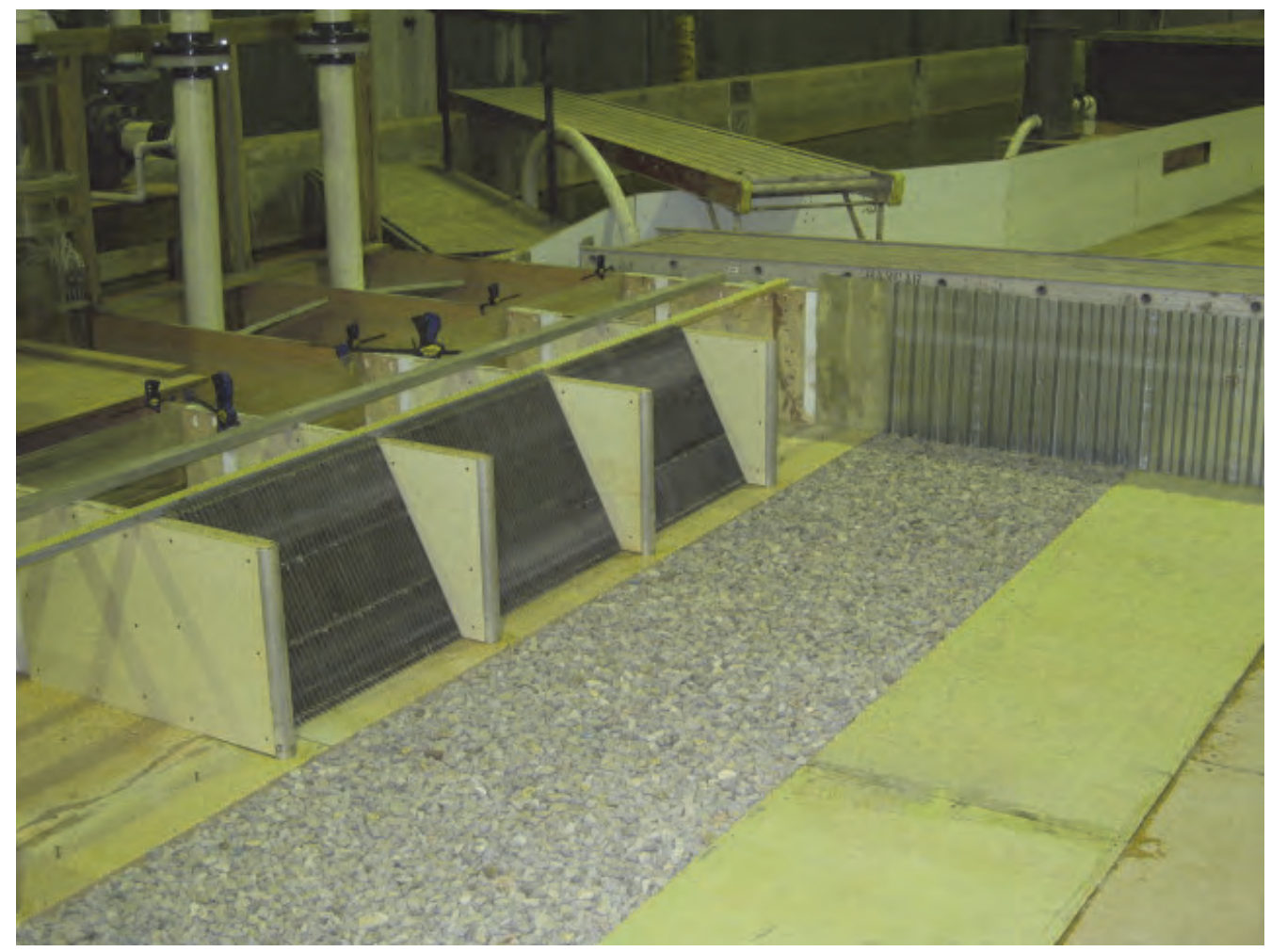

Figure 23. View showing model sheet pile wall used to form 300-ft long flow divider wall between the pump station and the sector gate.

\subsection{Selection of flow divider wall length for initial model tests}

A numerical model was used to simulate the region upstream of the closed sector gates to determine the inflow distribution to use in the physical model and to evaluate different lengths of the flow divider wall. The numerical model was the 2-D module of the Adaptive Hydraulics (AdH) finite element flow solver (http://adh.usace.army.mil/). The numerical model upstream limits extended well upstream on both Algiers and Harvey Canals. These tests were conducted when the station design included 13 pumps. Results are valid for the revised design having 11 pumps because the upstream end of the model was not altered. Flow divider wall lengths upstream of the pump station of $300 \mathrm{ft}, 500 \mathrm{ft}$, and $800 \mathrm{ft}$ were run in the numerical model. The 800-ft wall length was not considered after it became obvious that the upstream end of the wall was too close to the edge of the navigation channel. Velocities computed in the numerical model for the 300-ft long wall and 500-ft long wall for the typical 65 percent Algiers-35 percent Harvey Canal flow split, and all 13 pumps operating are shown in Figures 24 and 25, respectively. The outflow boundary was the upstream end of the dividing walls between the pump bays. The 300 - $\mathrm{ft}$ long wall had velocity approaching $2.5 \mathrm{ft} / \mathrm{sec}$ close to the intake whereas velocities of 


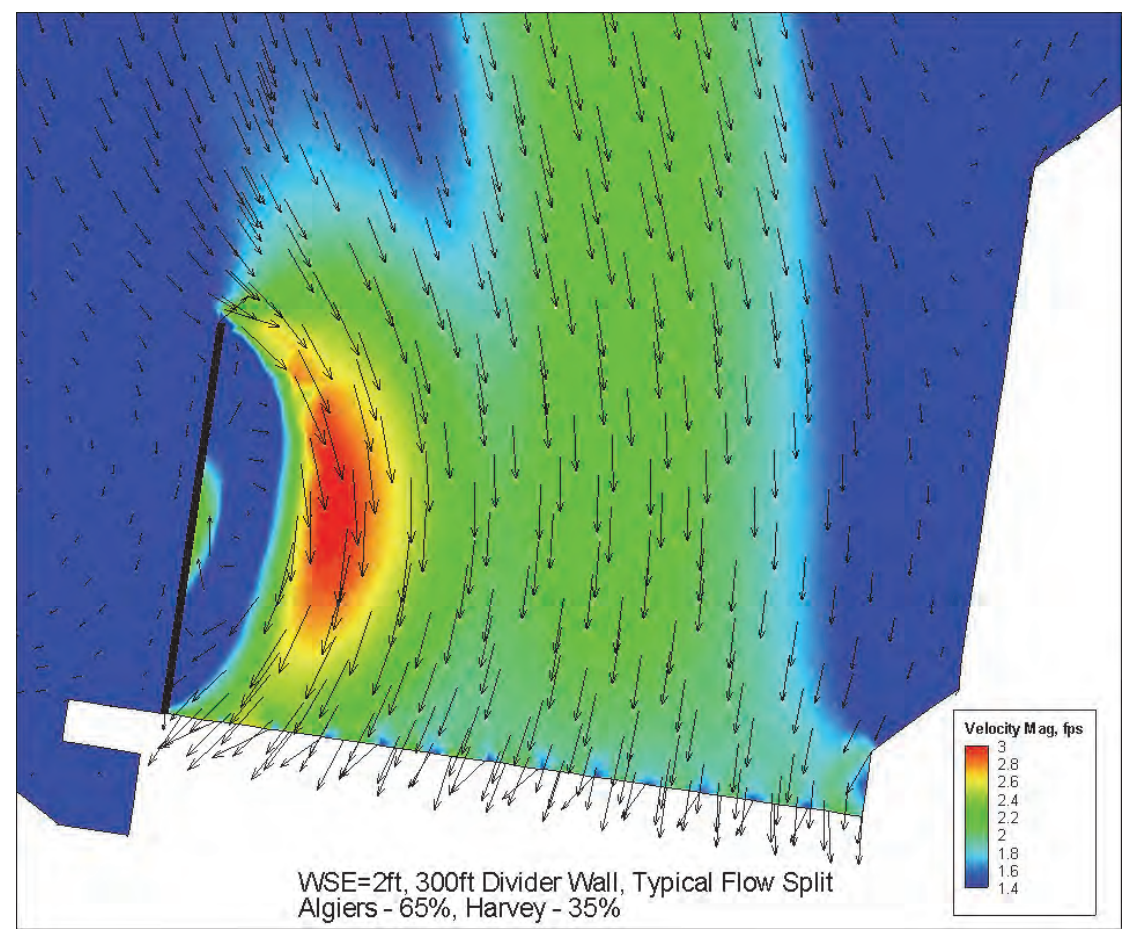

Figure 24. 300-ft long flow divider wall. Velocity vectors and velocity magnitude with original design having 13 pumps. Water surface at EL 2.0, normal flow split of 65 percent Algiers/35 percent Harvey Canal. All pumps operating.

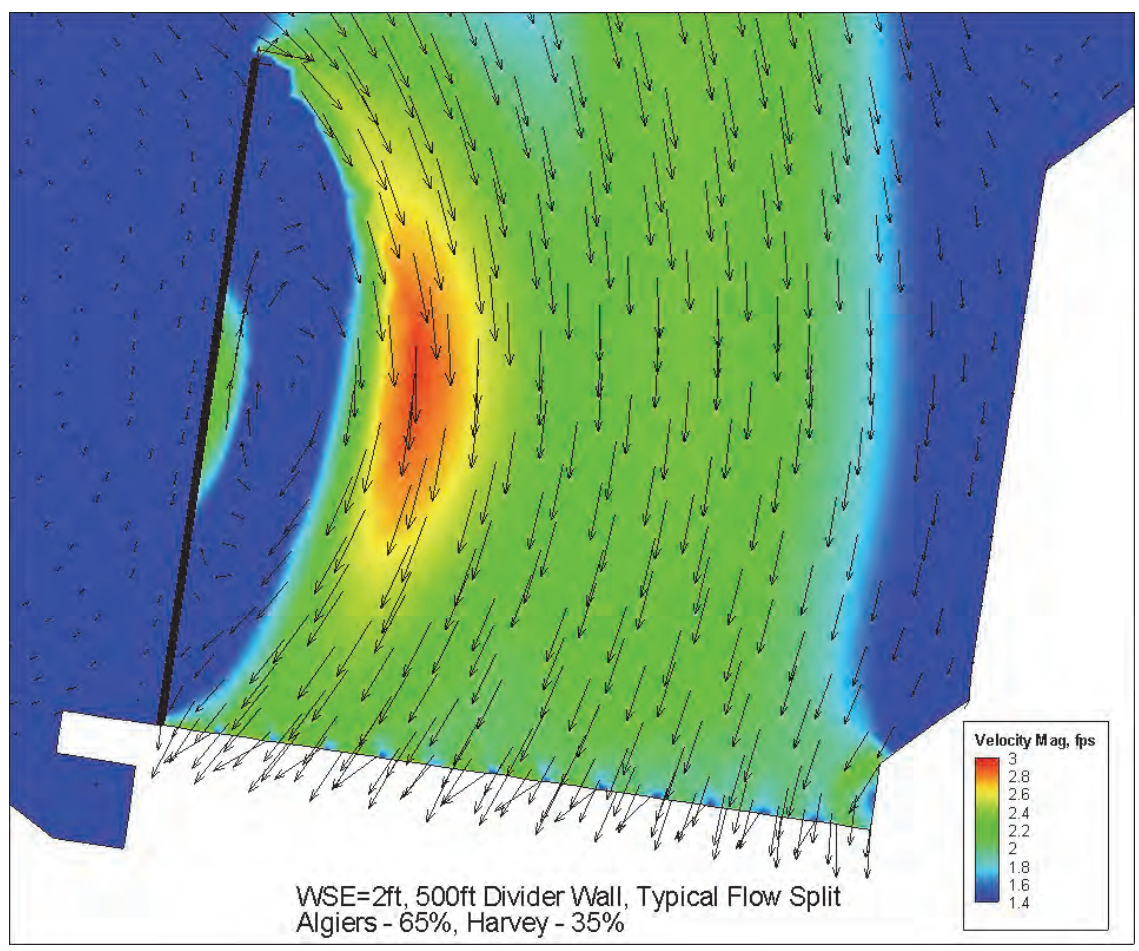

Figure 25. 500-ft long flow divider wall. Velocity vectors and velocity magnitude with original design having 13 pumps. Water surface at EL 2.0, normal flow split of 65 percent Algiers/35 percent Harvey Canal. All pumps operating. 
$2.5 \mathrm{ft} / \mathrm{sec}$ ended about 100-ft upstream of the intake with the 500 -ft wall. Preliminary tests with intake level at EL 2.0 showed that the 500 - $\mathrm{ft}$ wall was better than the 300-ft long wall concerning swirl and surface vortices. However, both were within HI standards. Tests with less than all pumps operating showed that the number of pumps operating was just as important to the angle of flow approaching the pump bay as was the length of the flow divider wall. Considering the cost of an additional $200-\mathrm{ft}$ of wall, the finding of swirl and vortices within $\mathrm{HI}$ standards, and the fact that we had an FSI and a contracted section to straighten the flow, the decision was made to adopt the 300-ft long wall for initial testing of the intakes.

Figure 24 with the 300 -ft long flow divider wall shows trends that were present for both dividing wall lengths and both 13 and 11 pump configurations. With all pumps operating, pumps on the west side (side closest to flow divider wall) had the most severe cross flows. Pumps on the east side had almost straight approach flow into the pump bay. These flow patterns will be addressed subsequently in more detail with the recommended 11 pump configuration.

The initial tests with the flow divider wall were conducted with a smooth wall to represent a reinforced concrete wall. The final design tested in the model was a "Z" section sheet pile that has a depth of 15.25-in.

After completion of testing with the 300 -ft long flow divider wall, shorter flow dividing walls were tested, and their results will be discussed subsequently.

\subsection{Calibration of Inflow Distribution in the Model}

Considering available shelters in which to place the physical model, a long distance upstream of the confluence of Harvey and Algiers Canals could not be modeled at the desired 1:20 scale. The flow at the upstream end of the physical model had to be divided into the correct Algiers/Harvey ratio and the flow had to be aligned to reflect the flow conditions leaving the Algiers and Harvey Canals.

The AdH numerical model of the region upstream of the closed sector gates was used to determine the inflow distribution to use in the physical model. Results from the numerical model are shown in Figure 26 at a location $300 \mathrm{ft}$ upstream of the pump station between the flow divider wall and the east bank of the pump station channel. These results were for a 500 -ft long 


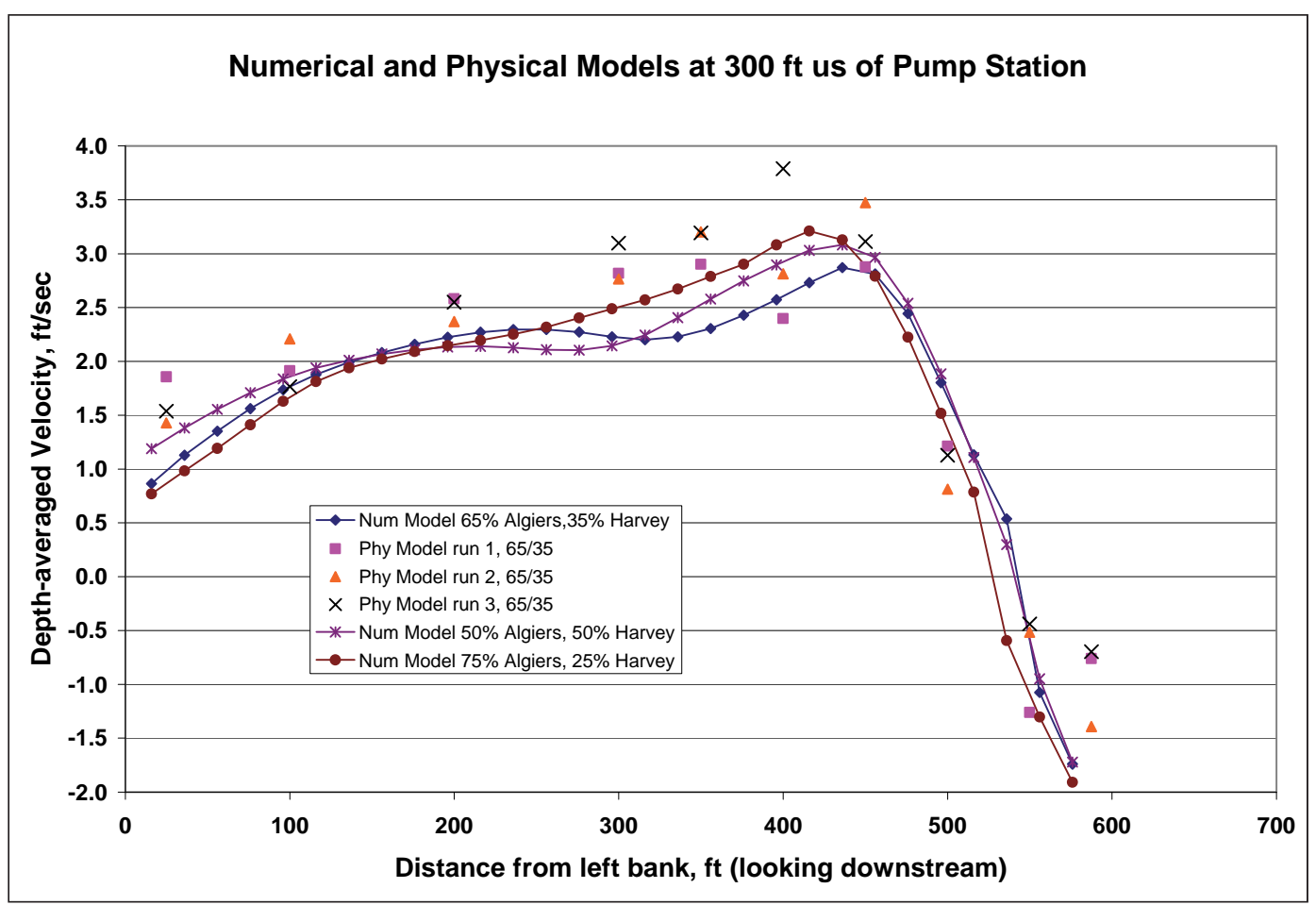

Figure 26. Numerical and physical model velocities $300 \mathrm{ft}$ upstream of pump station with 500-ft long flow divider wall.

flow divider wall with no rounding of the upstream end of the wall, water level set at EL 2, and 20,000 cfs discharge. The numerical model velocities are shown for inflow distributions of the typical 65 percent Algiers-35 percent Harvey, 50 percent-50 percent, and 75 percent Algiers- 25 percent Harvey. These results from the numerical model show that the inflow distribution does not make much difference in the velocity distribution at a location $300 \mathrm{ft}$ upstream of the pump intakes. Based on this finding, model tests were conducted with the typical 65-35 percent flow split.

The model had a level overflow wall at the upstream end, which distributed the flow from the discharge pipes from the pumps. The overflow wall was partitioned into two overflow sections. The overflow weir length in the model for Algiers Canal was $25.8 \mathrm{ft}$ long versus $14.0 \mathrm{ft}$ long for Harvey Canal for the typical 65 percent/ 35 percent flow split. The next step in obtaining the correct velocity distribution approaching the intake was to place vertical walls just downstream of the overflow sections to guide the flow in the proper direction indicated by the numerical model.

These vertical walls were constructed out of 8-in. x 16-in. x 8-in. concrete blocks. Different concrete block wall configurations were tested in the 
model and velocities were measured at the 300 -ft location upstream of the pump station. Figure 26 also shows three replicates of velocity measurements conducted for the inflow wall configuration having the best agreement with the numerical model velocities. Each of the data points in the figure was the average of three readings using an electromagnetic velocity meter placed at 0.6 of the depth below the surface. Each of the three readings was an average over $15 \mathrm{sec}$ (model) duration. Measured velocities with the best wall inflow configuration showed good agreement with the numerical model results. This wall configuration was used in all model tests along with the 65-35 percent inflow distribution. The three data points from the physical model at each lateral location showed some variations in magnitude, which were consistent with variations in dye movement in the model. Flow approaching the pump intakes was not steady, likely as a result of the presence of a dead area in front of the sector gates, flow separation at the left descending bank of Algiers Canal, and flow separation at the upstream end of the flow divider wall. This unsteadiness was observed in the flow entering the upstream end of each pump bay. The numerical model simulations exhibited fluctuations over time as in the physical model, indicating that these fluctuations were not the result of some problem in the physical model. Whether this unsteadiness was detrimental to the pumps was determined when HI standards were applied to the observations in the physical model intake. 


\section{Testing}

\subsection{Preliminary test results with 13 pumps}

During a visit from the design builder HNTB, several preliminary tests were run to look at high flows and low intake levels for the initial design having 13 pumps. Intake performance was not evaluated according the HI standards but several useful observations resulted from these tests and are presented herein. Tests were run with the FSI on Pump 11 and intake EL 0. The initial flow was set at 1540 cfs on all 13 pumps. Flow in Pump 11 was increased up to $1810 \mathrm{cfs}$. Swirl was low and vortices were Type 2 or less. All 13 pumps were set at a discharge of $1574 \mathrm{cfs}$ and intake level remained at EL 0 . The FSI was moved to Pump 8. Vortices were Type 2 or less and swirl was low. The intake level was reduced to $-1.0 \mathrm{ft}$ with all pumps operating at a discharge of $1574 \mathrm{cfs}$ and swirl and vortices were acceptable. The intake was then lowered to - $2.0 \mathrm{ft}$ and Pumps 7-9 were increased in discharge up to 1810 cfs. The FSI was still on Pump 8. Vortices and swirl remained acceptable. Tests were conducted by blocking about 60 percent of the trash rack. The blockage was placed on each side and in the middle. While frequency of vortices increased as did swirl, both appeared to be within acceptable limits. These preliminary tests were followed by tests according to HI standards.

\subsection{Approach flow patterns with 11 pumps}

Tests were conducted with various combinations of pumps operating to look at the relative magnitude of non-uniform or skewing of the flow entering the pump bay. Results presented herein were based on a 150-ft flow divider wall (which was ultimately recommended) and the longer, correct dividing walls between pump bays. Each side of the pump bay was evaluated for severity of flow contraction at the dividing wall between the pump bays. The observed flow contraction was a combination of both converging flow into the pump bay and the skewing of the approach flow. Approach flow skewing at pumps near the flow divider wall became greater with increasing number of pumps operating because of the greater effects of the flow divider wall and upstream geometry. Approach flow skewing also increased when adjacent pump bays were not operating. Tests were conducted without the model trash racks because the racks interfered with the dye observations. Based on observing the model, a four level ranking of the severity of contraction at the 
dividing wall was used based on dye measurements. Dye was injected $2.0 \mathrm{ft}$ upstream of the dividing walls and $2.0 \mathrm{ft}$ below the water level, as shown in Figure 27. The position of the dye was measured as it passed through a plane 20-ft downstream of the upstream end of the dividing walls as shown in Figure 27. The example shown in Figure 27 was based on the center of the dye trace measured $17 \mathrm{ft}$ from the wall of the pump bay. Expressed as a percentage of the pump bay width, this results in (17/38.5) x $100=44$ percent of the pump bay width. The first category of dividing wall contraction was $\mathrm{N}$ for "almost no contraction of flow at this dividing wall" if the measured distance from the dividing wall was five percent or less of the pump bay width. The next category of dividing wall contraction was $\mathrm{M}$ for "minor contraction of flow at this dividing wall" if the measured distance was greater than five percent but less than or equal to 20 percent of the pump bay width. The next category of dividing wall contraction was $\mathrm{S}$ for "significant contraction of flow at this dividing wall" if the measured distance was greater than 20 percent but less than or equal to 40 percent of the pump bay width. The largest category of dividing wall contraction was $\mathrm{L}$ for "large contraction of flow at this dividing wall with large cross flow" if the measured distance was greater than 40 percent of the pump bay width. These tests were only indicative of flow patterns near the water surface.

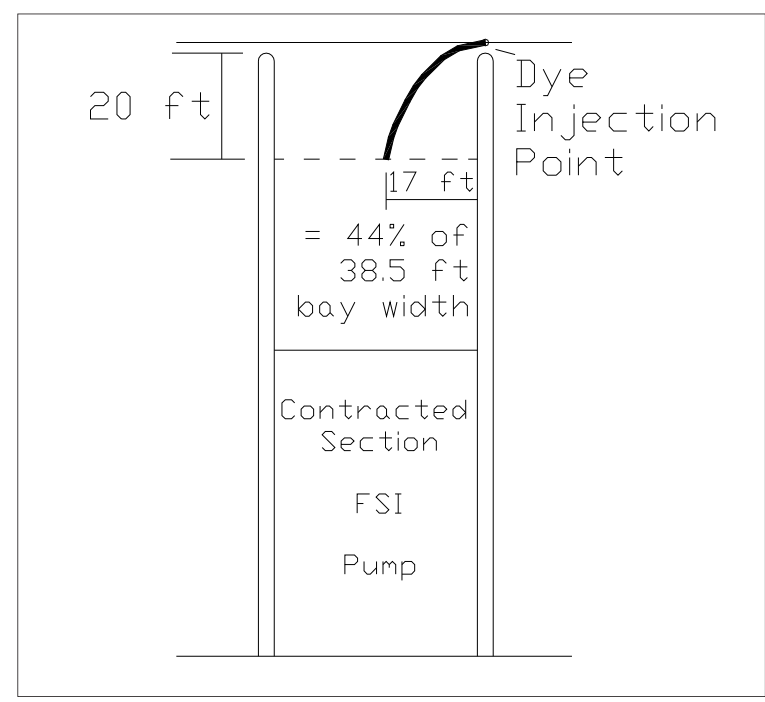

Figure 27. Location of dye injection and observed path of dye in evaluating dividing wall contraction. Applies to surface currents only.

Figure 28 shows the contraction at the dividing walls with Pumps 4-6 operating. In addition to the four level ranking, the measured percentage of the pump bay width from the dividing wall is also shown. The lack of 
dividing wall contraction at Pump 5 for this pump operating condition results in the most uniformly distributed approach flow of any pump at WCC. Note that a rating of $\mathrm{N}$ often requires the adjacent pump to be in operation. Pumps 4 and 6 had significant non-uniformity of approach flow because of dividing wall contraction on only one side of the pump bay. Pump operation of 3-5 and 5-7 resulted in these same flow patterns of the middle pump having a uniformly distributed approach velocity.

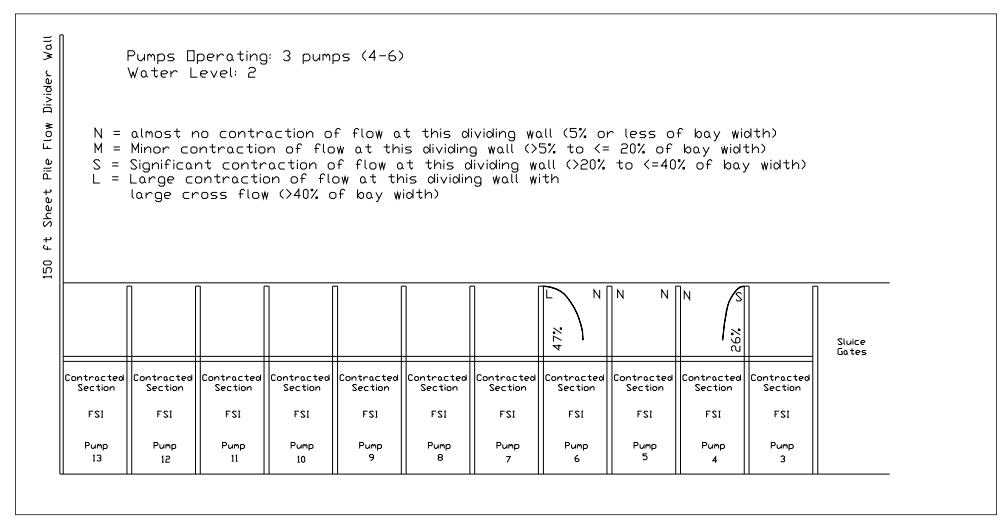

Figure 28. Dividing wall contraction with Pumps 4-6 operating. Water level at EL 2.0 and discharge $=1,740 \mathrm{cfs} /$ pump.

Figure 29 shows the contraction at the dividing walls with single pumps operating. All pumps are shown on this one plot but the contraction shown was for single pump operation. With only one pump operating, flow around the 150-ft long flow divider wall only affected those pumps near the flow divider wall. When operating by themselves, Pumps 3-8 did not have a significant imbalance of flow but did have a concentration of flow in the middle of the bay because of the significant dividing wall contraction effects on both sides of the pump bay. Pump bays 9-13 had various levels of imbalance of flow due to the effects of the flow divider wall. The level of flow imbalance with single pump operation was less than some of the pump operating combinations described subsequently. Figure 30 shows dye injections at Pump Bay 8 for single pump operation.

Figure 31 shows the contraction at the dividing walls with all pumps operating. Pump bays on the ends showed varying levels of flowimbalance up to the largest found in these tests that was Pump 3 with an L on one side and $\mathrm{N}$ on the other side. The HI tests presented subsequently will show whether the contracted section and the FSI could deal with this level of flow imbalance. Figures 32-35 show dye injection with all pumps operating at Pumps 3, 8, 12, and 13, respectively. 


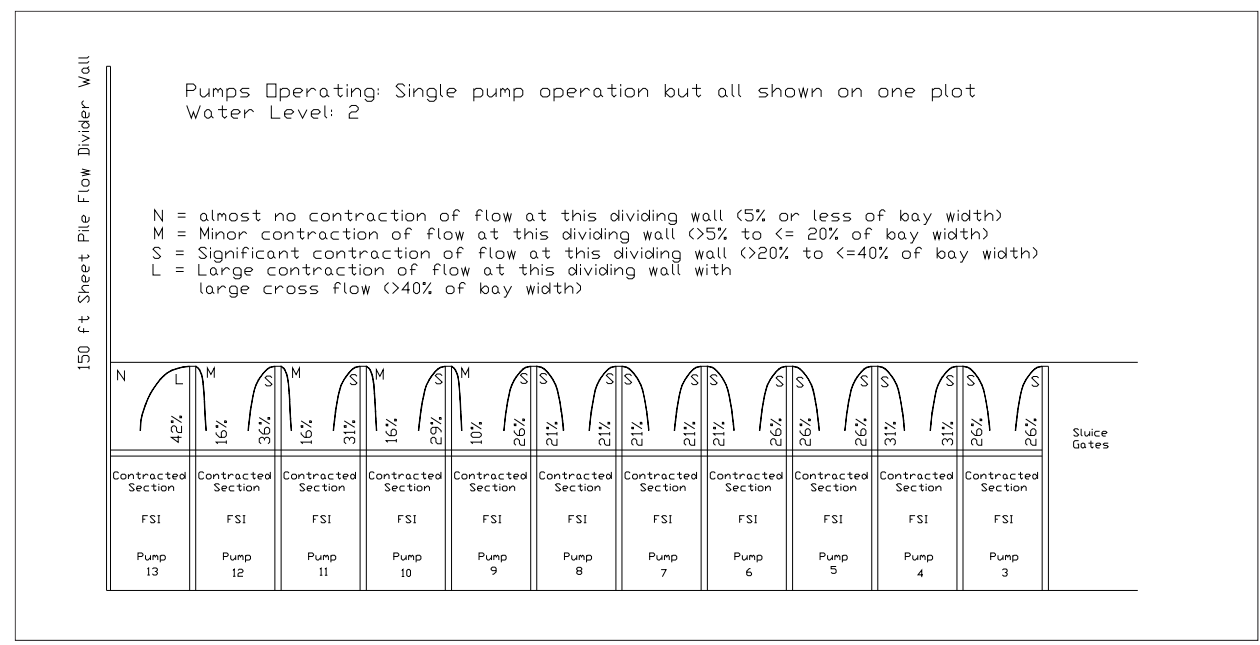

Figure 29. Dividing wall contraction with single pump operation. All pumps are shown but this plot was for only one pump in operation. Water level at EL 2.0.

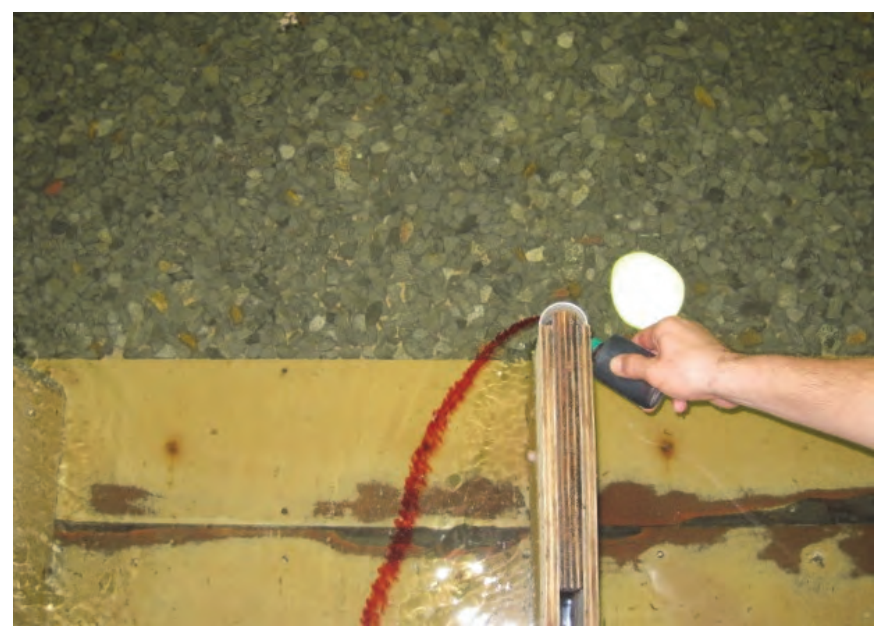

Figure 30. Dye injection for only Pump 8 operating.

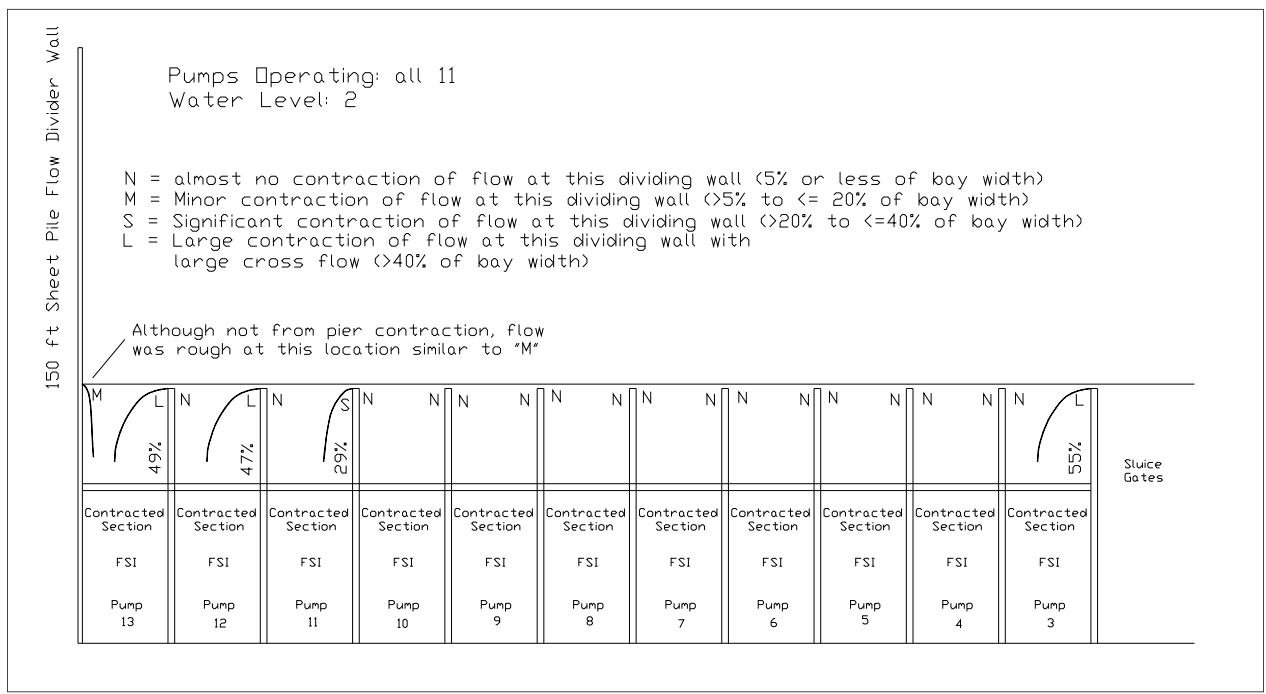

Figure 31. Dividing wall contraction with all pumps operating. Water level at EL 2.0. 


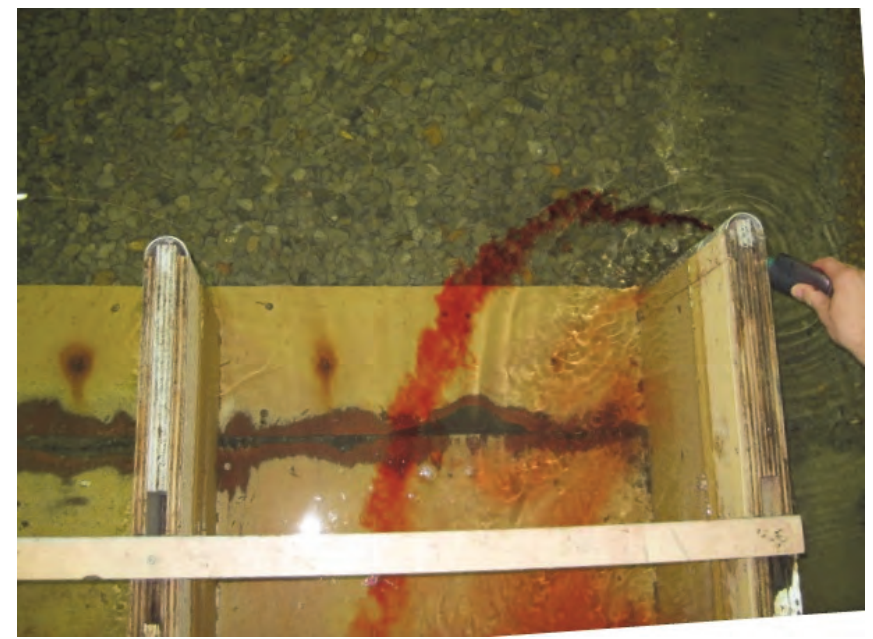

Figure 32. Dye injection at Pump 3 with all pumps operating.

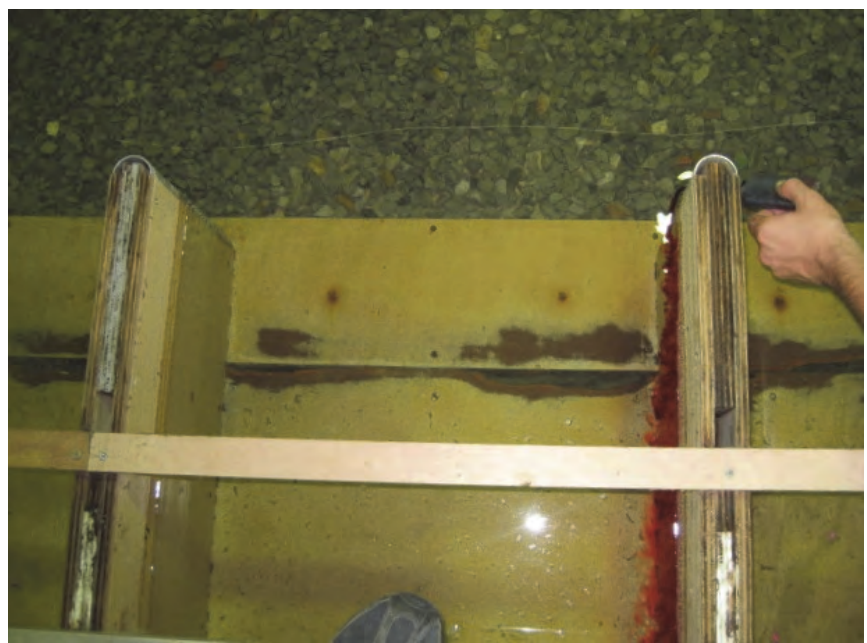

Figure 33. Dye injection at Pump 8 with all pumps operating.

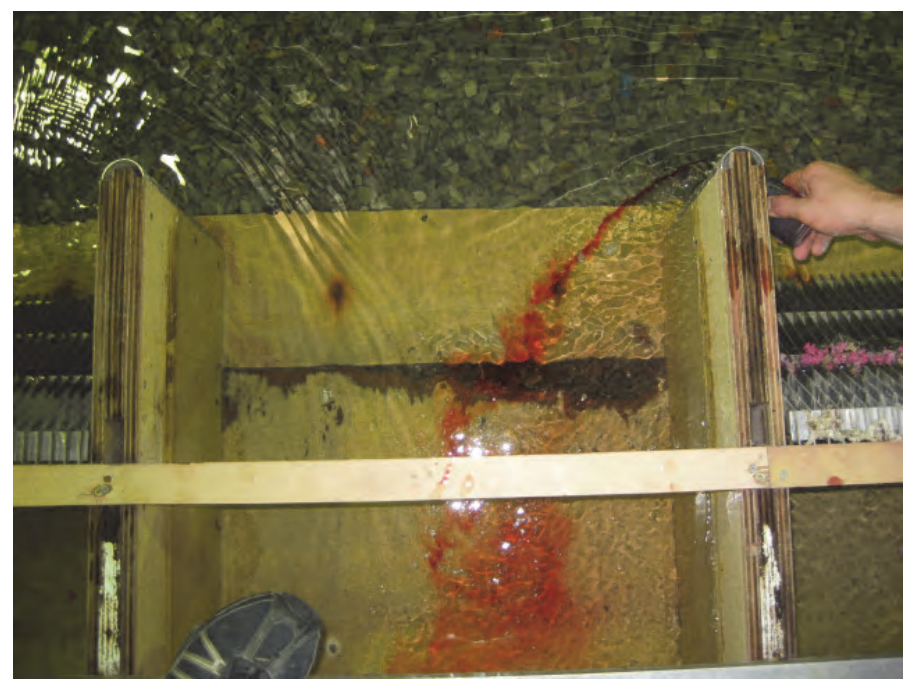

Figure 34. Dye injection at Pump 12 with all pumps operating. 


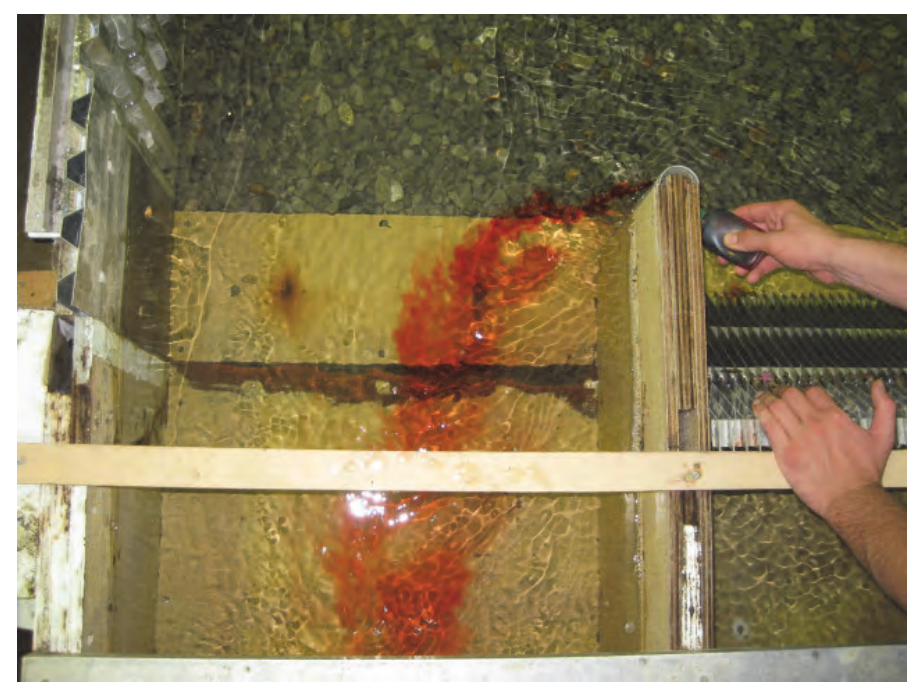

Figure 35. Dye injection at Pump 13 with all pumps operating.

Figure 36 shows the contraction at the dividing walls when every odd pump was operating or Pumps 3, 5, 7, 9, 11, and 13 operating. This combination resulted in large cross flows and thus large dividing wall contraction at Pump 13.

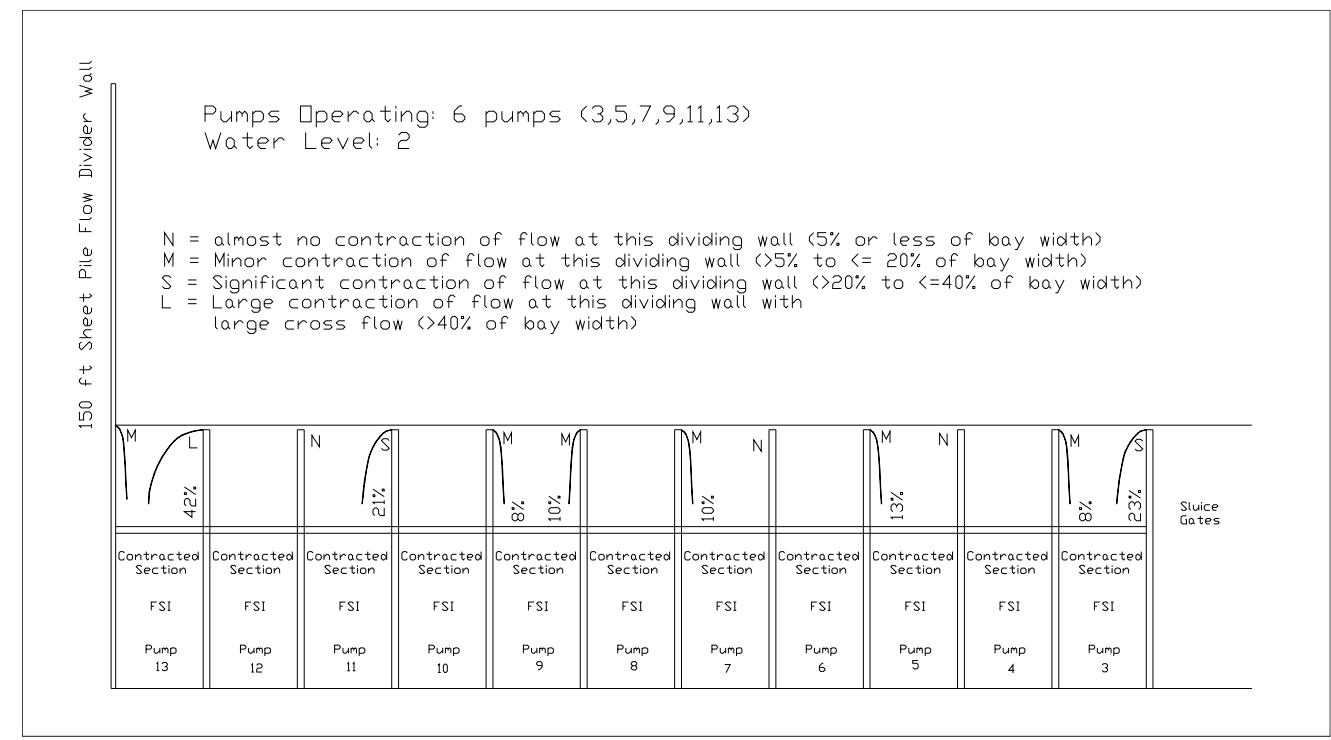

Figure 36. Dividing wall contraction with all six odd numbered pumps operating. Water level at EL 2.0.

Figure 37 shows contraction at the dividing walls when all five even numbered pumps was operating. Pump 12 had the highest dividing wall contraction affecting flow into the pump bay. 


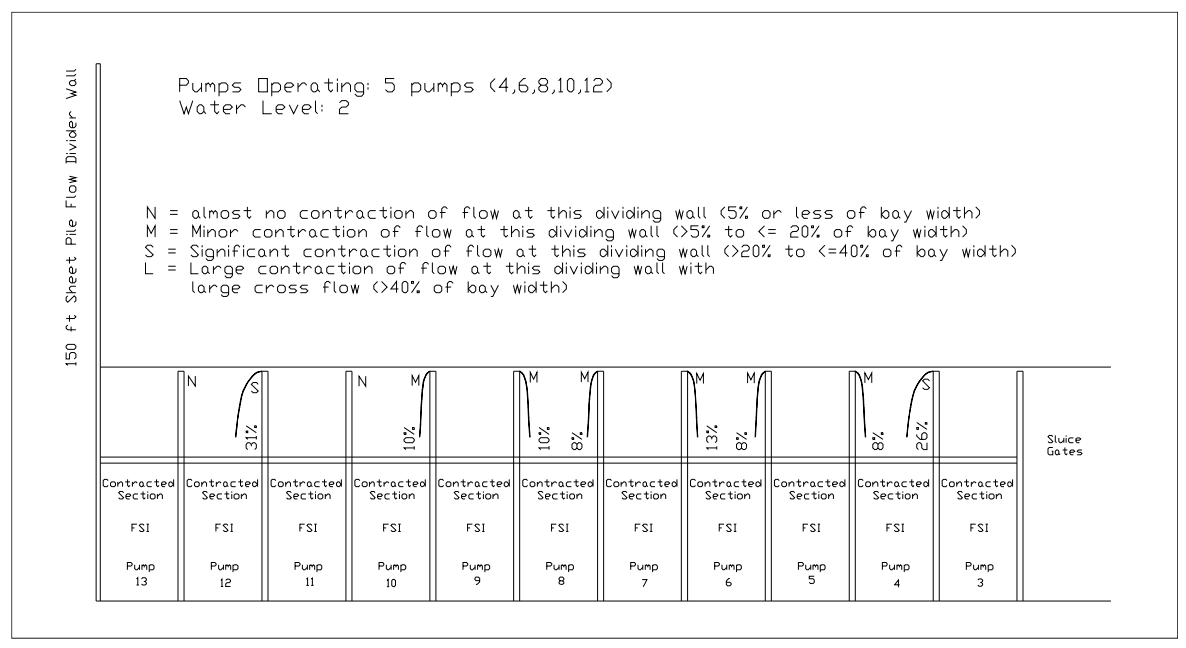

Figure 37. Dividing wall contraction with all five even numbered pumps operating. Water level at EL 2.0.

Figure 38 shows contraction at the dividing walls when three pumps on each end were operating. Pump 3 had large cross flow affecting flow into the pump bay.

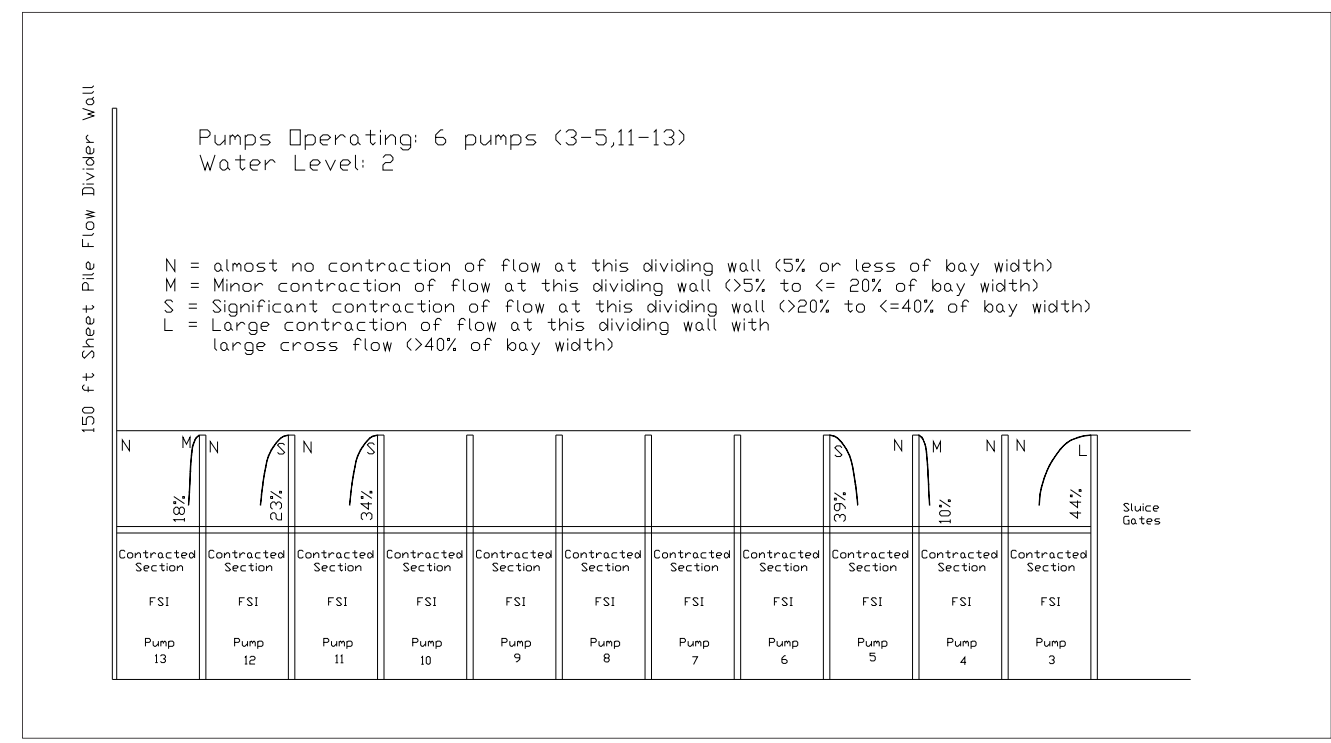

Figure 38. Dividing wall contraction with three pumps on each end operating. Water level at EL 2.0.

Figure 39 shows contraction at the dividing walls when four pumps on each end were operating. Pumps 3 and 13 had large dividing wall contraction affecting flow into the pump bay.

Figure 40 shows contraction at the dividing walls with Pumps 9-11 operating. Pump 9 had large cross flow affecting flow into the pump bay. 


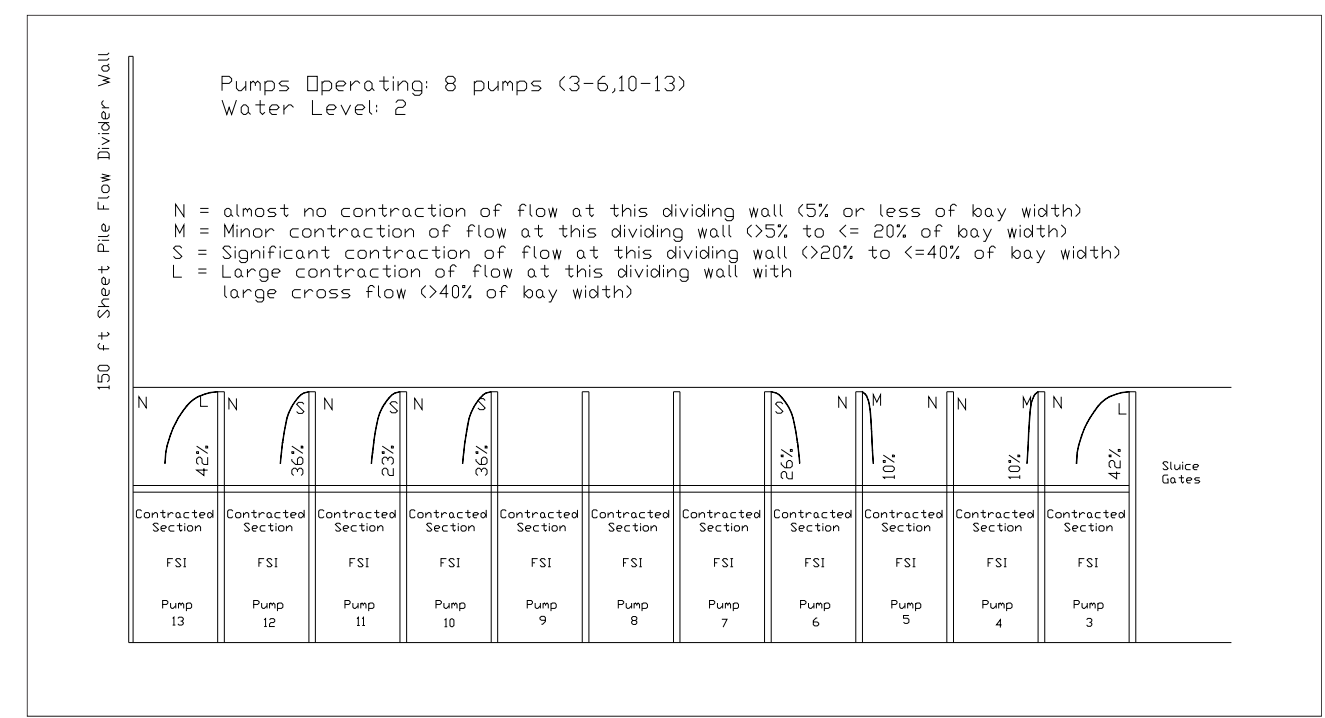

Figure 39. Dividing wall contraction with four pumps on each end operating. Water level at EL 2.0.

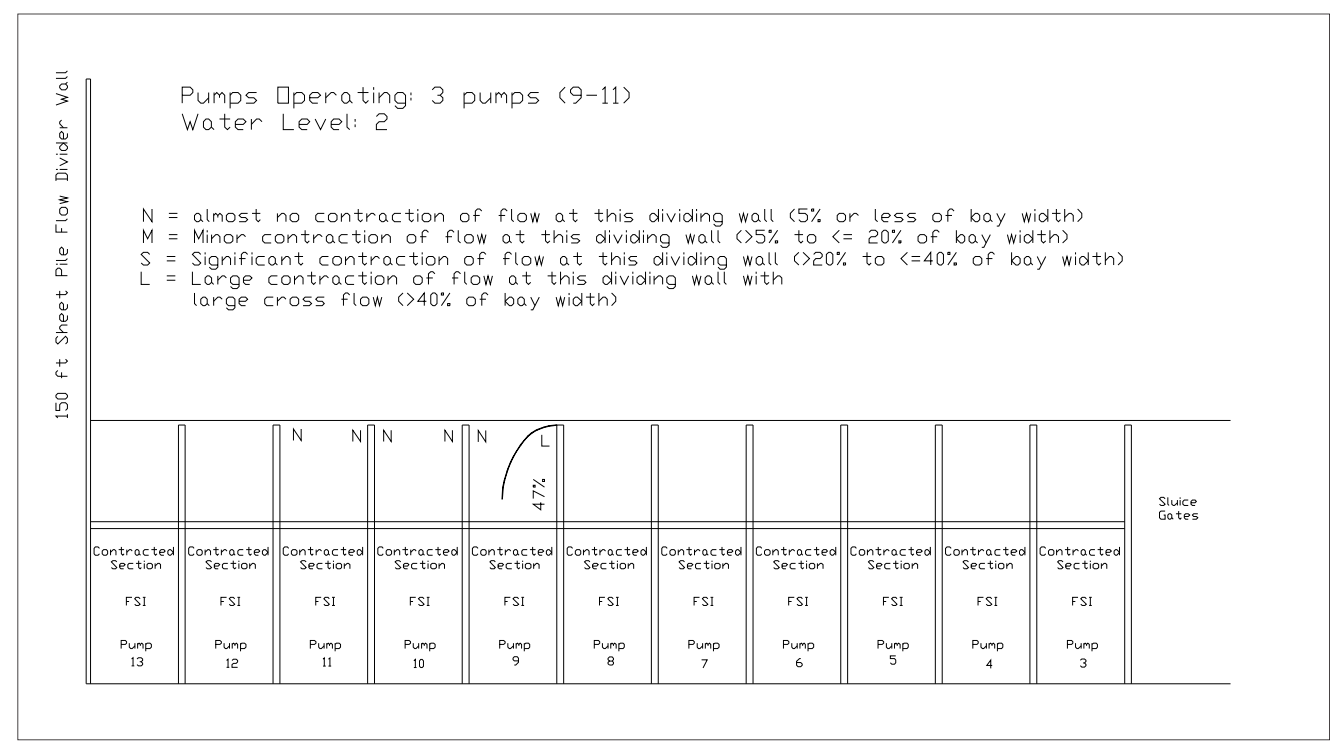

Figure 40. Dividing wall contraction with Pumps 9-11 operating. Water level at EL 2.0.

Figure 41 shows contraction at the dividing walls with pumps 10-12 operating. Pump 10 had large cross flow affecting flow into the pump bay.

Although not plotted, tests were run with Pumps 4 to 13, 5 to 13, 6 to 13, 7 to 13,8 to 13 , and 9 to 13 to evaluate the level of dividing wall contraction at the most eastern pump bay. In the above six combinations, dividing wall contraction on the eastern pump dividing wall ranged from 42 to 49 percent of the pump bay width, resulting in a classification of $\mathrm{L}$. 


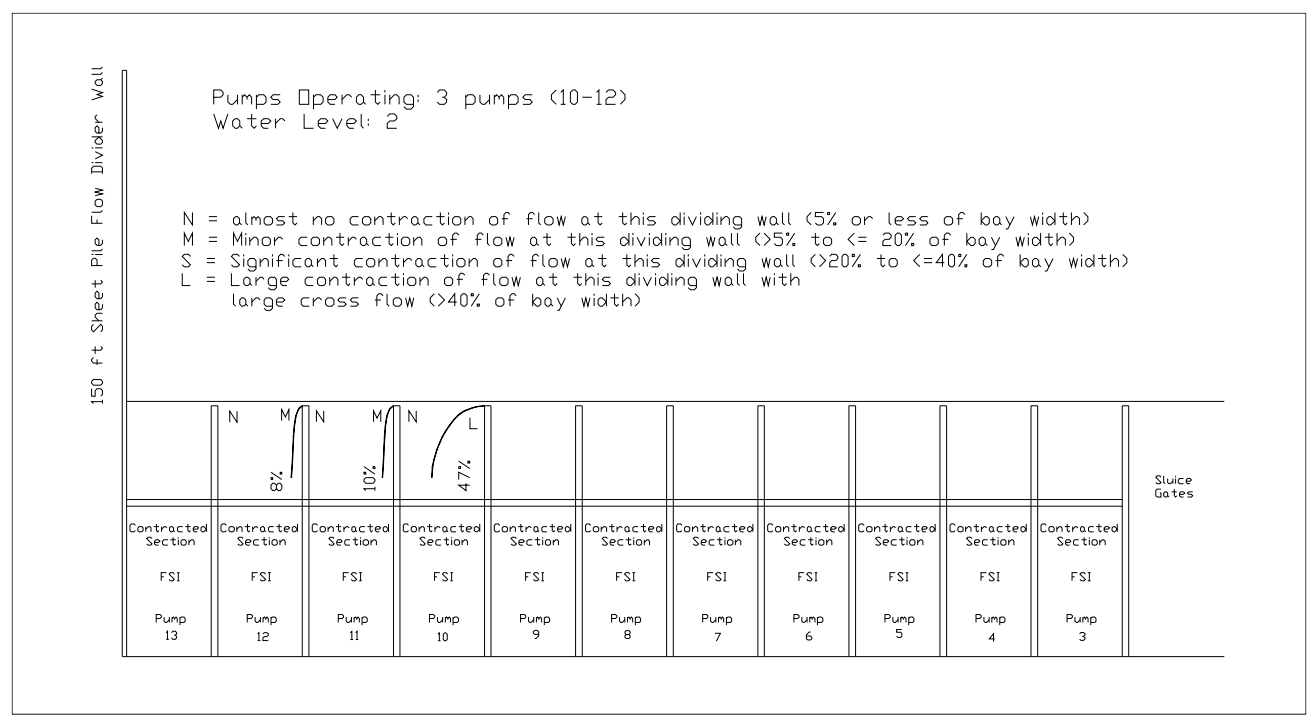

Figure 41. Dividing wall contraction with Pumps 10-12 operating. Water level at EL 2.0.

From these plots it can be seen that many of the pump bays have flow distribution in the pump bay ranging from almost uniform to highly skewed depending on which pumps were operating. Pump bay 10 was a good example. Figures 31 and 40 show almost no contraction at the dividing walls on both sides of the pump bay, indicating a relatively uniform pump bay flow distribution. Figures 29, 37, 39 and 41 show Pump 10 with various levels of dividing wall contraction at one dividing wall and no, or minor, dividing wall contraction at the other dividing wall. These combinations resulted in a flow distribution in the pump bay, which had a wide range of skewing to one side of the pump bay.

Because of the large number of pumps and pump operating combinations, the previous plots of dividing wall contraction were used to guide the selection of pumps and pump operating combinations for which the HI evaluation of pump intake performance was conducted. If swirl in the pump column and velocity distribution at the impeller location were the only considerations, the tests could likely be limited to those pumps and pump operating combinations having the greatest skew of flow in the pump bay. Vortices, particularly surface vortices, are far less predictable regarding the effects of flow skew. In some pump station intakes, the flow skew and circulation upstream of the pump become so strong that vortices cannot organize, form, and extend to the intake. In other pump station intakes where the flow is more uniformly distributed, the vortices have a greater tendency to organize and form. There is a large range of possibilities between these two extremes that can lead to surface vortices. The intake evaluation conducted herein will examine the full range of flow skew shown 
on the dividing wall contraction plots. Using the previous plots of contraction at each dividing wall, the pumps and pump operating combinations will be broken into four classes of skew at the upstream end of the pump bay. First will be pumps and pump operating conditions with no or minor dividing wall contraction on both sides of the pump bay. Second will be pumps and pump operating conditions with significant dividing wall contraction on both dividing walls but no skew of the flow to one side of the pump bay. This second class will be typical of single pump operation, which would likely be present when the pumps are routinely tested. Third will be pumps and pump operating conditions having significant contraction at one dividing wall and no or minor contraction at the other dividing wall. Fourth, will be pumps and pump operating conditions having large contraction at one dividing wall and no or minor contraction at the other dividing wall.

\subsection{Flow divider wall between pumps and sluice gates}

A series of tests was run with Pump 3 to determine the requirements of a flow divider wall between the last pump bay on the east side and the sluice gates. If needed, this wall would be constructed of the same " $\mathrm{Z}$ " section sheet pile used on the flow divider wall between the pump station and the sector gates. The upstream end of the wall could not be rounded or flared to the east because this would interfere with flow into the sluices. Tests were conducted with a 50-ft long " $Z$ " section sheet pile wall. With Pump 3 only, the swirl and surface vortices were within HI standards for intake levels of 0.0 and 2.0. For all 11 pumps operating, swirl and surface vortices were within $\mathrm{HI}$ standards for intake level of 2.0. For all 11 pumps operating and intake EL 0.0, swirl was within HI standards but Type 3 dye-core surface vortices were observed on the east side of the pump bay just upstream of the vertical wall at the entrance of the contracted section. In addition, these vortices remained coherent all the way to the elbow of the FSI. Each of these vortices lasted for an average of about $1 / 2$ sec in the model, which corresponds to $2.2 \mathrm{sec}$ in the prototype. Sixty two Type 3 surface vortices were observed over a five minute period. All 62 Type 3 vortices resulted in a total duration of $31 \mathrm{sec}$ over a $300 \mathrm{sec}$ interval. This exceeded the allowable duration of 10 percent.

The 50-ft long wall was extended to $100 \mathrm{ft}$, but the Type 3 surface vortices were still present. Although a longer wall would almost certainly work, preliminary tests were conducted with the wall removed. The preliminary tests showed no unacceptable surface vortices but these tests were conducted with a square nose on the east dividing wall of pump bay 3 and the 
effects of the sluice gates were not replicated in the model. The nose of the east dividing wall of Pump Bay 3 was rounded as specified by the sponsor if a flow divider wall on the east side was not used. In addition, the dividing walls between the sluices had their upstream ends downstream of the upstream end of the dividing walls in the pump station, as shown in Figures 20 and 21. Flow could approach pump bay 3 going downstream of the nose of the pump station bay walls and have to move upstream and wrap around the nose of the pump bay wall and cause more contraction of the flow. Without a flow divider wall between the pump station and the sluices, HI standards were met, and the result will be provided in a subsequent section. ERDC believes that the short flow divider wall on the east side, between the pumps and sluices, produced eddies that entered the pump bay, which resulted in the unacceptable surface vortices. ERDC also believes that no flow divider wall works on the east side because the amount of flow along the east bank was small and the contraction of flow that occurred at the nose of the east pump bay wall of Pump 3 was not significantly worse than the contraction that occurs for some of the pumps and pump operating combinations presented in the previous section of this report.

\subsection{Revision to contracted section to address submerged vortices}

When the pump station consisted of 13 pumps, tests were conducted to detect submerged vortices. A flexible dye injection tube having outside diameter of 1/32-in. was used to locate the submerged vortices. The tests were conducted with Pumps 5 and 12 with water levels set at EL 0 and EL 2 and flows of 1,510 to 1,900 cfs. Type 2 dye-core subsurface vortices were observed just upstream of the rounded part of the contracted section shown in Figure 3. Type 2 vortices were allowed only if they occur for less than 10 percent of the time or for infrequent operating conditions. Measuring the precise duration of dye-core surface or submerged vortices was extremely difficult because they refuse to stay in one place and they form and break up over and over. Whenever evaluating duration of subsurface vortices, the observer was constantly trying to make certain the dye tube was in the correct location. Getting the dye tube in the correct position was not 100 percent achievable because of movement of the vortices. Consequently, any duration measurement was likely to underestimate the duration of dye-core vortices. In a recent physical model study of $300 \mathrm{cfs}$ full scale pumps, ERDC measured the duration of sub-surface vortices and determined about five percent, and accepted that level of submerged vortex activity as meeting the HI standard. ERDC did not measure duration with the WCC original design, but the duration of occurrence of dye-core submerged vortices appeared to 
be much greater than what had been observed in the $300 \mathrm{cfs}$ study.

Although duration was not measured, the level of submerged vortex activity present for the WCC pumps appeared to be unacceptable and was described as frequent as opposed to infrequent. Each occurrence was generally of short duration but some lasted for up to about $1.0 \mathrm{sec}$ in the model, which would be about $4.5 \mathrm{sec}$ in the prototype. ERDC did not stop and do the duration tests because ERDC concluded that the level of submerged vortices appeared to be greater than the standard and ERDC was trying to move this project forward by shutting down the model and revising the approach channel and reducing to 11 pumps. During this model revision, a fillet was added to the contracted section as shown in Figure 3. All tests with the fillet were free of Type 2 dye-core subsurface vortices. The HI tests discussed subsequently had the fillet added to the contracted section. This fillet is similar to the fillet previously discussed and used by Werth and Demlow (1999) to eliminate submerged vortices just upstream of the entrance to an FSI not having a contracted section.

\subsection{Dye injections in FSI}

Using an underwater video camera placed on top of the roof of the FSI and looking toward the roof curve, dye was injected into the FSI at various locations using a tube having outside diameter of $1 / 32$-in. These tests were conducted with the FSI and contracted section on Pump 3 and all pumps operating, which has large skew of the flow. When injected just upstream of the junction of the flat roof and the roof curve, there was no indication of flow separation at this junction. As expected, there was significant turbulence downstream of the center pier of the FSI. The dye tube was moved from just downstream of the center pier along the roof curve to the downstream end of the truncated cone, keeping the tube downstream of and in line with the pier. While the level of turbulence indicated by dye movement decreased as the tube moved downstream (and up the roof curve), turbulence at the end of the truncated cone was greater than other dye injections that were not downstream of the center pier. This observation of greater turbulence downstream of the center pier all the way to the pump throat was seen in the velocity fluctuation measurements discussed subsequently. All dye injections showed no significant skewing of the flow relative to the axis of the pipe. 


\subsection{HI test results with short dividing walls}

As stated previously, the intake was initially built with shorter dividing walls than those used in the final design. The dividing walls extended $4.2 \mathrm{~d}$ upstream of the entrance to the contracted section. Because a full range of tests was conducted, some of the results of the shorter dividing wall tests are presented herein. Table 2 shows all tests conducted with the revised design having shallower approach channel, 11 pumps, short dividing walls, and fillet added to contracted section. Also shown is the four level rating of flow non-uniformity entering the pump bay. A designation of "None or Minor" refers to no or minor dividing wall contraction on both bays. A designation of "Single" refers to contraction with a single pump operating. A designation of "Significant" refers to significant contraction on one dividing wall and none or minor contraction on the other dividing wall. A designation of "Large" refers to a large contraction of flow at one of the dividing walls and "None or Minor" contraction at the other dividing wall.

Table 2. Tests conducted with design having 11 pumps, short dividing walls, revised approach channel, 300-ft long flow divider wall. Swirl angle in degrees shown in parenthesis was the maximum value of twenty $30-\mathrm{sec}$ readings.

\begin{tabular}{|l|l|l|l|l|l|l|}
\hline $\begin{array}{l}\text { Test } \\
\text { pump }\end{array}$ & $\begin{array}{l}\text { Pumps } \\
\text { operating }\end{array}$ & $\begin{array}{l}\text { Intake } \\
\text { level }\end{array}$ & Q, cfs & $\begin{array}{l}\text { Swirl or Vel } \\
\text { measured }\end{array}$ & Other & $\begin{array}{l}\text { Flow uniformity } \\
\text { entering bay }\end{array}$ \\
\hline 3 & All 11 & 0 & 1,740 & $\mathrm{~S}(0.6)$ & 50 -ft wall on east & Large \\
\hline 3 & 3 & 0 & 1,740 & $\mathrm{~S}(0.2)$ & 50 -ft wall on east & Single \\
\hline 3 & All 11 & 0 & 1,740 & & 100 -ft wall on east & Large \\
\hline 3 & All 11 & 2 & 1,740 & $\mathrm{~S}(0.3)$ & 50 -ft wall on east & Large \\
\hline 3 & 3 & 2 & 1,740 & $\mathrm{~S}(0.5)$ & 50 -ft wall on east & Single \\
\hline 3 & All 11 & 0 & 1,740 & $\mathrm{~S}(0.3), \mathrm{V}$ & & Large \\
\hline 3 & 3 & 0 & 1,740 & $\mathrm{~S}(0.0), \mathrm{V}$ & & Single \\
\hline 3 & 3 & 2 & 1,740 & $\mathrm{~S}(0.2), \mathrm{V}$ & & Single \\
\hline 3 & All 11 & 2 & 1,740 & $\mathrm{~S}(0.2), \mathrm{V}$ & & Large \\
\hline 3 & All 11 & 7 & 1815 & $\mathrm{~S}(1.5), \mathrm{V}$ & & Large \\
\hline 3 & 3 & 7 & 1815 & $\mathrm{~S}(0.2), \mathrm{V}$ & & Single \\
\hline 5 & 5 & 0 & 1,740 & $\mathrm{~S}(0.0)$ & & Single \\
\hline 5 & $4-6$ & 0 & 1,740 & $\mathrm{~S}(0.0)$ & & None or Minor \\
\hline 5 & $4-6$ & 2 & 1,740 & $\mathrm{~S}(0.0)$ & & None or Minor \\
\hline 5 & 5 & 2 & 1,740 & $\mathrm{~S}(0.5)$ & Sub V* & Single \\
\hline 5 & $4-6$ & 7 & 1815 & $\mathrm{~S}(0.2)$ & Sub V & None or Minor \\
\hline
\end{tabular}




\begin{tabular}{|c|c|c|c|c|c|c|}
\hline $\begin{array}{l}\text { Test } \\
\text { pump }\end{array}$ & $\begin{array}{l}\text { Pumps } \\
\text { operating }\end{array}$ & $\begin{array}{l}\text { Intake } \\
\text { level }\end{array}$ & Q, cfs & $\begin{array}{l}\text { Swirl or Vel } \\
\text { measured }\end{array}$ & Other & $\begin{array}{l}\text { Flow uniformity } \\
\text { entering bay }\end{array}$ \\
\hline 5 & 5 & 7 & 1815 & $\mathrm{~S}((0.2)$ & & Single \\
\hline 8 & All 11 & 0 & 1,740 & V & & None or Minor \\
\hline 8 & 8 & 0 & 1,740 & V & & Single \\
\hline 8 & $7-9$ & 0 & 1,740 & V & & None or Minor \\
\hline 8 & $8-13$ & 0 & 1,740 & V & & Large \\
\hline 8 & All 11 & 7 & 1815 & V & & None or Minor \\
\hline 8 & 8 & 7 & 1815 & $\mathrm{~V}$ & & Single \\
\hline 11 & $11-13$ & 2 & 1,740 & V & & Large \\
\hline 12 & All 11 & 0 & 1,740 & $\mathrm{~S}(0.9), \mathrm{V}$ & Sub V & Large \\
\hline 12 & 12 & 0 & 1,740 & $S(0.0), V$ & & Single \\
\hline 12 & All 11 & 2 & 1,740 & $S(1.1), V$ & & Large \\
\hline 12 & 12 & 2 & 1,740 & V & & Single \\
\hline 12 & All 11 & 7 & 1815 & V & & Large \\
\hline 12 & 12 & 7 & 1815 & V & & Single \\
\hline 13 & All 11 & 0 & 1,740 & $S(0.0)$ & Sub V & Large \\
\hline 13 & Odd \#s & 0 & 1,740 & $S(0.0)$ & & Large \\
\hline 13 & 13 & 0 & 1,740 & $S(0.0)$ & Sub V & Single \\
\hline 13 & All 11 & 2 & 1,740 & $S(0.5)$ & & Large \\
\hline 13 & 13 & 2 & 1,740 & $\mathrm{~S}(0.0)$ & Sub V & Single \\
\hline 13 & All 11 & 5 & 1815 & & Surf V only & Large \\
\hline 13 & All 11 & 7 & 1815 & $S(0.5)$ & & Large \\
\hline 13 & 13 & 7 & 1815 & $\mathrm{~S}(0.2)$ & Sub V & Single \\
\hline
\end{tabular}

*Sub V = submerged vortices were observed and met HI standards.

Velocity distributions at the location of the impeller for the shorter dividing walls were plotted for many of the tests listed in Table 2. The plots were not presented herein because the shorter dividing walls were not used at WCC and to keep the size of this report manageable. The plots were almost identical to the plots with the correct dividing wall presented subsequently. The various plots with the short dividing wall had point time-average velocity/ area weighted time averaged velocity from a minimum of 0.94 to a maximum of 1.05 and always met HI standards of \pm 10 percent. 
Based on all of the testing shown in Table 2, the revised 11 pump design with the shallower and realigned approach channel, contracted section with fillet added, 300-ft long flow divider wall on west, no flow divider wall on east, and original design shorter dividing walls met the $\mathrm{HI}$ standards for swirl, time-averaged velocity distribution at the impeller, and surface and submerged vortices. The combination of the contracted section and the FSI results in swirl and time-averaged velocity distribution that met $\mathrm{HI}$ standards. The addition of the fillet to the contracted section resulted in meeting HI standards for submerged vortices. The primary concern from the outset of this study was the issue of surface vortices for the relatively low submergence in the intake whose floor elevation was set at EL -18. An FSI without a contracted section generally requires vortex beams just upstream of the FSI entrance to address surface vortices when submergence is similar to WCC. Results of this study with the shorter dividing walls showed that the contracted section reduced surface vortices to an acceptable level. Throughout this study, the results of surface vortices were the same for almost all of the different test conditions. Type 3 dye-core surface vortices formed upstream of the entrance to the contracted section but for less than 10 percent of the time. On infrequent occasions, the dye-core surface vortices were found to turn and travel just past the roof curve at EL - 2.9. On rare occasions, the dye-core made it halfway through the contracted section. With one exception, the dye-core never made it to the entrance of the pump, which was defined herein as halfway through the contracted section. The only HI requirement not addressed with the shorter dividing walls was the velocity fluctuation requirement, which will be addressed with the correct dividing walls presented subsequently.

\subsection{HI test results with correct dividing wall length}

As shown in Figure 3, the dividing walls between the pump bays were initially constructed to a design that was later modified to have longer dividing walls. The selection of test conditions with the longer walls was based on the same approach with the shorter walls, namely using the four different levels of flow uniformity at the entrance to the pump bay. Table 3 shows the test conditions with the correct dividing walls.

Repeating what was said about the tests with the shorter dividing walls between pumps, the results of surface vortices was the same for almost all of the different test conditions. Type 3 dye-core surface vortices formed upstream of the entrance to the contracted section but less than 10 percent of the time. On infrequent occasions, the dye-core surface vortices turned 
Table 3. Tests conducted with design having 11 pumps, correct dividing wall length, revised approach channel, 300$\mathrm{ft}$ long flow divider wall. Swirl angle in degrees shown in parenthesis was maximum value of twenty 30 -sec readings.

\begin{tabular}{|c|c|c|c|c|c|c|}
\hline $\begin{array}{l}\text { Test } \\
\text { pump }\end{array}$ & $\begin{array}{l}\text { Pumps } \\
\text { operating }\end{array}$ & $\begin{array}{l}\text { Intake } \\
\text { level }\end{array}$ & Q, cfs & $\begin{array}{l}\text { Swirl or Vel } \\
\text { measured }\end{array}$ & Surface vortices & $\begin{array}{l}\text { Flow uniformity } \\
\text { entering bay* }\end{array}$ \\
\hline 3 & All 11 & -1.5 & 1,740 & $\mathrm{~S}(1.2) \mathrm{Vel}$ & $\begin{array}{l}\text { Short duration dye-core }<<10 \\
\text { percent, none entering } \\
\text { contracted section }\end{array}$ & Large \\
\hline 3 & $3-8$ & -1.5 & 1,740 & $\mathrm{~S}(1.2)$ & NM & Large \\
\hline 3 & 3 & -1.5 & 1,740 & $\mathrm{~S}(0.0) \mathrm{Vel}$ & Type 1 and 2 & Single \\
\hline 3 & All 11 & 0 & 1,740 & $\mathrm{~S}(0.9) \mathrm{Vel}$ & $\begin{array}{l}\text { Short duration dye-core }<<10 \\
\text { percent, none entering } \\
\text { contracted section }\end{array}$ & Large \\
\hline 3 & $3-8$ & 0 & 1,740 & $\mathrm{~S}(1.2) \mathrm{Vel}$ & $\begin{array}{l}\text { Short duration dye-core } \\
\text { vortices } 1 / 2 \text { thru contracted } \\
\text { section, }<<10 \text { percent }\end{array}$ & Large \\
\hline 3 & 3 & 0 & 1,740 & $\mathrm{~S}(0.5) \mathrm{Vel}$ & “ & Single \\
\hline 3 & 3 & 0 & 1,740 & Vel 8 pos & “ & Single \\
\hline 3 & All 11 & 2 & 1,740 & $\begin{array}{l}\mathrm{S}(0.5) \mathrm{Vel} 8 \\
\text { pos }\end{array}$ & $\begin{array}{l}\text { Short duration dye-core }<<10 \\
\text { percent, none entering } \\
\text { contracted section }\end{array}$ & Large \\
\hline 3 & 3 & 2 & 1,740 & $\begin{array}{l}\mathrm{S}(0.2) \mathrm{Vel} 8 \\
\text { pos }\end{array}$ & $\begin{array}{l}\text { Short duration dye-core } \\
\text { vortices } 1 / 2 \text { thru contracted } \\
\text { section, }<<10 \text { percent }\end{array}$ & Single \\
\hline 3 & All 11 & 7 & 1815 & $S(1.8)$ & NM & Large \\
\hline 3 & 3 & 7 & 1815 & $\begin{array}{l}\mathrm{S}(1.2) \mathrm{Vel} 8 \\
\text { pos }\end{array}$ & NM & Single \\
\hline 8 & $8-13$ & -1.5 & 1,710 & Vel & $\begin{array}{l}\text { Short duration dye-core } \\
\text { vortices } 1 / 2 \text { thru contracted } \\
\text { section, }<<10 \text { percent }\end{array}$ & Large \\
\hline 8 & 8 & -1.5 & 1,710 & Vel & “ & Single \\
\hline 8 & All 11 & 0 & 1,740 & Vel & $\begin{array}{l}\text { Short duration dye-core }<<10 \\
\text { percent, none entering } \\
\text { contracted section }\end{array}$ & None or Minor \\
\hline 8 & $8-13$ & 0 & 1,740 & Vel & “ & Large \\
\hline 8 & All 11 & 2 & 1,740 & Vel & $\begin{array}{l}\text { Short duration dye-core } \\
\text { vortices } 1 / 2 \text { thru contracted } \\
\text { section, }<<10 \text { percent }\end{array}$ & None or Minor \\
\hline 8 & $8-13$ & 2 & 1,740 & Vel & $\begin{array}{l}\text { Short duration dye-core } \\
\text { vortices } 1 / 2 \text { thru contracted } \\
\text { section, }<<10 \text { percent }\end{array}$ & Large \\
\hline 8 & All 11 & 7 & 1815 & Vel & $\begin{array}{l}\text { Short duration dye-core }<<10 \\
\text { percent, none entering } \\
\text { contracted section }\end{array}$ & None or Minor \\
\hline & & & & & & \\
\hline
\end{tabular}




\begin{tabular}{|c|c|c|c|c|c|c|}
\hline $\begin{array}{l}\text { Test } \\
\text { pump }\end{array}$ & $\begin{array}{l}\text { Pumps } \\
\text { operating }\end{array}$ & $\begin{array}{l}\text { Intake } \\
\text { level }\end{array}$ & Q, cfs & $\begin{array}{l}\text { Swirl or Vel } \\
\text { measured }\end{array}$ & Surface vortices & $\begin{array}{l}\text { Flow uniformity } \\
\text { entering bay* }\end{array}$ \\
\hline 11 & All 11 & 0 & 1,740 & Vel & “ & Significant \\
\hline 11 & Odd \#s & 0 & 1,740 & Vel & “ & Significant \\
\hline 11 & $10-12$ & 0 & 1,740 & Vel & $\begin{array}{l}\text { Short duration dye-core } \\
\text { vortices } 1 / 2 \text { thru contracted } \\
\text { section, }<<10 \text { percent }\end{array}$ & None or Minor \\
\hline 11 & $11-13$ & 0 & 1,740 & Vel & $\begin{array}{l}\text { Short duration dye-core }<<10 \\
\text { percent, none entering } \\
\text { contracted section }\end{array}$ & Large \\
\hline 11 & 11 & 0 & 1,740 & Vel & $\begin{array}{l}\text { Short duration dye-core } \\
\text { vortices } 1 / 2 \text { thru contracted } \\
\text { section, }<<10 \text { percent }\end{array}$ & Single \\
\hline 11 & All 11 & 2 & 1,740 & Vel & $\begin{array}{l}\text { Short duration dye-core }<<10 \\
\text { percent, none entering } \\
\text { contracted section }\end{array}$ & Significant \\
\hline 11 & $10-12$ & 2 & 1,740 & Vel & $\begin{array}{l}\text { Short duration dye-core } \\
\text { vortices } 1 / 2 \text { thru contracted } \\
\text { section, }<<10 \text { percent }\end{array}$ & None or Minor \\
\hline 11 & 11 & 2 & 1,740 & Vel & “ & Single \\
\hline 11 & All 11 & 5 & 1815 & Vel & $\begin{array}{l}\text { One short duration dye-core } \\
\text { vortices } 1 / 2 \text { thru contracted } \\
\text { section }\end{array}$ & Significant \\
\hline 11 & All 11 & 7 & 1815 & Vel & “ & Significant \\
\hline 11 & $10-12$ & 7 & 1815 & Vel & $\begin{array}{l}\text { Short duration dye-core }<<10 \\
\text { percent, none entering } \\
\text { contracted section }\end{array}$ & None or Minor \\
\hline 13 & All 11 & 0 & 1,740 & Vel & $\begin{array}{l}\text { Short duration dye-core } \\
\text { vortices } 1 / 2 \text { thru contracted } \\
\text { section, }<<10 \text { percent }\end{array}$ & Large \\
\hline 13 & Odd \#s & 0 & 1,740 & Vel & $\begin{array}{l}\text { Short duration dye-core }<<10 \\
\text { percent, none entering } \\
\text { contracted section }\end{array}$ & Large \\
\hline 13 & All 11 & 2 & 1,740 & Vel & “" & Large \\
\hline 13 & Odd \#s & 2 & 1,740 & Vel & “ & Large \\
\hline 13 & All 11 & 7 & 1815 & Vel & “ & Large \\
\hline
\end{tabular}

and made it just past the roof curve at the entrance of the contracted section at EL -2.9. On rare occasions, the dye-core surface vortex made it halfway through the contracted section. With one exception, the dye-core surface vortex never made it to the entrance of the pump that was defined herein as the halfway through the contracted section. 
Measured velocities with the final design are shown in Figures 42 to 62 for many of the conditions in Table 3. One observation should be noted about velocities in an FSI versus a pump suction bell. In a past study of velocities in a pump suction bell, when approach velocities were negligible, submergence was high enough to prevent surface vortices, and no submerged vortices were present, the velocity distribution in the pump throat of a suction bell approached an almost uniform distribution except for extremely close to the wall where the boundary layer reduces the velocity. A Type 10 FSI, even under the best of approach flow conditions and submergence, has a distinctive velocity distribution, which almost always meets the HI standards but is not completely uniform. Consider the velocity distributions presented previously on the 17th Street Canal and the Yazoo Pump stations in Figures 5 and 6. Both show a low velocity region at the edge nearest the approach flow. Figure 42 from this study shows a similar trend on the approach flow side but to a lesser extent than the two other studies. This lesser extent was likely due to the contracted section effects on the velocity profile. The velocity distributions measured at WCC also show a relatively low region on the side of the pump away from the approach flow. These trends were evident for all levels of flow uniformity entering the pump bay. In all cases, the velocities met HI standards for uniformity. Most plots met the IIHR requirement of \pm 5 percent and all were within one percent of meeting the requirement of \pm five percent. The figures based on eight velocity measurements show the unique distribution resulting from the FSI and contracted section at WCC. The velocity plots are presented using the weighted cross section average to make the point velocities dimensionless. If evaluated along constant radii as suggested by Nakato (2000), the velocities met HI standards of \pm 10 percent and were within one percent of meeting the IIHR requirement of \pm five percent.

\subsection{Trash rack blockage tests}

Tests were conducted to simulate blockage of the trash rack on each side of the pump bay using Pump 3 only. Although these tests were conducted with the 300-ft long flow divider wall between pump station and sector gates, Pump 3 is far from the flow divider wall and was not affected significantly by the flow divider wall length. A solid plate was used to completely block 25 and 50 percent of the flow on either side of the trash rack. Swirl results are shown in Table 4. 


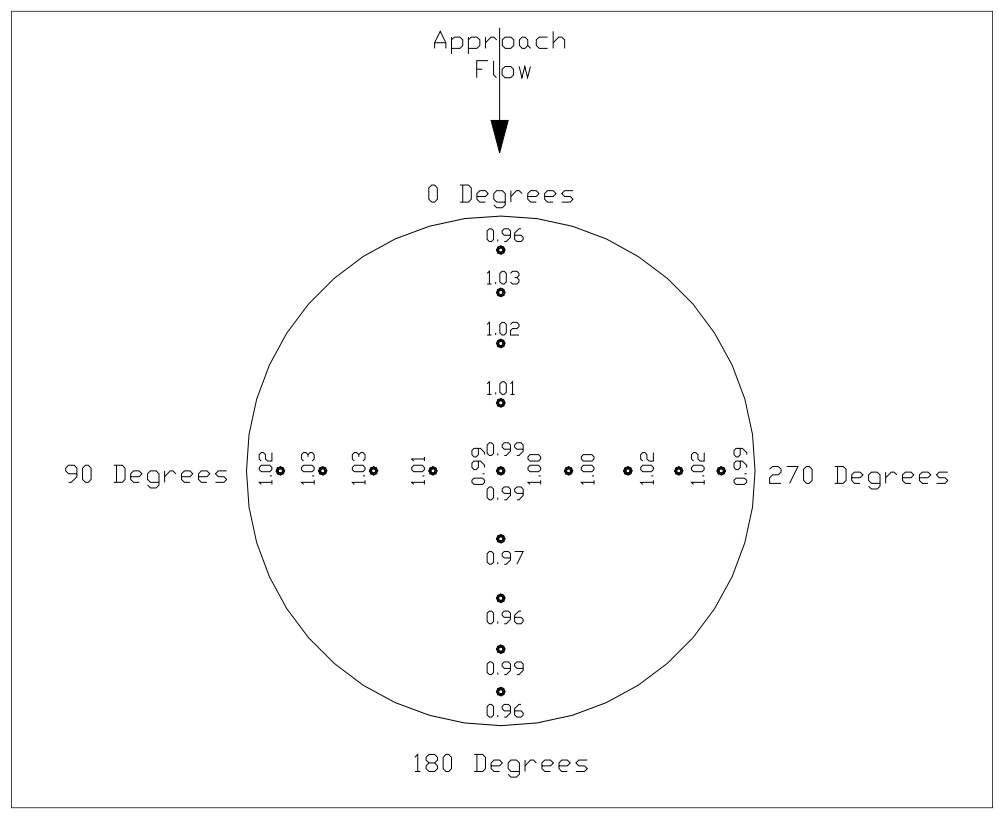

Figure 42. Velocity distribution at pump impeller for Pump 3, with correct dividing wall, water level at EL 0.0 , only Pump 3 operating, flow non-uniformity for single pump operation at entrance to pump bay. Based on 4 velocity position measurements at 90 degrees.

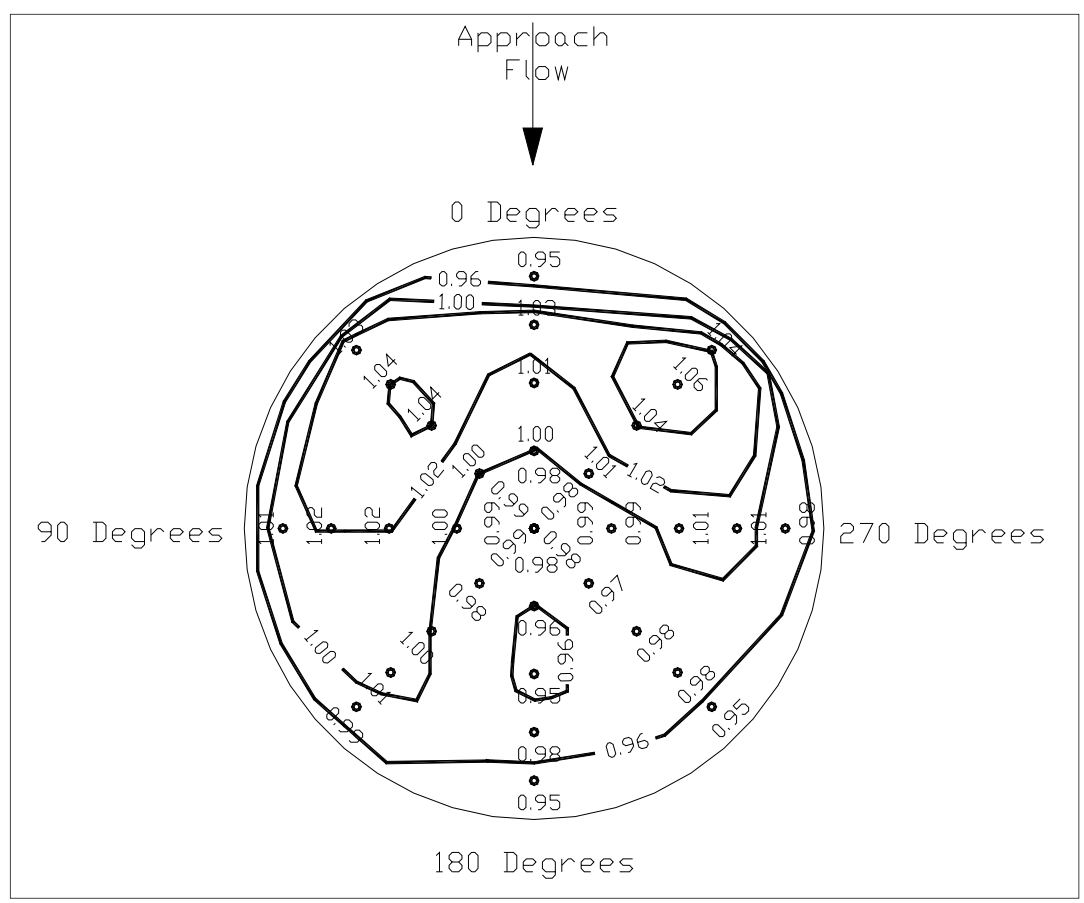

Figure 43. Velocity distribution at pump impeller for Pump 3, with correct dividing wall, water level at EL 0.0 , only Pump 3 operating, flow non-uniformity for single pump operation at entrance to pump bay. Based on eight velocity position measurements at $\mathbf{4 5}$ degrees. 


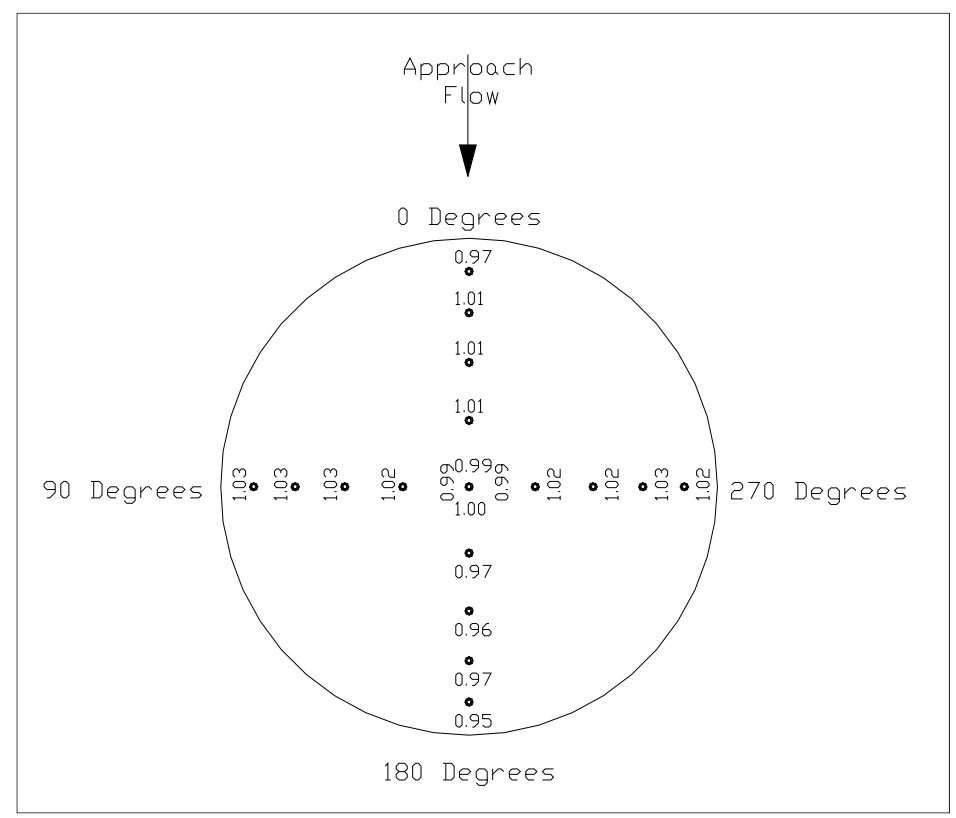

Figure 44. Velocity distribution at pump impeller for Pump 3, with correct dividing wall, water level at EL 2.0, only Pump 3 operating, flow non-uniformity for single pump operation at entrance to pump bay. Based on four velocity position measurements at 90 degrees.

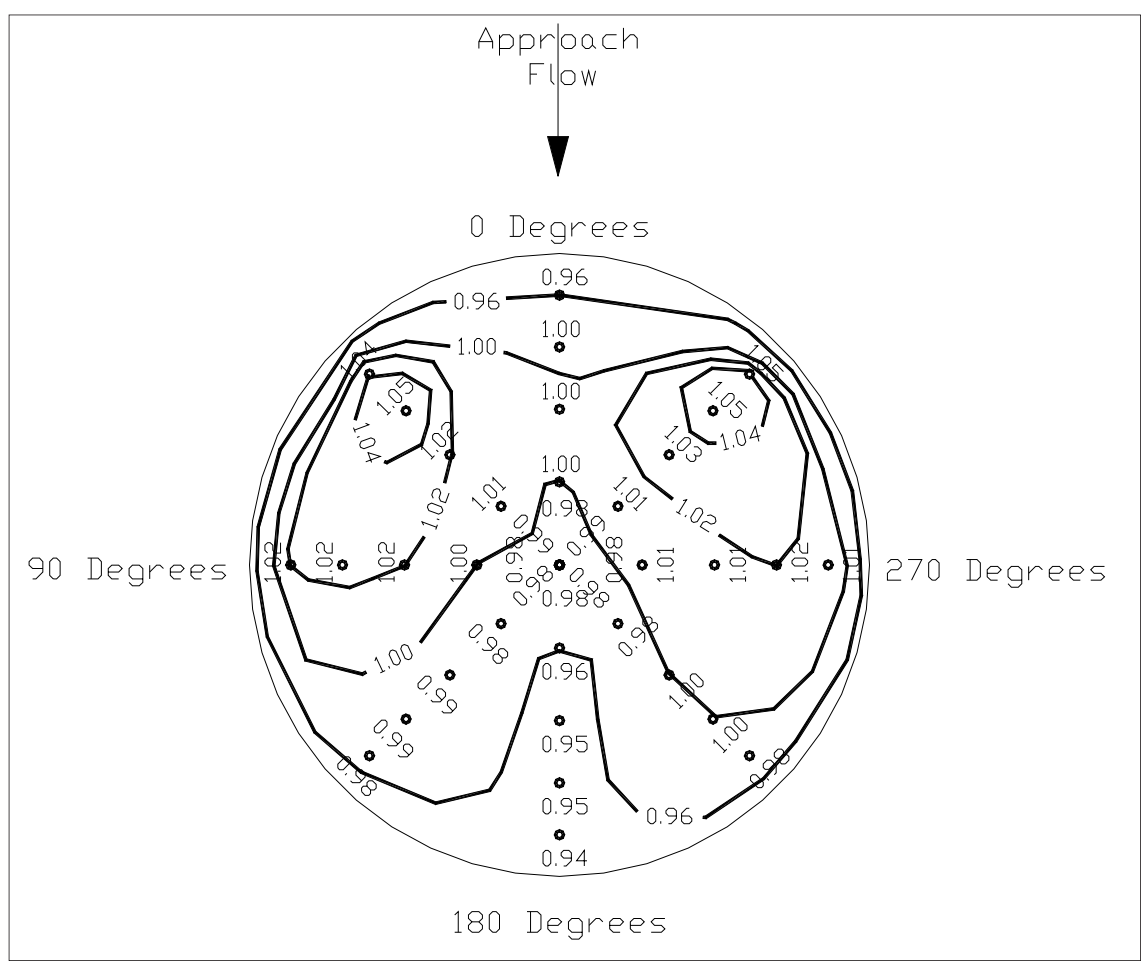

Figure 45. Velocity distribution at pump impeller for Pump 3, with correct dividing wall, water level at EL 2.0, only Pump 3 operating, flow non-uniformity for single pump operation at entrance to pump bay. Based on eight velocity position measurements at 45 degrees. 


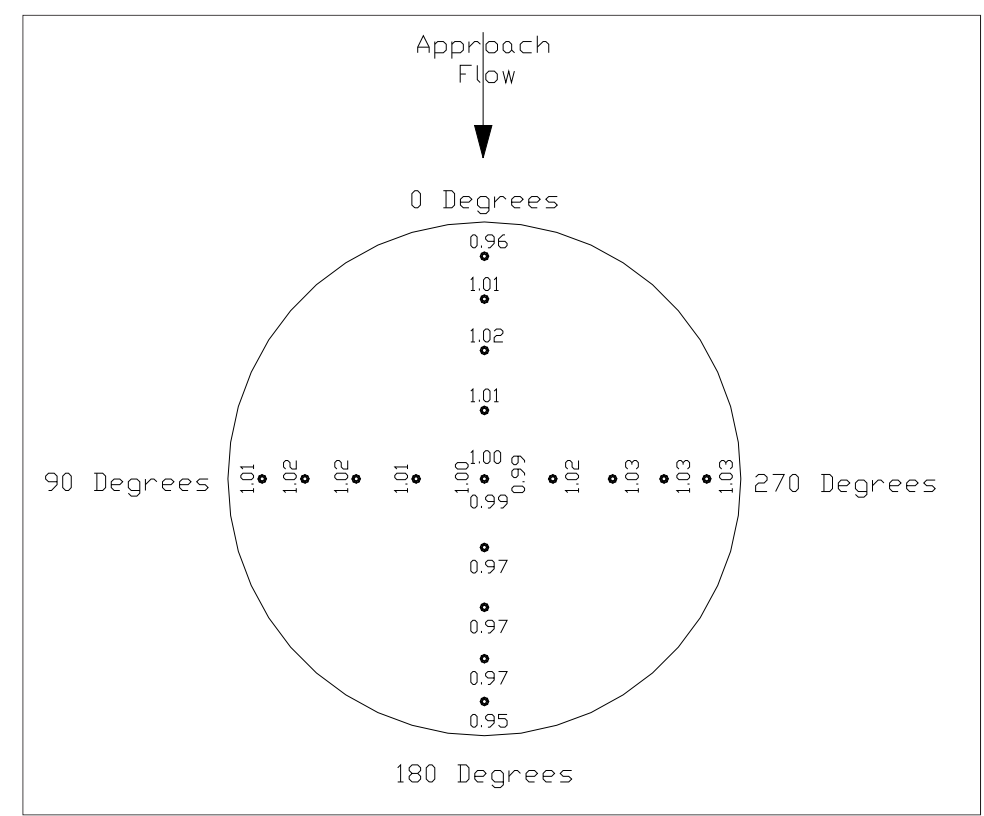

Figure 46. Velocity distribution at pump impeller for Pump 3, with correct dividing wall, water level at EL 7.0, only Pump 3 operating, flow non-uniformity for single pump operation at entrance to pump bay. Based on four velocity position measurements at 90 degrees.

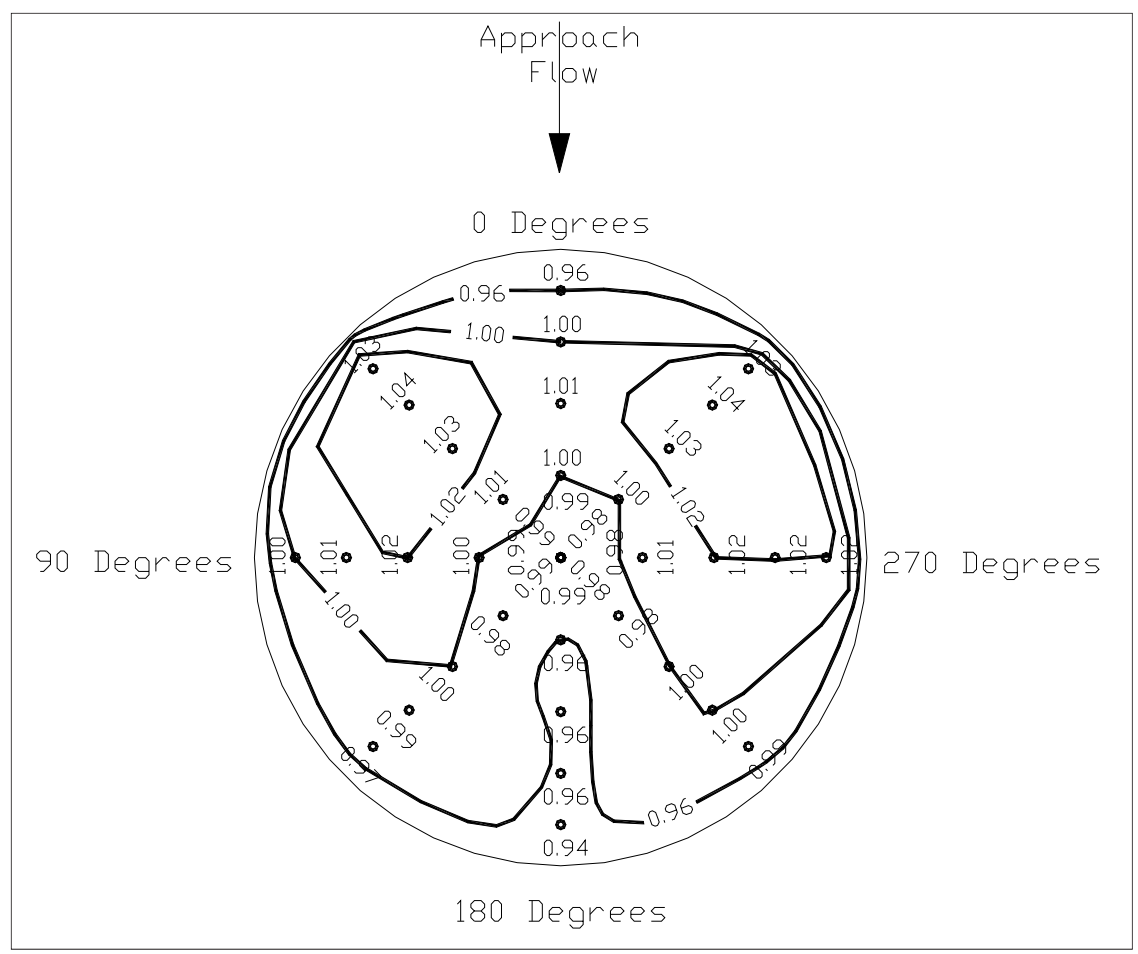

Figure 47. Velocity distribution at pump impeller for Pump 3, with correct dividing wall, water level at EL 7.0, only Pump 3 operating, flow nonuniformity for single pump operation at entrance to pump bay. Based on eight velocity position measurements at 45 degrees. 


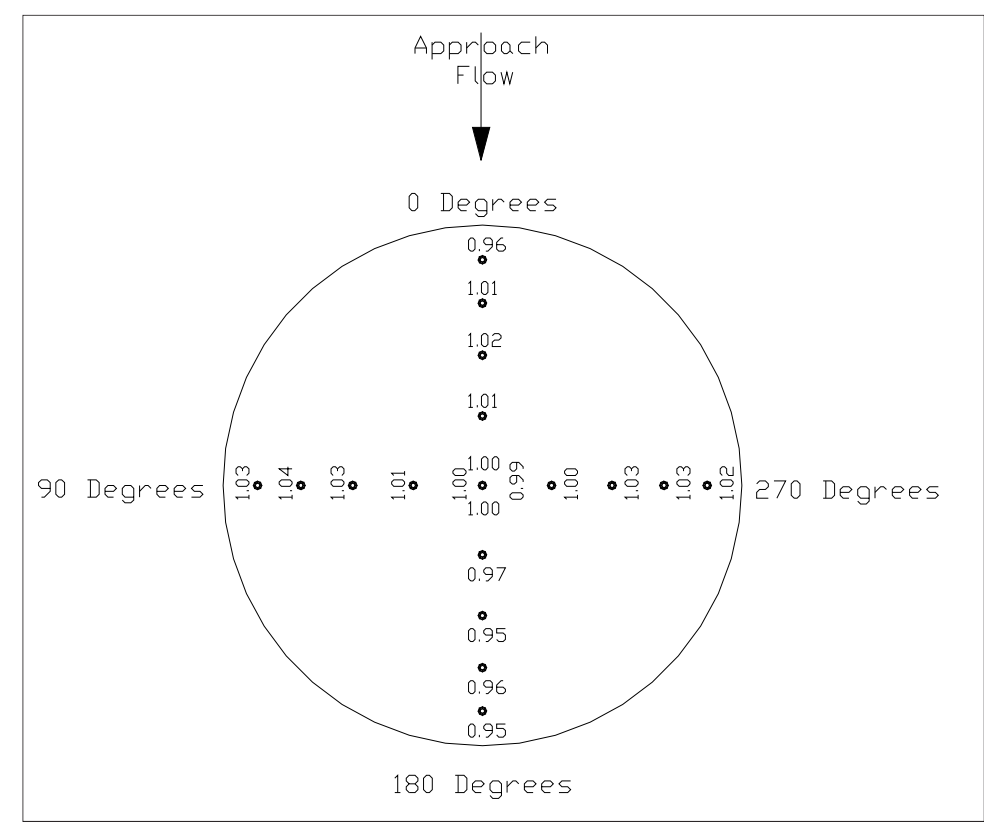

Figure 48. Velocity distribution at pump impeller for Pump 3, with correct dividing wall, water level at EL 2.0, all 11 pumps operating, flow non-uniformity for single pump operation at entrance to pump bay. Based on four velocity position measurements at 90 degrees.

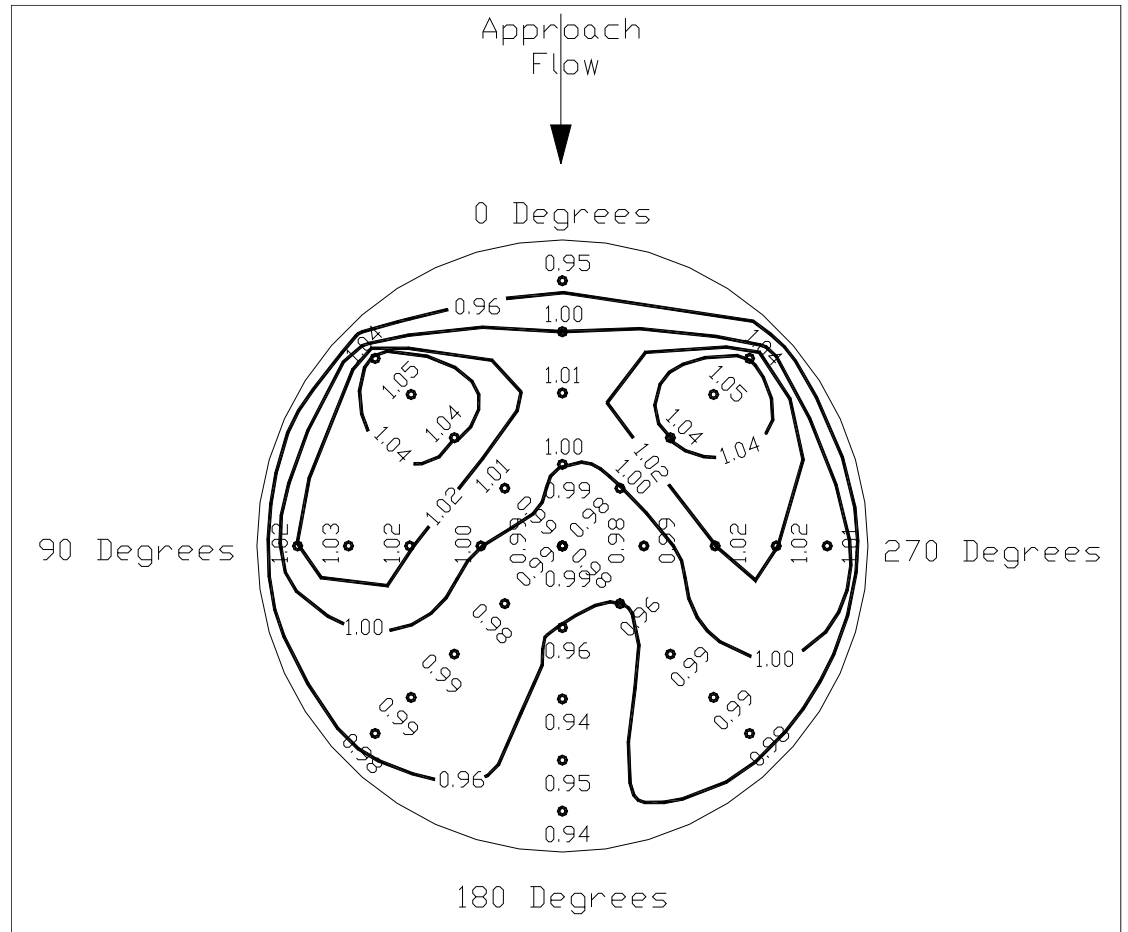

Figure 49. Velocity distribution at pump impeller for Pump 3, with correct dividing wall, water level at EL 2.0, all 11 pumps operating, flow nonuniformity for single pump operation at entrance to pump bay. Based on eight velocity position measurements at 45 degrees. 


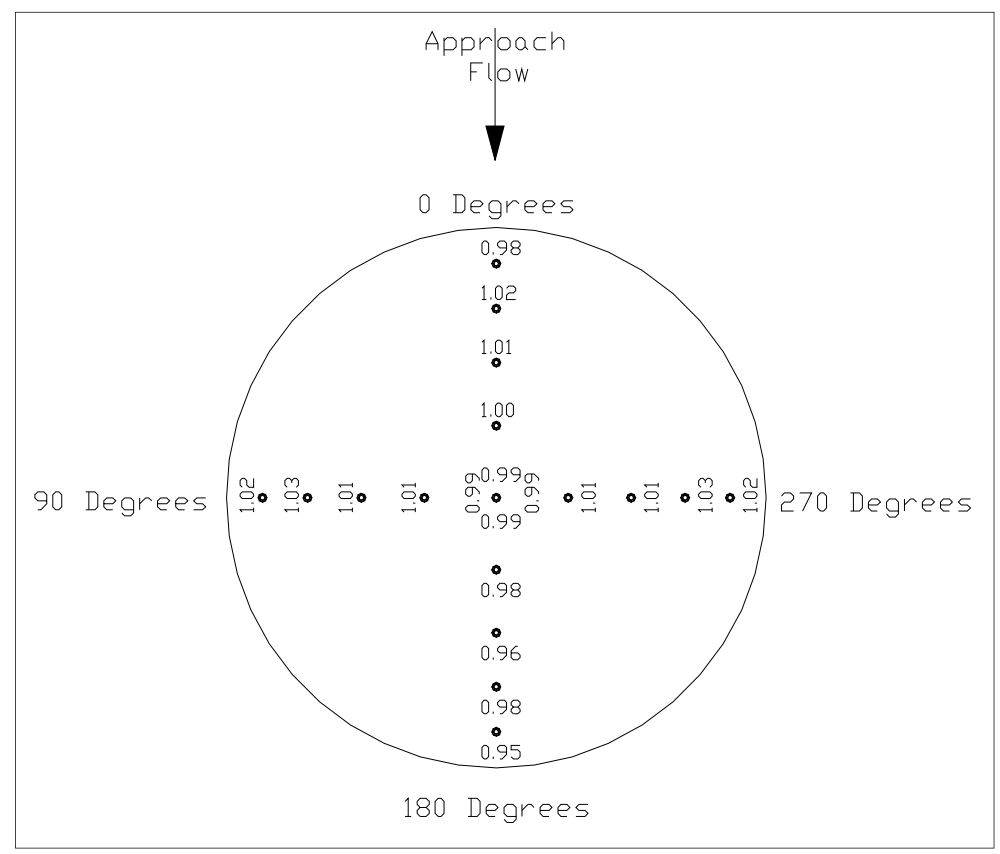

Figure 50. Velocity distribution at pump impeller for Pump 8, with correct dividing wall, water level at EL 0.0, all 11 pumps operating, almost no flow non-uniformity at entrance to pump bay.

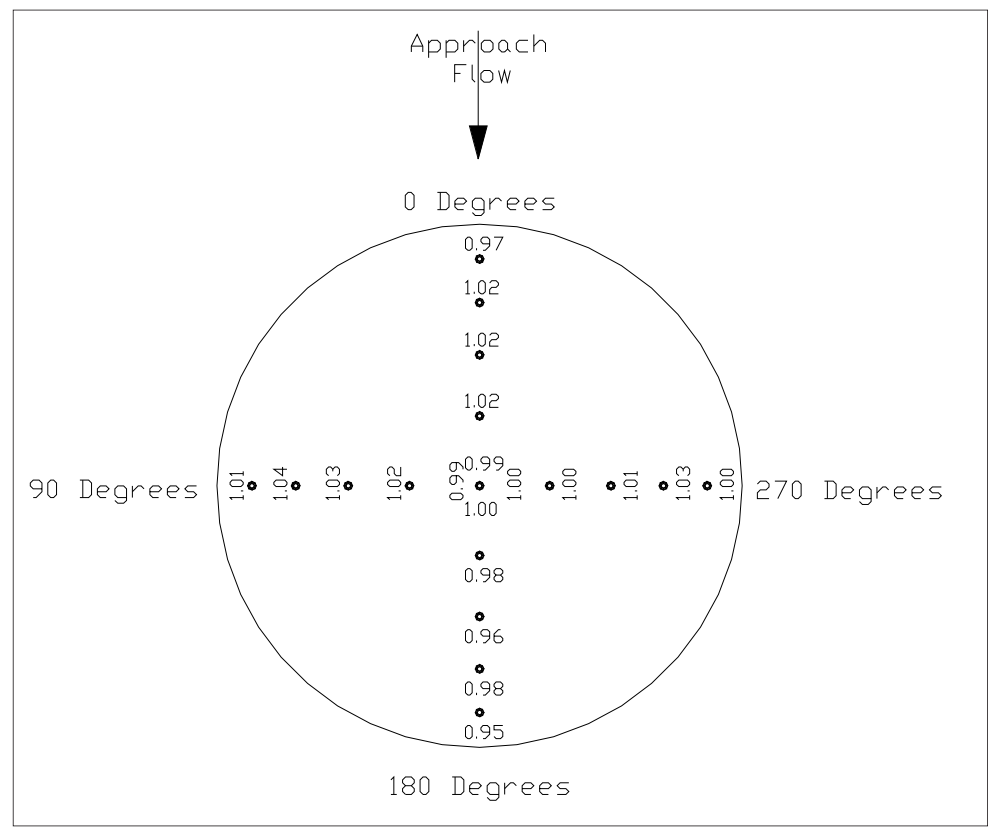

Figure 51. Velocity distribution at pump impeller for Pump 8, with correct dividing wall, water level at EL 0.0, Pumps 8-13 operating, large flow non-uniformity at entrance to pump bay. 


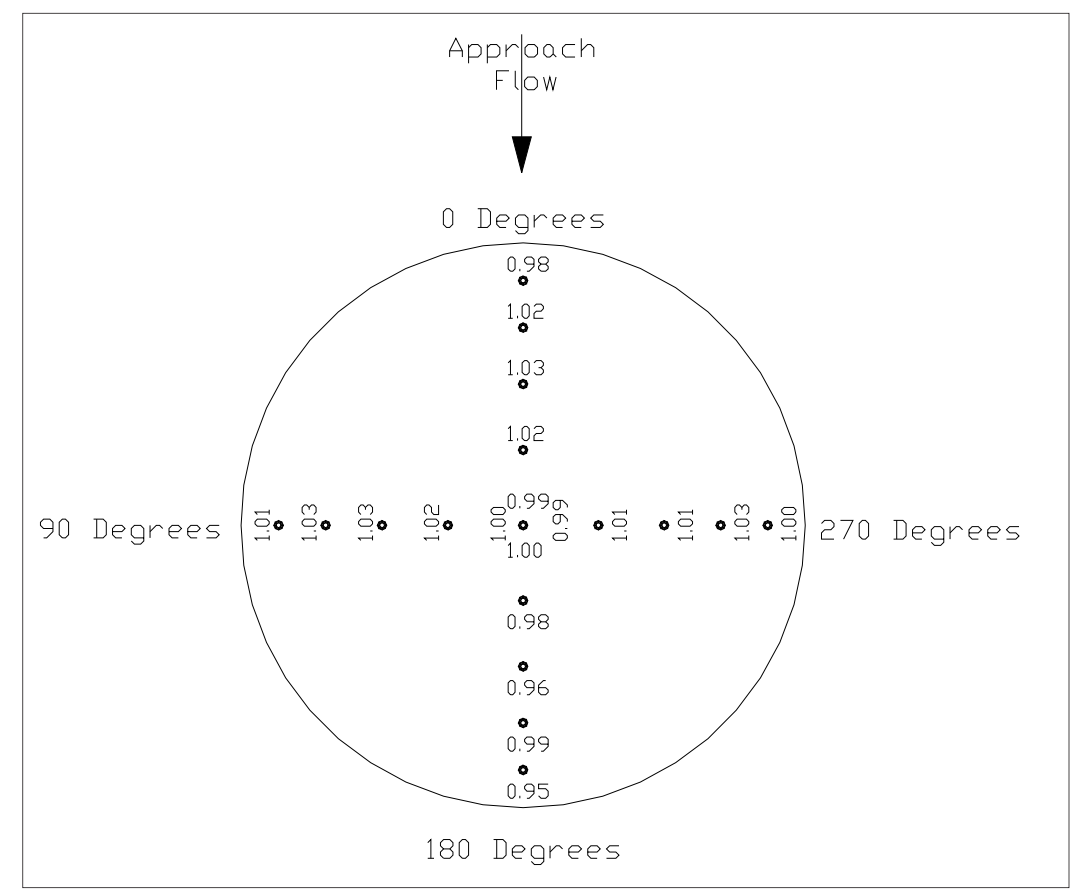

Figure 52. Velocity distribution at pump impeller for Pump 8, with correct dividing wall, water level at EL 2.0, all 11 pumps operating, almost no flow non-uniformity at entrance to pump bay.

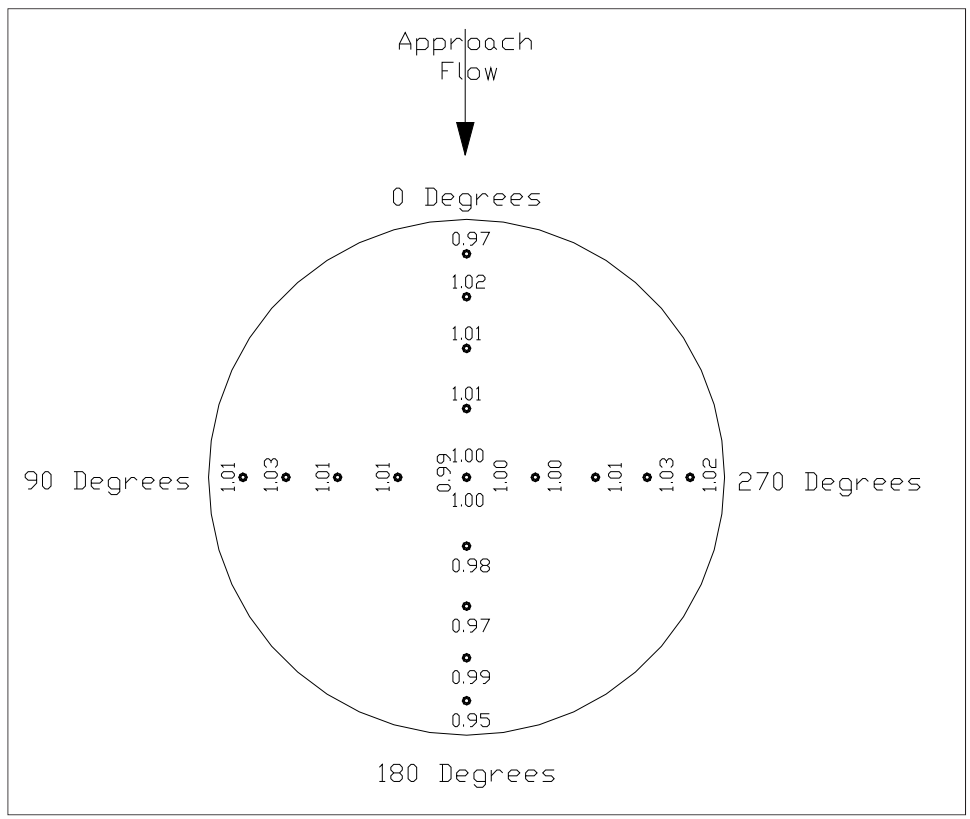

Figure 53. Velocity distribution at pump impeller for Pump 8, with correct dividing wall, water level at EL 2.0, Pumps 8-13 operating, large flow non-uniformity at entrance to pump bay. 


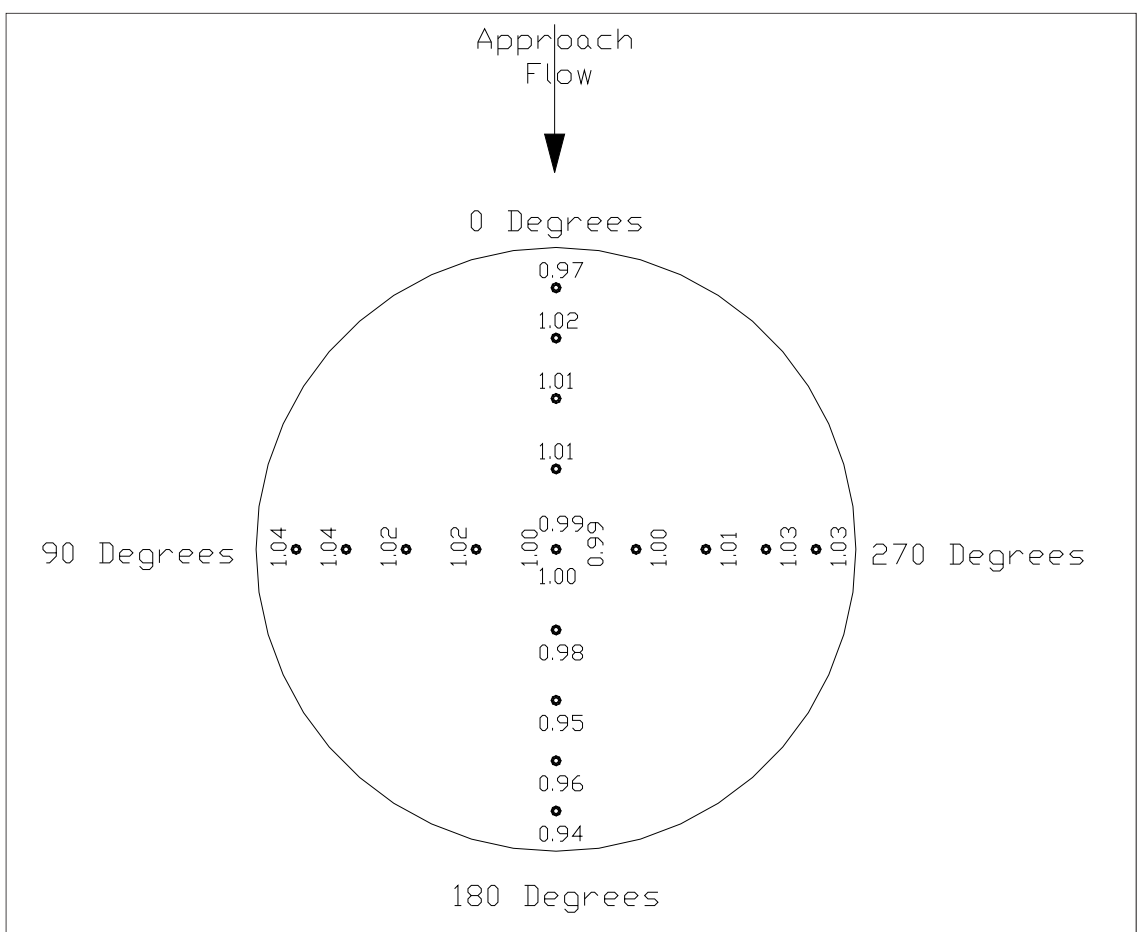

Figure 54. Velocity distribution at pump impeller for Pump 8, with correct dividing wall, water level at EL 7.0, all pumps operating, almost no flow nonuniformity at entrance to pump bay.

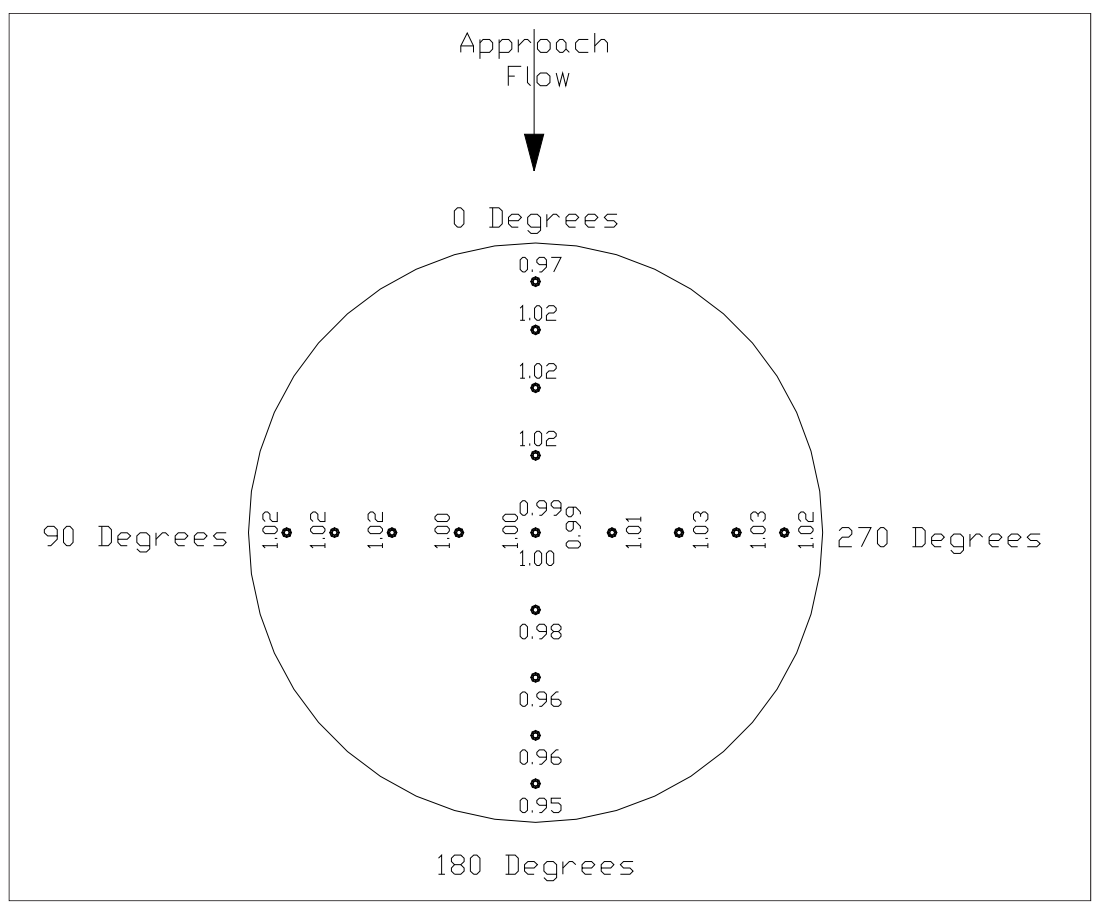

Figure 55. Velocity distribution at pump impeller for Pump 11, with correct dividing wall, water level at EL 0.0 , all pumps operating, significant flow non-uniformity at entrance to pump bay. 


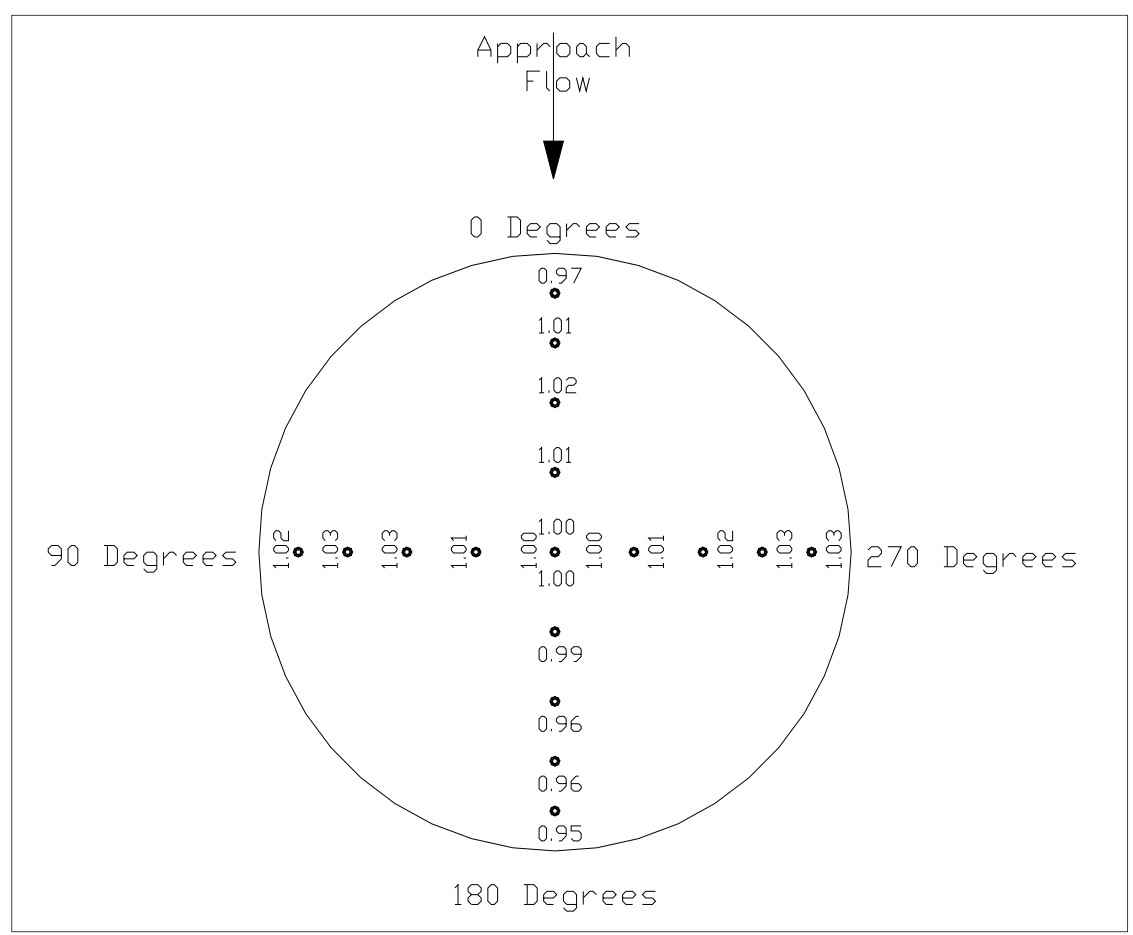

Figure 56. Velocity distribution at pump impeller for Pump 11, with correct dividing wall, water level at EL 0.0 , odd number pumps operating, large flow non-uniformity at entrance to pump bay.

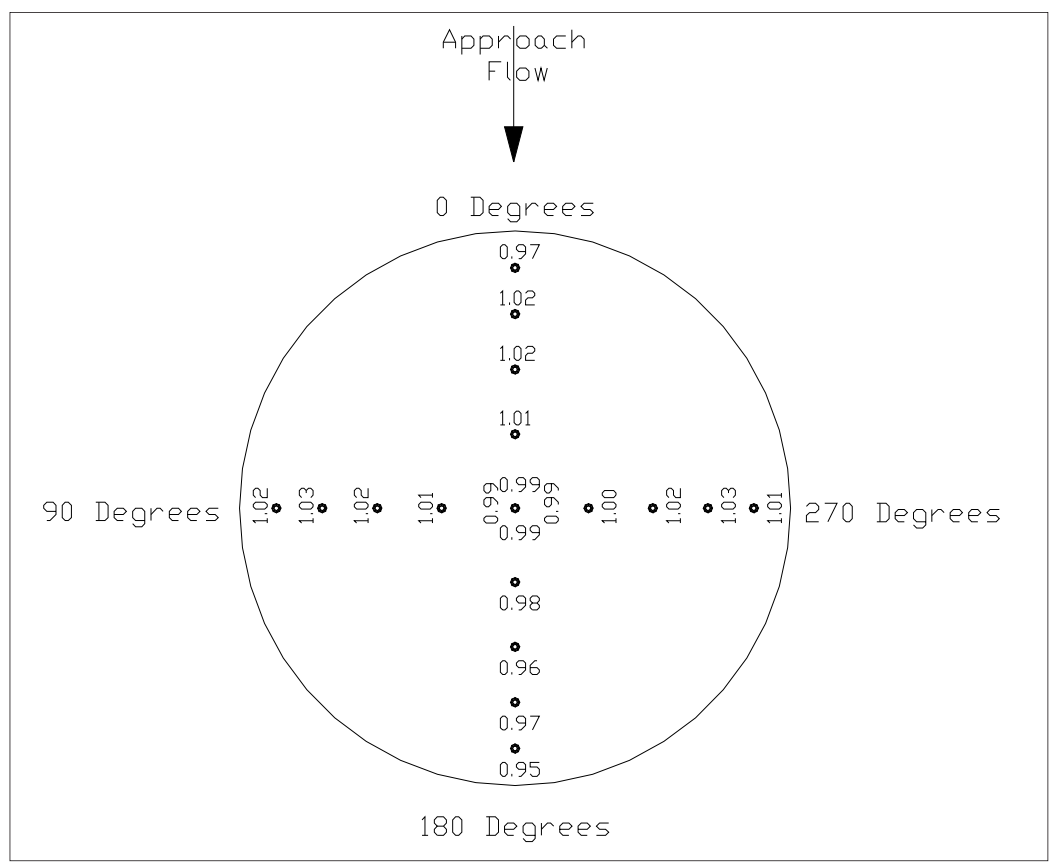

Figure 57. Velocity distribution at pump impeller for Pump 11, with correct dividing wall, water level at EL 0.0, Pumps 11-13 operating, large flow non-uniformity at entrance to pump bay. 


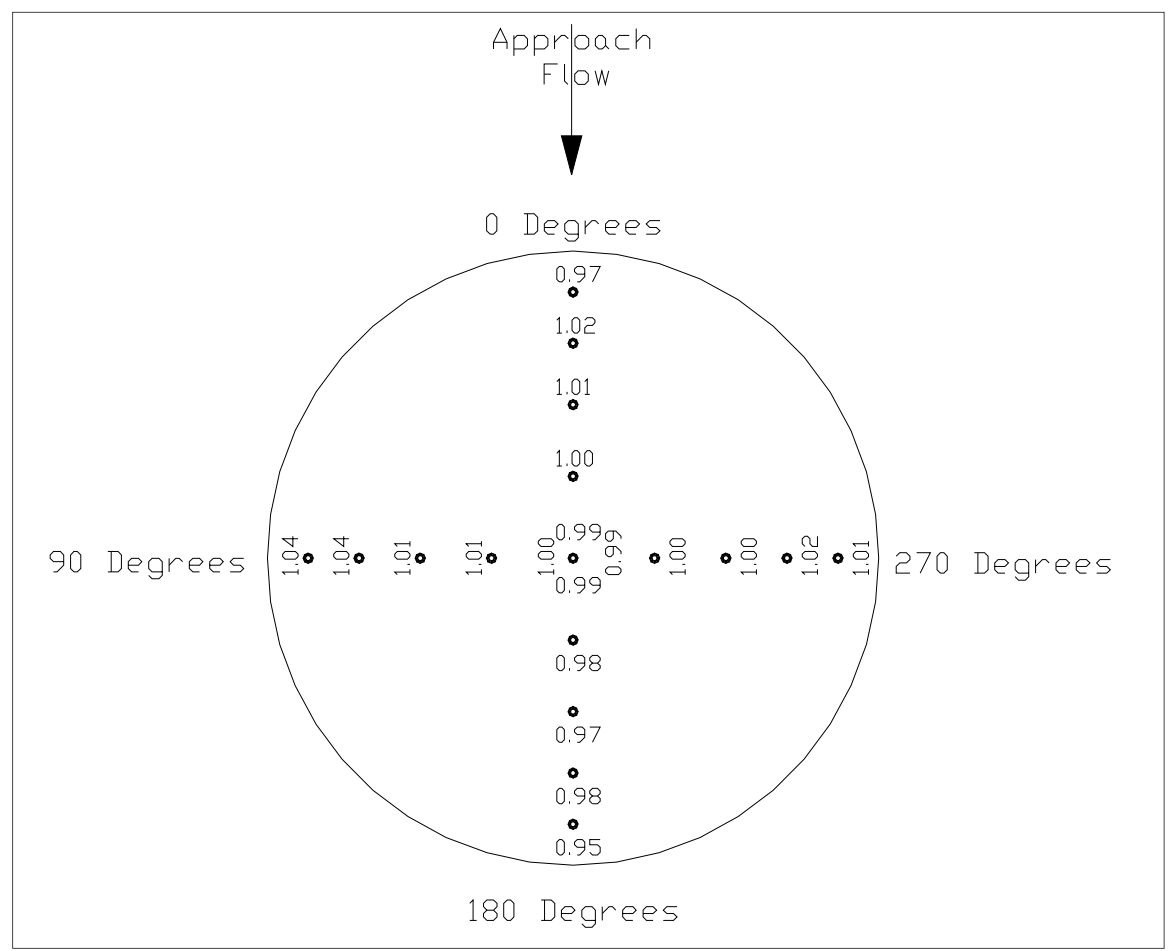

Figure 58. Velocity distribution at pump impeller for Pump 13, with correct dividing wall, water level at EL 0.0 , all 11 pumps operating, large flow nonuniformity at entrance to pump bay.

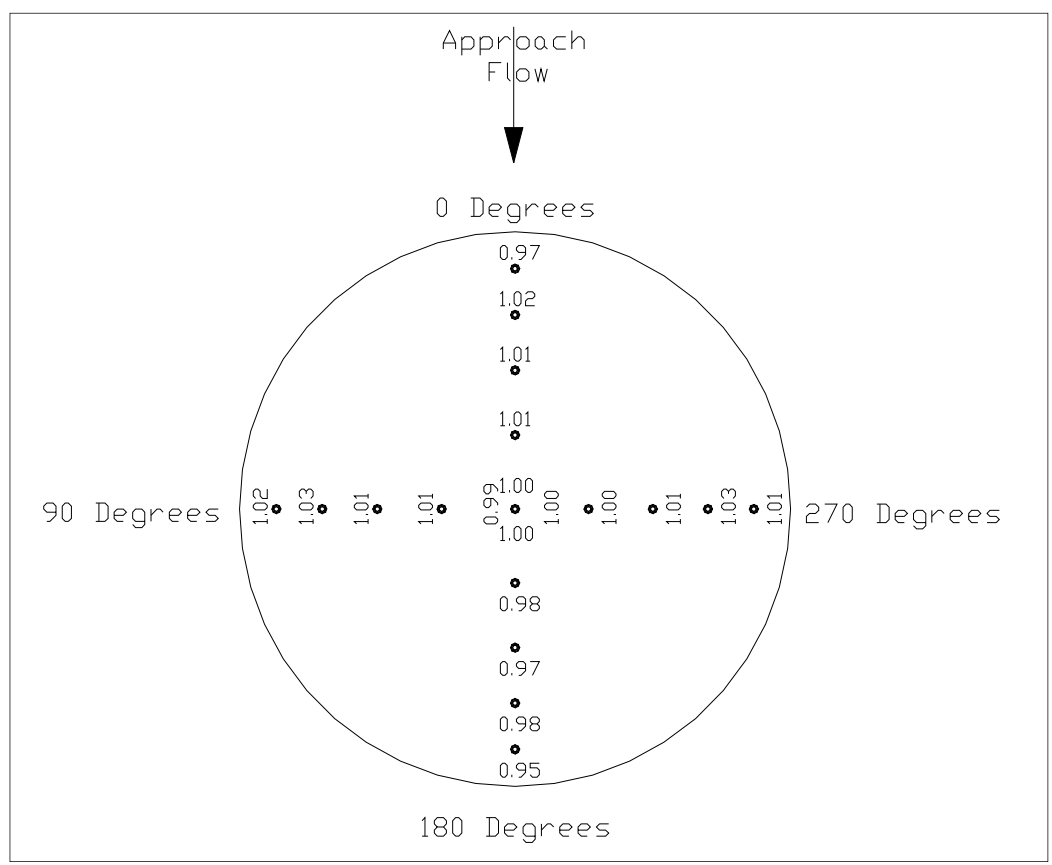

Figure 59. Velocity distribution at pump impeller for Pump 13, with correct dividing wall, water level at EL $0.0,6$ odd number pumps operating, large flow non-uniformity at entrance to pump bay. 


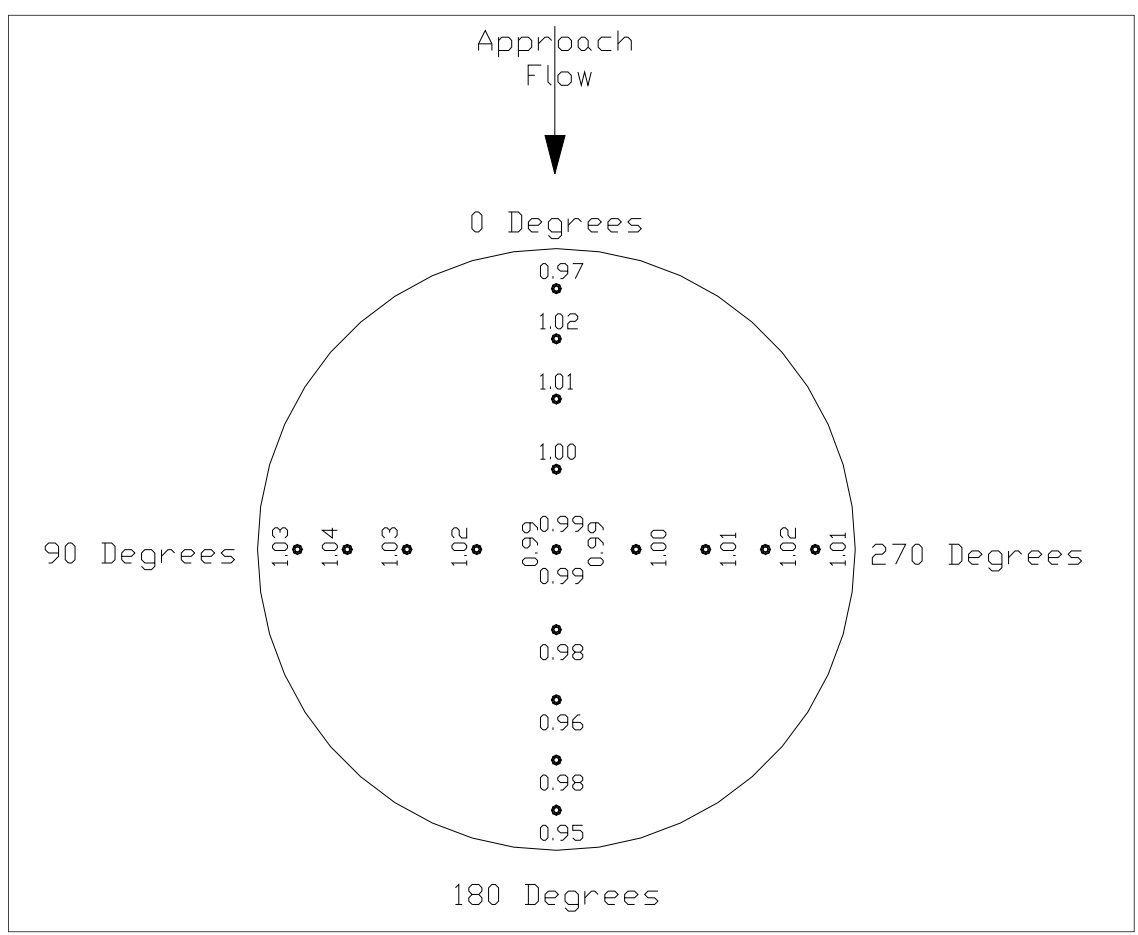

Figure 60. Velocity distribution at pump impeller for Pump 13, with correct dividing wall, water level at EL 2.0, all 11 pumps operating, large flow nonuniformity at entrance to pump bay.

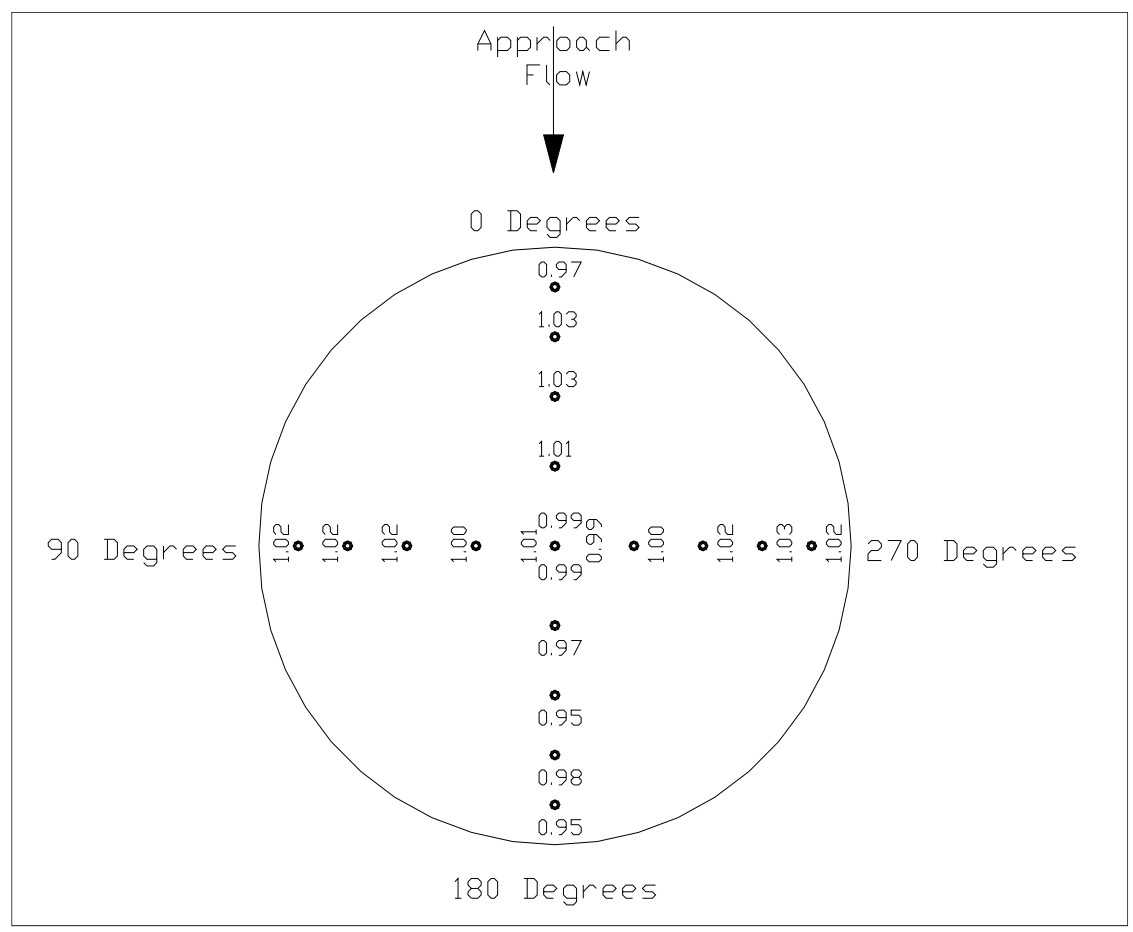

Figure 61. Velocity distribution at pump impeller for Pump 13, with correct dividing wall, water level at EL 2.0, 6 odd number pumps operating, large flow non-uniformity at entrance to pump bay. 


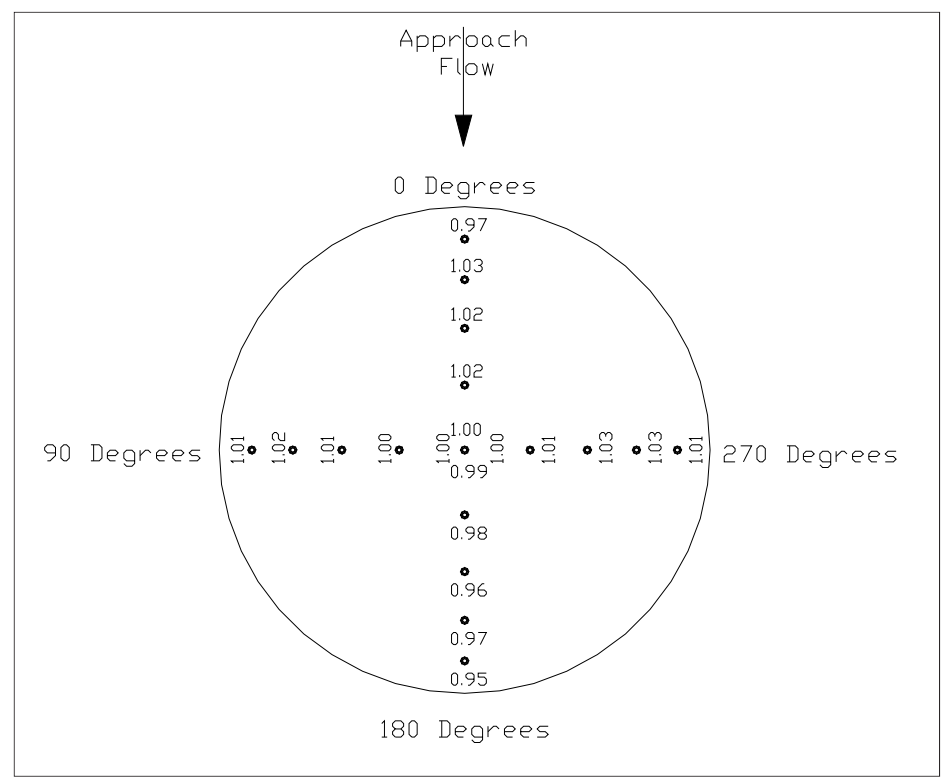

Figure 62. Velocity distribution at pump impeller for Pump 13, with correct dividing wall, water level at EL 7.0, all 11 pumps operating, large flow non-uniformity at entrance to pump bay.

Table 4. Swirl angle for trash rack blockage tests conducted with Pump 3, only Pump 3 operating, water level at EL 2, with correct dividing wall length, revised approach channel, $300-f t$ long flow divider wall.

\begin{tabular}{|l|l|}
\hline $\begin{array}{l}\text { Blockage, looking } \\
\text { downstream }\end{array}$ & Swirl, deg \\
\hline 25 percent left & 0.6 \\
\hline 25 percent right & 0.6 \\
\hline 50 percent left & 2.4 \\
\hline 50 percent right & 3.0 \\
\hline
\end{tabular}

Velocity distributions with the two 50 percent levels of trash rack blockage are shown in Figures 63 and 64. The velocity plots and the swirl measurements show how robust the contracted section and FSI were at maintaining low swirl and producing a uniform velocity distribution at the pump impeller when approach flows were highly skewed.

\subsection{Water level difference across flow divider wall}

For structural design purposes, the water level difference was measured across the 300-ft long flow divider wall. Results are shown in Table 5. The flow through each pump was set at 1,740 cfs, and all pumps were running. The inflow distribution was the typical 65 percent from Algiers Canal and 35 percent from Harvey Canal. 


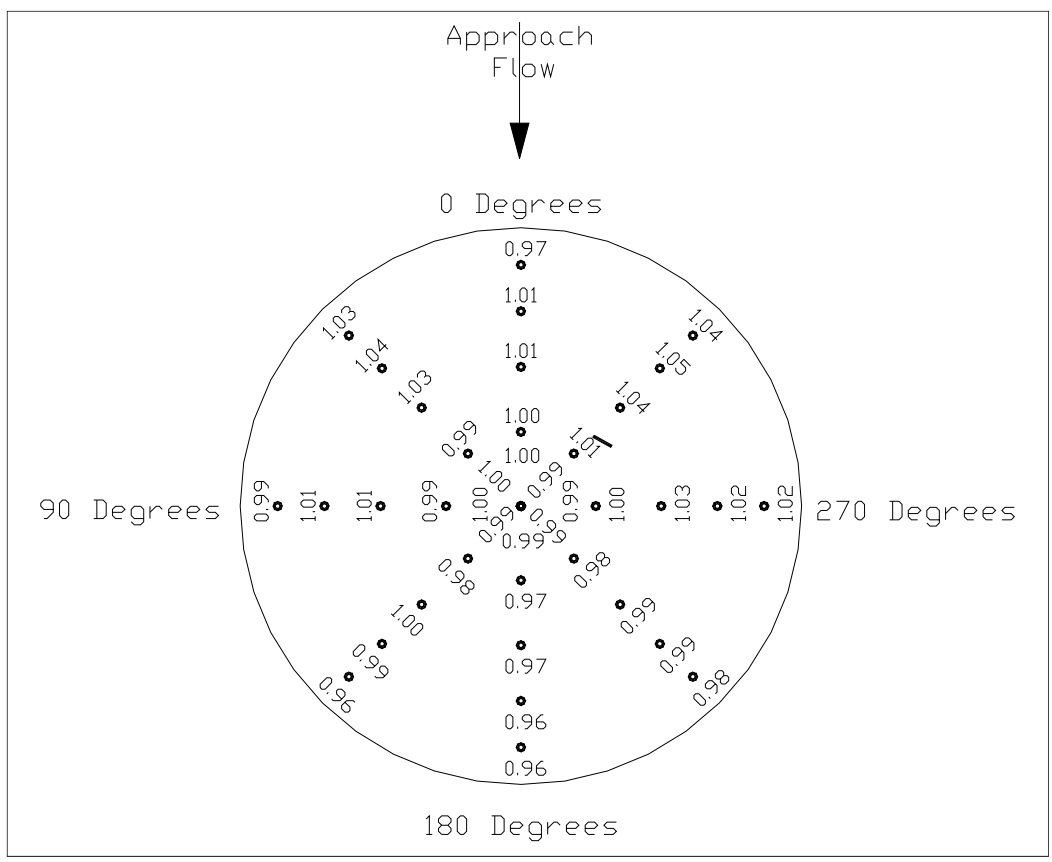

Figure 63. Velocity distribution at pump impeller for Pump 3, with correct dividing wall, water level at EL 2.0, Pump 3 operating, and trash rack blocked on right one-half of pump bay (looking downstream).

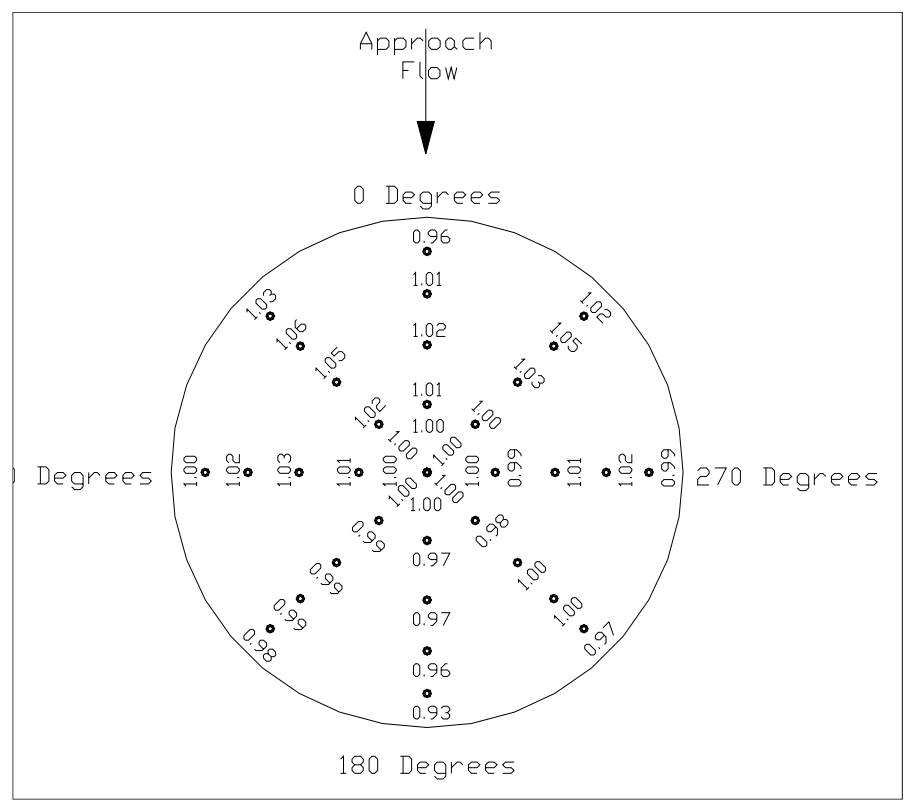

Figure 64. Velocity distribution at pump impeller for Pump 3, with correct dividing wall, water level at EL 2.0, Pump 3 operating, and trash rack blocked on left one-half of pump bay (looking downstream). 
Table 5. Water level difference across the 300-ft long flow divider wall measured in physical model. All pumps operating.

\begin{tabular}{|l|l|l|l|}
\hline Point along wall & $\begin{array}{l}\text { Prototype distance } \\
\text { from upstream edge } \\
\text { of intake, } \mathrm{ft} *\end{array}$ & $\begin{array}{l}\text { Prototype difference } \\
\text { at intake EL 0.0 }\end{array}$ & $\begin{array}{l}\text { Prototype difference } \\
\text { at intake El -1.5 }\end{array}$ \\
\hline 1 & 270 & 0.26 & 0.34 \\
\hline 2 & 210 & 0.24 & 0.42 \\
\hline 3 & 150 & 0.24 & 0.50 \\
\hline 4 & 90 & 0.28 & 0.44 \\
\hline 5 & 30 & 0.22 & 0.46 \\
\hline
\end{tabular}

Differential water levels across the flow divider wall were measured using a movable stand that was placed along the flow divider wall. The stand was wide enough to allow placement of a point gage on either side of the wall while keeping the stand stationary. The stand was leveled at each of the locations. The readings along the wall were not related to a common datum and are only valid to determine the difference in surface water level across the wall. The readings were taken at 1-in. away from the wall in the model that corresponds to 20 -in. in the prototype.

Test results shown in Table 5 show a maximum water level difference of $0.5 \mathrm{ft}$ for the -1.5 water level and 0.28 for the 0.0 water level.

\subsection{Velocity fluctuations}

One of the velocity requirements of the HI standards is velocity fluctuations must not be excessive. The standard deviation of the velocity at a point must not exceed 10 percent of the average velocity at the same point. The HI states that "Velocity traverses along at least two perpendicular axes at the throat of the model suction bell or at the plane of the pump suction in a piping system shall be obtained for the final design using a Pitot-static tube or other suitable instrument capable of determining the axial velocity component with a repeatability of \pm two percent or better. To allow velocity fluctuations to be properly measured and recorded versus time, care should be taken that no unnecessary physical or electronic dampening is introduced".

Measurement of velocity fluctuations inside a pump intake is a difficult undertaking and little information can be found in the literature. The available measurement options include Laser Doppler Velocimetry (LDV), 
hot-wire anemometry, miniature propeller meter, and using a differential pressure cell with a Pitot tube. Each of these has some advantages and also significant drawbacks. The LDV is clearly the best technique for quantifying fluctuating velocity in just about any hydraulic application. Frequency response is fast and the LDV gives velocity at a point because of its small sampling volume. ERDC did not have an LDV available to use on the WCC pump intake model and the cost of a new LDV system and the delivery time were not acceptable. In addition, the 1:20 scale WCC pump intake model likely does not have adequate space around the sides of the pump intake to use an LDV meter to measure velocities. The water in the shelter used for the large WCC intake model was not protected from dust and debris intrusion, which would prevent use of a hot-wire anemometer. The miniature propeller meter has been used by some investigators and was discussed in Sweeney and Rockwell (1982). Use of the 0.4-in. (1-cm) diameter propeller is most applicable to large models where the area over which velocity is sampled (based on about the propeller diameter) is not a significant portion of the total area. In addition, a large model has large model velocities, large speed of rotation of the propeller, and thus faster response time. The available 1-cm (0.4-in.) diameter propeller meter is not truly a point velocity in the 6 -in. diameter intake used in the WCC model intake where the diameter of the propeller would be seven percent of the pipe diameter. The frequency response may not be adequate in the model size used in WCC. Sweeney and Rockwell (1982) state that "The low inertia of the propeller and the electronic characteristics of the system allow fluctuations within approximately 0.1 seconds to be quantified. The quantified velocity fluctuation being a function of the measuring system, it is meaningless to define a generally applicable allowable measured fluctuation. However, experience allows excessive fluctuations to be identified and, where possible, corrected." Sweeney and Rockwell also point out that the propeller is subject to fibers collecting on the shaft of the propeller, which would be present in the WCC flume. The fibers would have been difficult to detect and remove with the propeller inside the pump intake. The last method, the Pitot tube, has the advantages of being small enough to be considered a point velocity and has no moving parts, which can be affected by dust, debris, or fibers. Sweeney and Rockwell (1982) note that the Pitot tube approach has limitations concerning response time that introduce some dampening of fluctuations. It is likely that only the LDV provides a true measure of the standard deviation at a point in the flow. Other methods are not point velocities and/ or do not have a low enough response time. This author agrees with Sweeney and Rockwell that the propeller meter is 
primarily applicable to finding areas of excessive fluctuations and believes this same concept is applicable to the Pitot tube.

The approach used herein was to connect a differential pressure cell to the Pitot tubes in the array used to measure time-averaged velocity presented previously. The 1/ 8-in. diameter Pitot tube was two percent of the diameter of the 6-in. intake at the WCC model and closer to a point velocity than would be the propeller meter. A differential pressure transducer was mounted to the Pitot tube array in the pump throat. One pressure transducer was used and was moved to each of the five Pitot tubes. The differential cell and Pitot tube were rotated to measure all positions around the pump throat. Rigid polyethylene tubing about 12 -in. long was used to connect the transducer and the Pitot tube. The transducer had a range of \pm $0.5 \mathrm{psi}$ and model data was collected at $25 \mathrm{~Hz}$. typical differential on the Pitot tube was about $0.17 \mathrm{psi}$. Data were taken for $60 \mathrm{sec}$ at each location. The setup is shown in Figure 65.

Tests were conducted on Pump 3 with all 11 pumps operating at water level of EL 2 (Figure 66) and Pump 3 with only Pump 3 operating at a water level of EL 2 (Figure 67). Results are shown as percentage determined from (100 x standard deviation)/ average velocity) to compare to the HI Standard of \pm 10 percent. Two of the readings were repeated to check consistency of the measurements. Note that the highest readings occurred along the axis of zero and 180 degrees. These readings were the positions most affected by turbulence downstream of the center pier of the FSI and were consistent with the dye observations discussed previously. The average of all readings in the two plots was 2.7 percent. Using the Sweeney and Rockwell (1982) concept of identifying locations of excessive fluctuations, none of the individual readings were excessive compared to the average value. While the amount of dampening was unknown, the maximum fluctuation was less than one-half of the $\mathrm{HI}$ standard of 10 percent.

\subsection{Testing at water levels below EL 0}

The design with a 300-ft long flow divider wall was tested with water levels at EL -1.5 for several conditions as shown in Table 3. Tests were also conducted with Pump 12 and the 150-ft long flow divider wall at lower water levels. The goal of these tests was to insure that the acceptable performance of the intake at EL 0 was not near a threshold of adequate intake performance. In addition, if the intake performed adequately at water levels below EL 0, this provided additional flexibility in the operation of the pump 


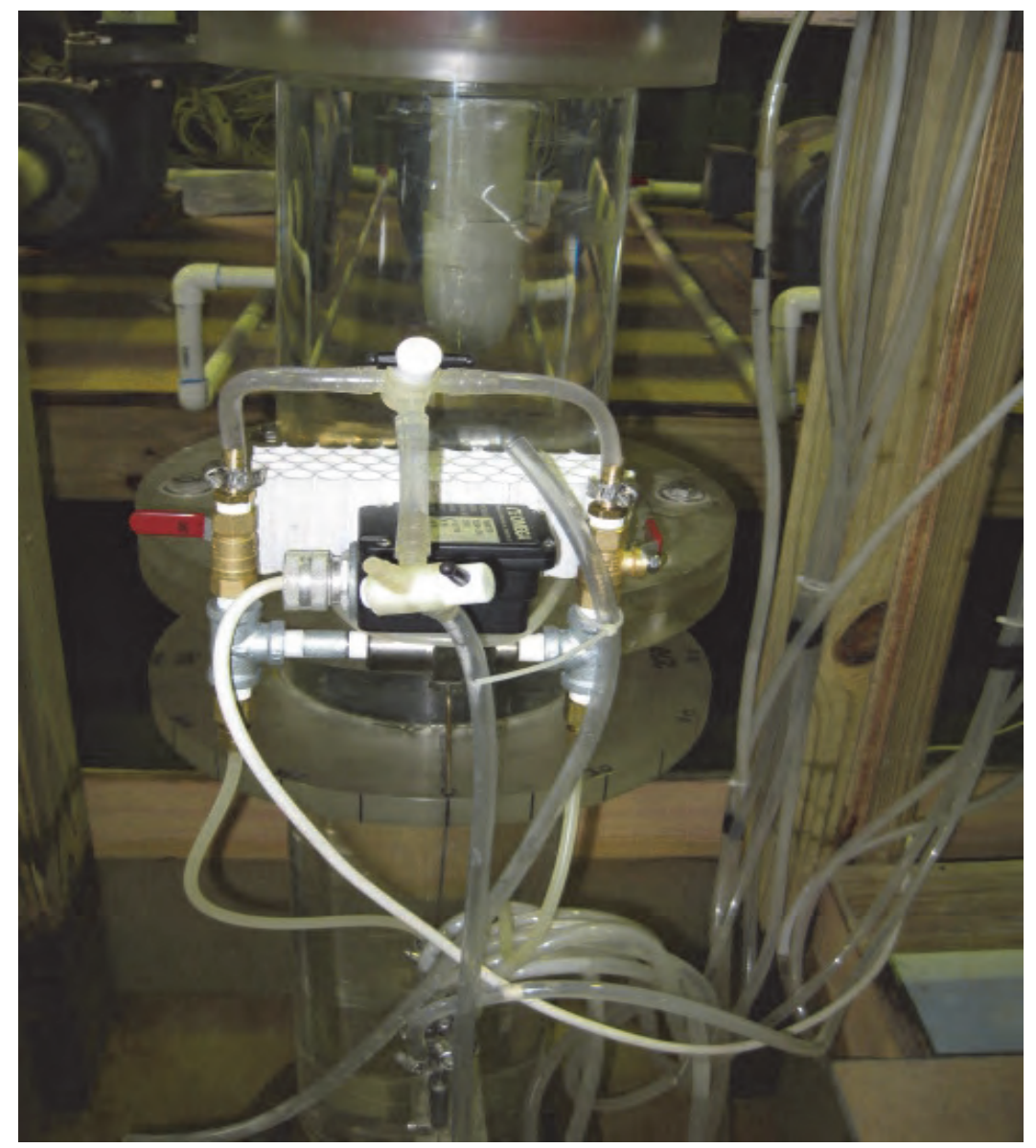

Figure 65. Differential pressure transducer used to measure velocity fluctuations. Although some soft tubing was used to purge air from the system, rigid tubing was used between the pressure transducer and the Pitot tube.

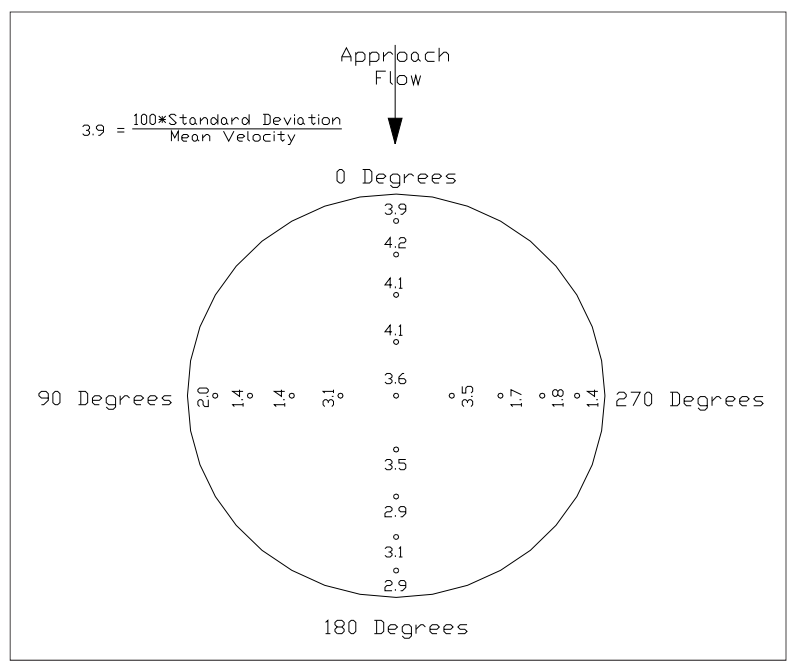

Figure 66. Velocity fluctuations. Pump 3, with correct dividing wall, water level at EL 2.0, all 11 pumps operating, large flow non-uniformity at entrance to pump bay. 


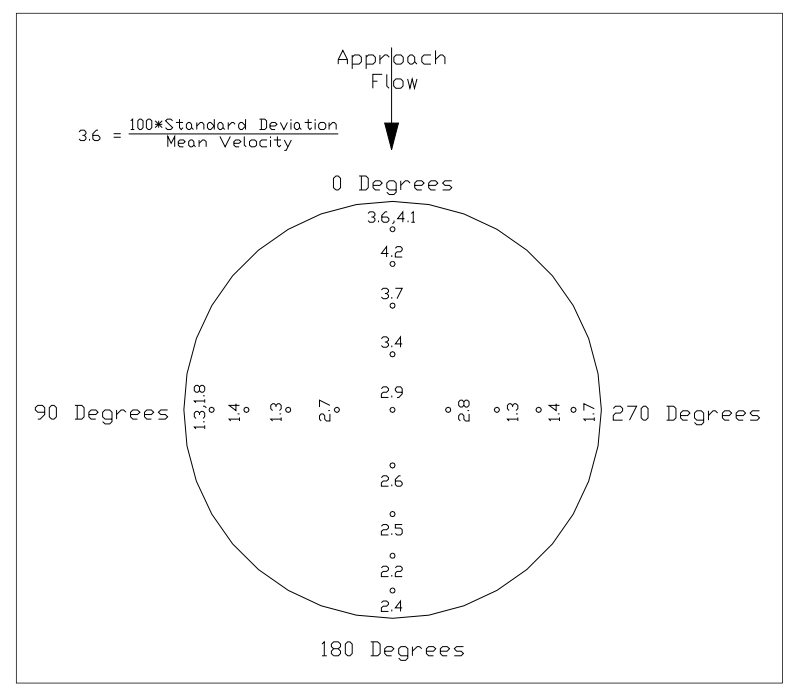

Figure 67. Velocity fluctuations. Pump 3, with correct dividing wall, water level at EL 2.0, only Pump 3 operating, single pump flow non-uniformity at entrance to pump bay.

station. These tests did not address the required suction head on the pumps. The pump manufacturer should be consulted to make certain the lower water levels meet pump suction head and starting requirements. In addition, Sweeney and Rockwell (1982) state that when pumps approach operating conditions near the required suction head, the requirements for time averaged velocity uniformity and velocity fluctuations become more stringent. As shown in Table 3, swirl remained low for the water level at EL -1.5 for Pumps 3 and 8 for various pump operating combinations. Velocity distributions with Pump 3 are shown in Figures 68 and 69 for different operating combinations. All met HI standards for time averaged velocity uniformity. Tests were also conducted with lower water levels with Pump 12 as the test pump. The Pump 12 tests only examined the potential for surface vortices with the lower water levels. The test results are shown in Table 6. At an intake level of -1.0 and -2.0, no unacceptable surface vortices were found for both Pump 12 alone and Pumps 12 and 13 both operating. Type 1 and 2 vortices formed but no dye-core vortices formed to the intake. Pump 12 alone at intake EL -3.0 also resulted in no unacceptable vortices. The lack of surface vortices was likely due in part to the high approach velocities at the lower intake levels preventing vortex organization and formation. At an intake level of - 3 and discharge of 1,740 cfs, approach velocity in the $38.5 \mathrm{ft}$ wide intake was $3.0 \mathrm{ft} / \mathrm{sec}$. 


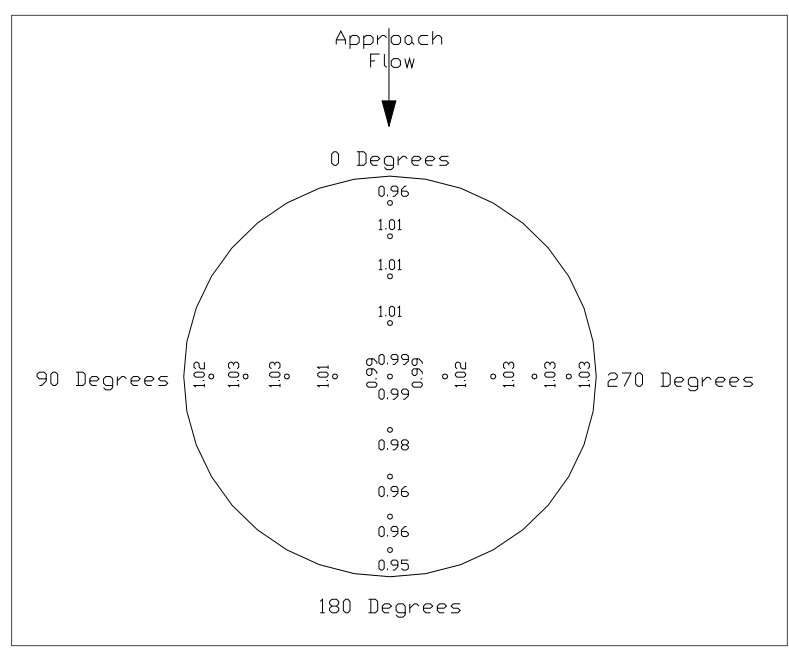

Figure 68. Velocity distribution at pump impeller for Pump 3, with correct dividing wall, water level at EL 1.5, Pump 3 operating.

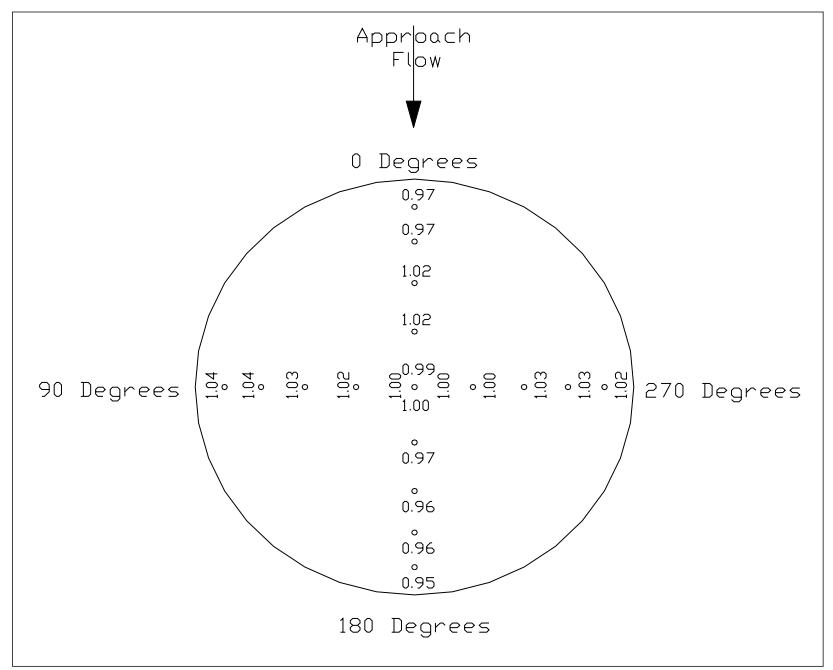

Figure 69. Velocity distribution at pump impeller for Pump 3, with correct dividing wall, water level at EL -1.5 , all 11 pumps operating.

\subsection{Testing with reduced flow divider wall length between sector gate and pump station}

After testing showed that the 300-ft long flow divider wall plan met the various $\mathrm{HI}$ standards, tests were conducted to determine if the flow divider wall could be reduced in length. Tests were conducted initially in the WCC navigation model to make certain that navigation would not be affected adversely by a shorter flow divider wall. The navigation model showed that a flow divider wall could be as short as $150 \mathrm{ft}$ and adverse effects on navigation would not be significant. The navigation study was reported in MoCollum (in prep). 
Table 6. Tests with 150-ft flow divider wall. Swirl in degrees was the highest value of twenty 30 -sec (model duration) readings.

\begin{tabular}{|c|c|c|c|c|c|c|}
\hline $\begin{array}{l}\text { Test } \\
\text { Pump }\end{array}$ & $\begin{array}{l}\text { Pumps } \\
\text { operating }\end{array}$ & $\begin{array}{l}\text { Intake } \\
\text { Level }\end{array}$ & $\mathrm{Q}, \mathrm{cfs}$ & $\begin{array}{l}\text { Swirl, } \\
\text { deg }\end{array}$ & $\begin{array}{l}\text { Surface vortices over } 5 \\
\text { minutes }\end{array}$ & $\begin{array}{l}\text { Flow uniformity } \\
\text { entering bay }\end{array}$ \\
\hline 12 & 12 & -3 & 1,740 & NM & Type 1 & Single \\
\hline 12 & 12 & -2 & 1,740 & NM & Type 1 & Single \\
\hline 12 & $12-13$ & -2 & 1,740 & NM & Type 1 & None or Minor \\
\hline 12 & 12 & -1 & 1,740 & NM & Type 1 and 2 & Single \\
\hline 12 & $12-13$ & -1 & 1,740 & NM & “ & None or Minor \\
\hline 12 & All 11 & 0 & 1,740 & 1.7 & $\begin{array}{l}\text { Short duration* dye-core } \\
\text { vortices but none entering } \\
\text { contracted section }\end{array}$ & Large \\
\hline 12 & $3-12$ & 0 & 1,740 & NM & “ & Significant \\
\hline 12 & $8-13$ & 0 & 1,740 & 0.9 & “ & Significant \\
\hline 12 & $11-13$ & 0 & 1,740 & 1.1 & “ & None or Minor \\
\hline 12 & 12 & 0 & 1,740 & NM & “ & Single \\
\hline 12 & All 11 & 2 & 1,740 & 1.7 & $\begin{array}{l}\text { Short duration dye-core } \\
\text { vortices } 1 / 2 \text { thru } \\
\text { contracted section. }<<10 \\
\text { percent. }\end{array}$ & Large \\
\hline 12 & $11-13$ & 2 & 1,740 & NM & Only type $1 \mathrm{~s}$ & None or Minor \\
\hline 12 & $12 \& 13$ & 2 & 1,740 & NM & “ & Significant \\
\hline 12 & 12 & 2 & 1,740 & NM & $\begin{array}{l}\text { Short duration dye-core } \\
\text { vortices } 1 / 2 \text { thru } \\
\text { contracted section. }<<10 \\
\text { percent. }\end{array}$ & Single \\
\hline 12 & $8-13$ & 2 & 1,740 & NM & $\begin{array}{l}\text { Short duration dye-core } \\
\text { vortices }<<10 \text { percent but } \\
\text { none entering contracted } \\
\text { section }\end{array}$ & Significant \\
\hline 12 & All 11 & 4 & 1,740 & 0.9 & $\begin{array}{l}\text { Short duration dye-core } \\
\text { vortices but none entering } \\
\text { contracted section }\end{array}$ & Large \\
\hline 12 & All 11 & 7 & 1815 & 1.2 & $\begin{array}{l}\text { Short duration dye-core } \\
\text { vortices but none entering } \\
\text { contracted section }\end{array}$ & Large \\
\hline 13 & 13 & 0 & 1,740 & NM & $\begin{array}{l}\text { Short duration dye-core } \\
\text { vortices but none entering } \\
\text { contracted section }\end{array}$ & Single \\
\hline 13 & $11-13$ & 0 & 1,740 & 0.6 & $\begin{array}{l}\text { Short duration dye-core } \\
\text { vortices } 1 / 2 \text { thru } \\
\text { contracted section }<<10 \\
\text { percent }\end{array}$ & None or Minor \\
\hline
\end{tabular}




\begin{tabular}{|c|c|c|c|c|c|c|}
\hline $\begin{array}{l}\text { Test } \\
\text { Pump }\end{array}$ & $\begin{array}{l}\text { Pumps } \\
\text { operating }\end{array}$ & $\begin{array}{l}\text { Intake } \\
\text { Level }\end{array}$ & Q, cfs & $\begin{array}{l}\text { Swirl, } \\
\text { deg }\end{array}$ & $\begin{array}{l}\text { Surface vortices over } 5 \\
\text { minutes }\end{array}$ & $\begin{array}{l}\text { Flow uniformity } \\
\text { entering bay }\end{array}$ \\
\hline 13 & All 11 & 0 & 1,740 & 1.1 & $\begin{array}{l}\text { Short duration dye-core } \\
\text { vortices but none entering } \\
\text { contracted section }\end{array}$ & Large \\
\hline 13 & $8-13$ & 0 & 1,740 & 1.1 & $\begin{array}{l}\text { Short duration dye-core } \\
\text { vortices } 1 / 2 \text { thru } \\
\text { contracted section }<<10 \\
\text { percent }\end{array}$ & Significant \\
\hline 13 & 13 & 2 & 1,740 & NM & $\begin{array}{l}\text { Short duration dye-core } \\
\text { vortices but none entering } \\
\text { contracted section }\end{array}$ & Single \\
\hline 13 & $11-13$ & 2 & 1,740 & NM & $\begin{array}{l}\text { Frequent short duration } \\
\text { dye-core vortices entering } \\
\text { contracted section. Three } \\
\text { made it } 1 / 2 \text { way thru } \\
\text { contracted section, } 1 \text { made } \\
\text { it to entrance of FSI. }\end{array}$ & None or Minor \\
\hline 13 & $8-13$ & 2 & 1,740 & 0.2 & \begin{tabular}{|l|} 
Short duration dye-core \\
vortices entering \\
contracted section $<<10$ \\
percent. None extending \\
$1 / 2$ thru contracted section
\end{tabular} & Significant \\
\hline 13 & All 11 & 2 & 1,740 & 1.1 & $\begin{array}{l}\text { Short duration dye-core } \\
\text { vortices } 1 / 2 \text { thru } \\
\text { contracted section }<<10 \\
\text { percent }\end{array}$ & Large \\
\hline 13 & All 11 & 4 & 1,740 & 1.2 & None & Large \\
\hline 13 & All 11 & 7 & 1,740 & 1.8 & None & Large \\
\hline
\end{tabular}

*Short duration $=0.5$ to $1.0 \mathrm{sec}$ in model

The length of the flow divider wall mainly affects higher flows with numerous pumps operating and those pumps closest to the flow divider wall. The evaluation of flow divider wall length was based on testing Pumps 12 and 13 for various pump operating combinations and various water levels. The location of the bottom transition upstream of the pump station from EL - 18 to EL - 15 was not changed in the flow divider wall length tests.

The initial tests were conducted with the flow divider wall decreased from $300 \mathrm{ft}$ long to $200 \mathrm{ft}$ long. The 200 -ft long flow divider wall was found to meet HI standards. Because the shorter $150-\mathrm{ft} \mathrm{long} \mathrm{flow} \mathrm{divider} \mathrm{wall} \mathrm{was}$ also found to be acceptable, the 200 - $\mathrm{ft}$ long wall results were not presented. 
Because all other tests showed a velocity distribution that met HI standards even for 50 percent trash blockage, only swirl and surface vortices were evaluated for the 150 -ft flow divider wall. Table 6 shows results of the Pump 12 and 13 tests with the 150 -ft flow divider wall.

Subsequent testing in the navigation model showed that navigation was acceptable even with no divider wall between the sector gate and the pump station. The divider wall was removed from the pump intake model and a series of tests were conducted to assess the performance of the intakes with focus on Pumps 12 and 13, because they would be most affected by not having the divider wall. As with the 150-ft divider wall tests, only swirl and surface vortices were evaluated for the condition of no divider wall. Neither showed any significant difference from the tests with the 150-ft divider wall.

\subsection{Testing at increased velocity to evaluate scale effects}

The HI standards require testing at increased velocity to evaluate if the surface vortices in the model were affected by the viscous and surface tension forces being relatively too large in the model. At the beginning of this study when the pumps were to be 1,250 cfs, the model pumps were purchased with enough capacity to increase flow by 50 percent as required in the HI standards. When the pump discharge was increased to 1,740 cfs, the model pumps did not have the capacity to simulate a 50 percent increase. The pumps provided up to 2,015 cfs that was a 16 percent increase in the flow above $1,740 \mathrm{cfs}$. The increased velocity tests were run with only Pump 13 operating with a water level of 0.0 and the 150 -ft long flow divider wall. Less than 10 percent of the dye-core vortices reached the middle of the contracted section that was defined herein as entering the pump.

Meeting the HI standards for increased velocity would have required either some creative plumbing to tie two pumps into one intake or the purchase of one or more larger pumps and replacing one or more of the existing pumps. The literature was not conclusive about the need for these increased velocity tests. Past studies at ERDC were generally conducted without increased velocity tests. The Reynolds number in the 1:20 scale model used herein was 50 percent greater than the minimum Reynolds number required by HI standards. The decision was made to accept the results with the 16 percent increase in velocity. 


\subsection{Keel coolers in intakes}

\subsubsection{General}

Radiator type devices called keel coolers are used to keep the mechanical equipment cooled and will be mounted where flowing water passes along and through the bars of the coolers. The intake bay of the pumps was one of the locations that were considered for placement of the keel coolers. The objective of the intake tests was to insure that velocity along the coolers was adequate to dissipate the heat from the coolers and to insure that the coolers did not adversely affect intake performance.

\subsubsection{Intake bay velocity}

The range of intake levels, discharges, and average velocity in the intake bay are shown in Table 7. The coolers were designed for a minimum of 1.0 knot velocity for adequate heat dissipation. As shown in Table 7, an intake EL 7.0 had an average channel velocity close to the $1.0 \mathrm{knot}$ value.

Table 7. Intake elevation, pump discharge, and average channel velocity in pump intake channel.

\begin{tabular}{|l|l|l|}
\hline Intake EL & Q, cfs & Average Velocity, knots* \\
\hline 0 & 1697 & 1.45 \\
\hline 2 & 1,740 & 1.34 \\
\hline 7 & 1,800 & 1.11 \\
\hline
\end{tabular}

*Pump bay is $38.5 \mathrm{ft}$ wide and has a floor EL -18 .

The initial configuration of the coolers had them mounted on the dividing walls immediately downstream of the trash rack. Along the west wall of the pump intake, coolers were proposed to be placed at a maximum of about 12-ft above the floor of the intake. Along the east wall of each pump intake, coolers were proposed to be placed at a maximum of about 8-ft above the floor of the intake. The average velocities in Table 7 were not adequate to analyze the keel cooler performance because the various pump operating combinations result in different velocity on the two opposing walls of the pump intake channel.

Point velocities were measured in the 1:20 scale model of the WCC pump intake at the proposed locations of the keel coolers. The velocities were measured across the intake at a transect $16 \mathrm{ft}$ upstream of the upstream side of the bulkhead slot as shown in Figure 70. The velocities were measured with a Nixon propeller meter, which has a lower limit of full scale velocity of 0.5-0.6 knots in a 1:20 scale model. 


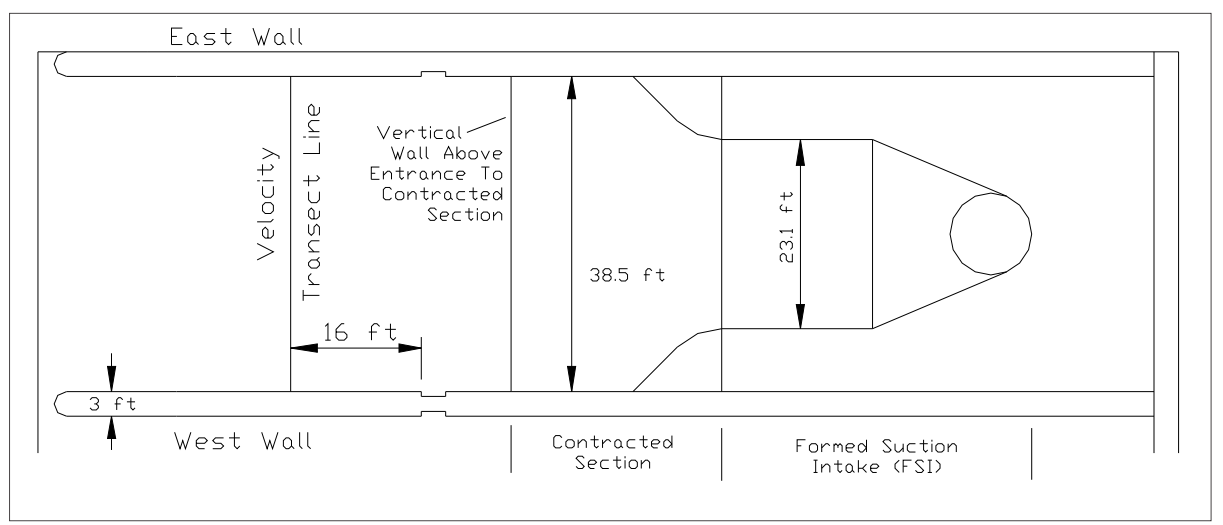

Figure 70. Location of velocity measurement transect for keel coolers.

With various pump operating combinations, the velocity distribution ranges from relatively uniform across the pump bay to highly skewed as shown on Figures 28-41. Note that the dividing wall contraction plots apply strictly to the surface flows as indicated by dye injected just below the water surface. In addition, these plots were developed based on tests at intake EL 2.0, but observations show their trends to be applicable to other intake elevations.

Figure 71 shows the point velocities measured in the Pump 12 intake with only Pump 12 operating. Some imbalance of flow exists across the pump bay, as is also shown in Figure 2. The velocity with "US\&DS" stands for velocity alternating between upstream and downstream. The zero velocity near the east wall at 9-ft above the floor was above the top of the coolers on the east wall, but was shown to provide more complete information about flow distribution in the intake.

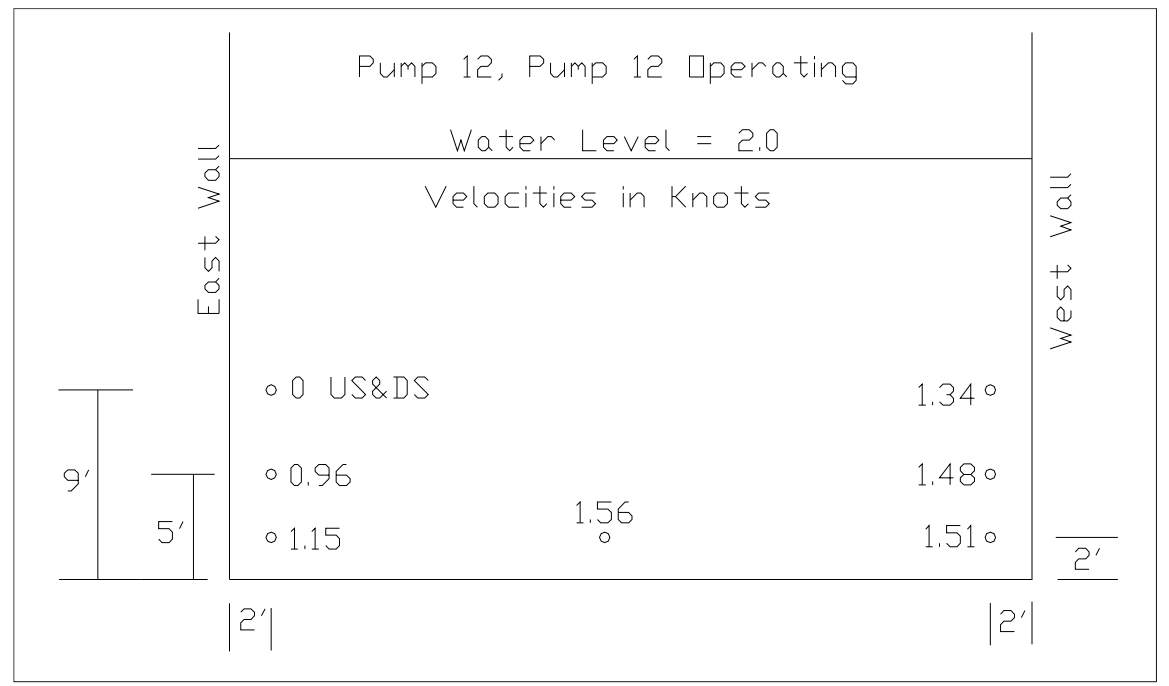

Figure 71. Velocities in Pump 12 intake, intake level $=2.0$, only Pump 12 operating. Cross section looking downstream. Discharge $=1,740 \mathrm{cfs}$. 
With three pumps operating and measuring velocity in the middle pump, the distribution becomes more uniform as shown in Figure 72. Velocities exceed 1.0 knot at all measurement locations except the 0.72 knot reading on the east wall, which was above the top of the proposed east wall coolers.

Figure 73 shows the velocities for Pump 12 with all 11 pumps operating and intake EL 2.0.

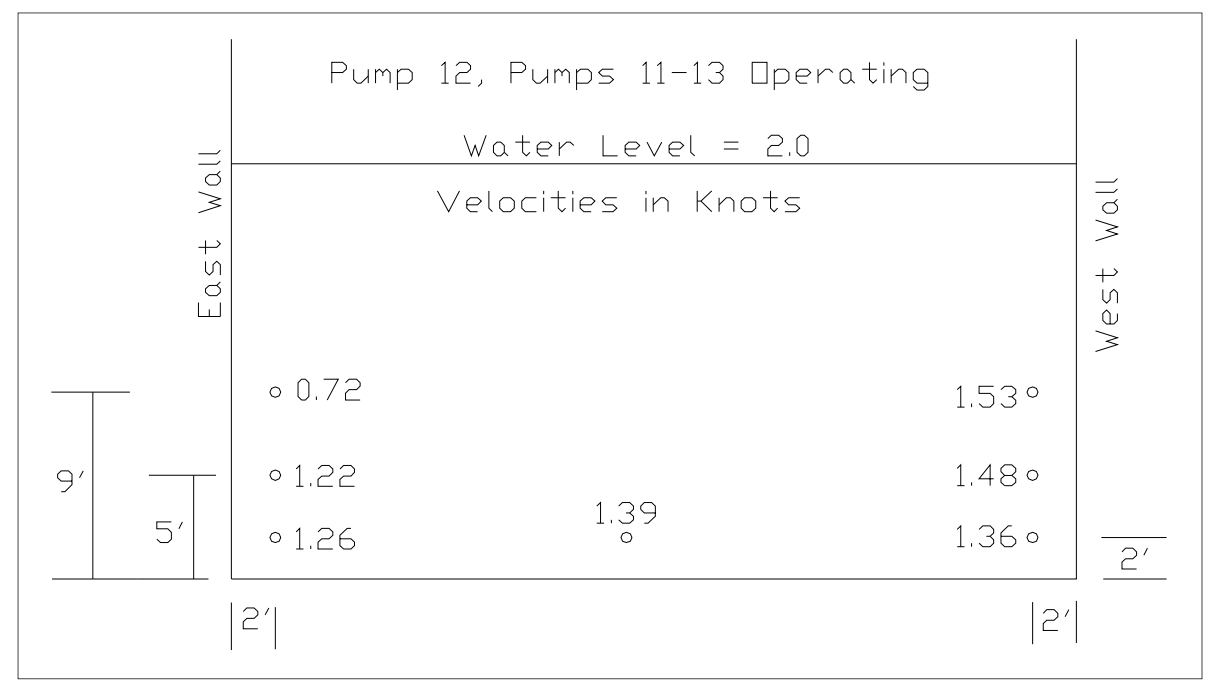

Figure 72. Velocities in Pump 12 intake, intake level $=2.0$, Pumps 11-13 operating. Cross-section looking downstream. Discharge $=1,740 \mathrm{cfs}$.

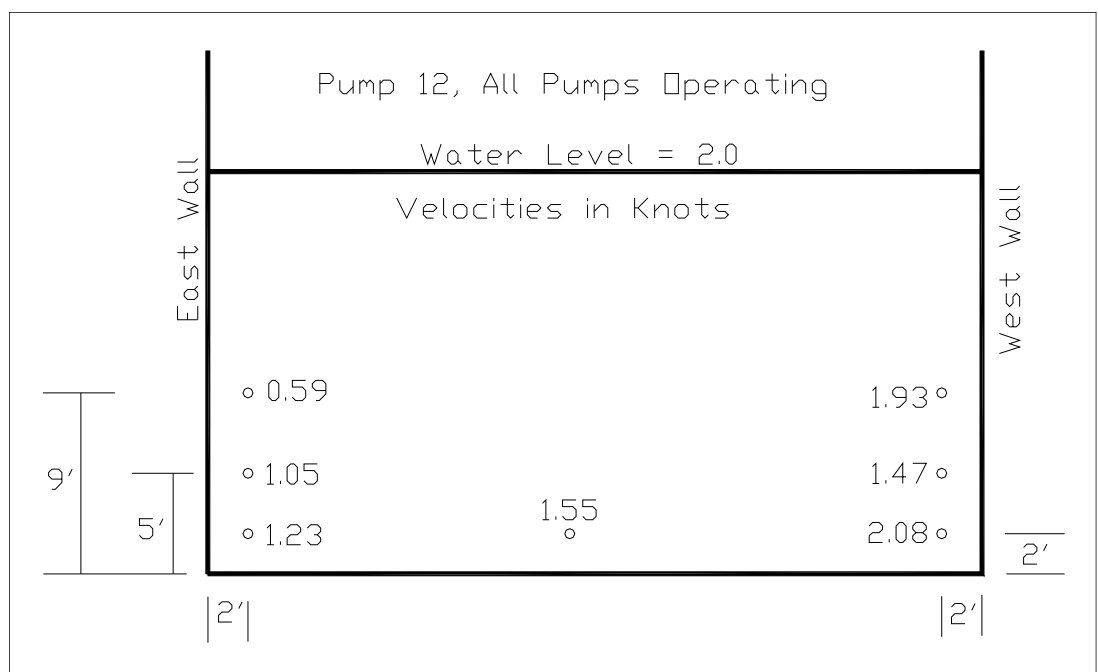

Figure 73. Velocities in Pump 12 intake, intake level $=2.0$, all 11 pumps operating. Cross-section looking downstream. Discharge $=1,740 \mathrm{cfs}$.

Intake EL 7.0 had the lowest average intake velocity as shown in Table 7. Figure 74 shows the velocities in the Pump 12 intake with all 11 pumps operating and an intake EL 7.0. Velocities along the east wall have fallen to less than 1.0 knot at all three depths. 


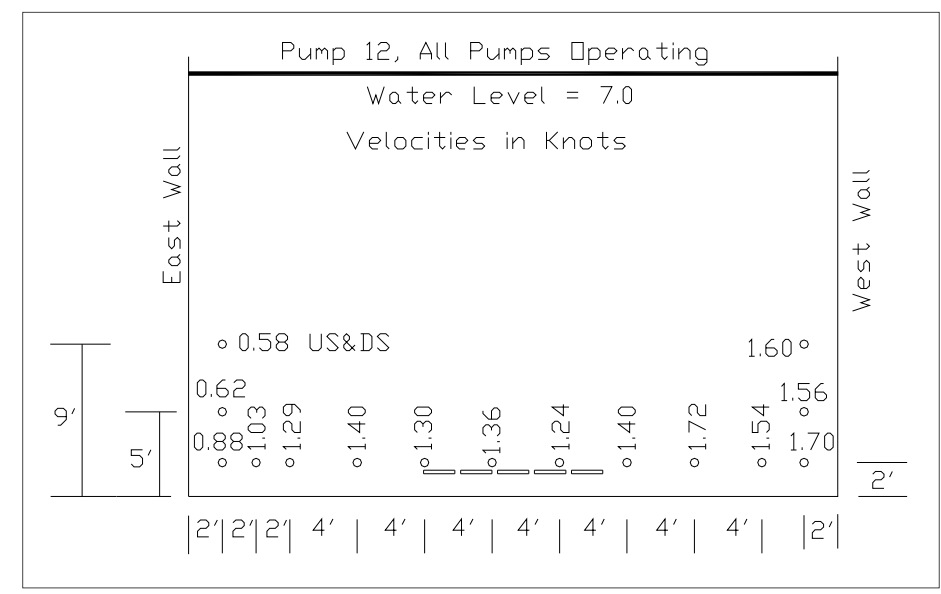

Figure 74. Velocities in Pump 12 intake, intake level $=7.0$, all 11 pumps operating. Cross-section looking downstream. Discharge $=1,800 \mathrm{cfs}$.

As shown in the previous figures, velocity along the east wall was often less than 1.0 knot and velocity along the bottom of the intake and the west wall generally exceeded $1.0 \mathrm{knot}$. If this trend was always true for any pump operating combination, the coolers could be placed along the west intake wall as currently planned and the east intake wall coolers could be moved to the floor. However, under some pump operating conditions, flow concentrates against the east wall of the pump bay. Figure 75 shows Pump 6 velocities with Pumps 4-6 operating at intake EL 7.0. Velocities were greater than 1.0 knot on the east wall and less than 1.0 knot on the west wall.

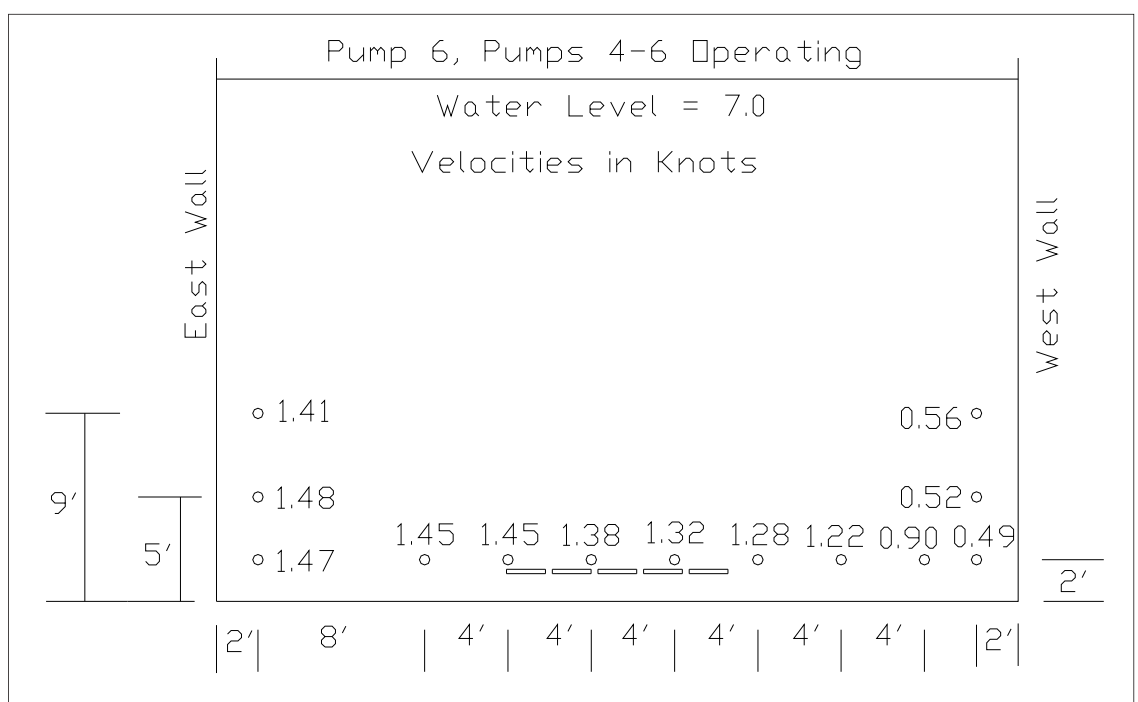

Figure 75. Velocities in Pump 6 intake, intake level $=7.0$, Pumps 4-6 operating. Cross-section looking downstream. Discharge $=1,800 \mathrm{cfs}$. 
Figures 74 and 75 provide an alternate cooler location of placing all coolers on the floor close to the centerline of the pump bay. The floor location near the center of the pump bay meets the $1.0 \mathrm{knot}$ requirement. The figures show five Type 3224 coolers ( 22 5/ 16-in. wide) placed 4-in. apart and centered on the pump bay. Downstream of these five coolers would be four more Type 3224 coolers and the two smaller coolers in the same configuration with a slightly greater total width. Although a wider configuration could be used, the velocities show that the coolers should not be less than about 10 -ft from the walls to provide an allowable margin of safety on the velocities.

\subsection{Intake performance with all keel coolers on floor}

In addition to insuring adequate velocity, tests were conducted to insure that the floor mounted coolers did not have an adverse effect on intake performance. Tests were conducted in Pump Bay 12 with the floor keel cooler design shown in Figure 76. The piping to and from the coolers runs along the floor upstream of the gate slots, is buried in the slab under the gates, and runs vertically up the wall downstream of the gate slots.

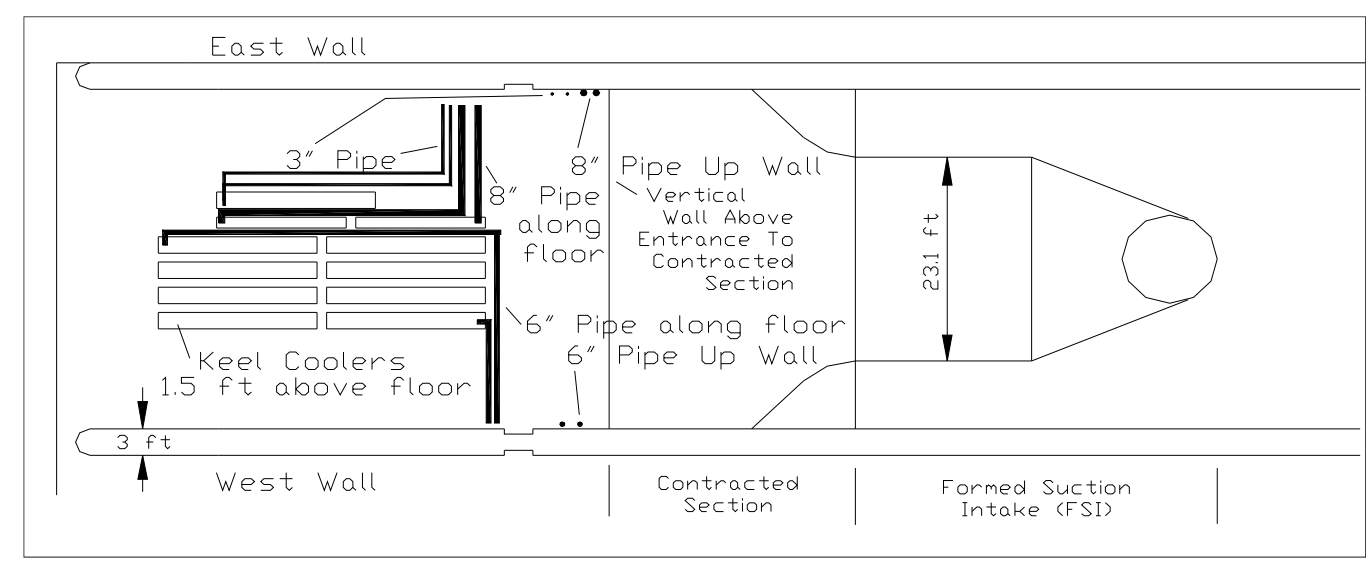

Figure 76. Layout of floor coolers and piping along floor and up walls.

Tests were conducted in the pump intake model with the keel coolers located as shown in Figure 76. The model coolers and the 6-in. vertical pipes on the west dividing wall are shown in Figure 77. Tests of the effects of the keel coolers on intake performance were conducted with the FSI and contracted section on Pump 12. Swirl was measured and was less than 1.0 degree for intake EL 2.0 and pump operating combinations of 12 only, 12 and 13 , and 11 through 13 . Since the velocity distribution met HI standards with 50 percent blockage in the trash rack tests, velocity distributions at the top of the FSI were not measured. The primary concern was surface vortices. 


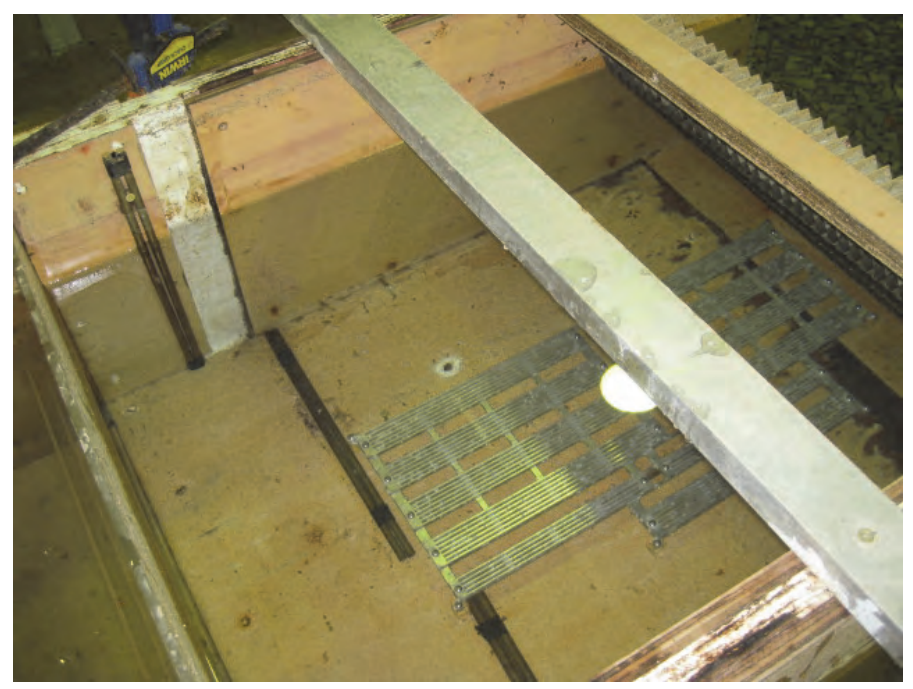

Figure 77. Keel coolers and pipes on floor of pump intake model and 6-in. diameter vertical pipes on west wall.

Note in Figure 77 that the vertical pipes going up the divider walls were positioned in the 8-ft space between the downstream end of the gate slot and the vertical wall above the entrance to the contracted section. Tests were conducted at an intake EL 2.0 with pump operating combinations of 12 only, 12 and 13, 11 and 12, and 11 through 13 . All combinations resulted in greater frequency of dye-core vortices extending halfway into the contracted section. Without the vertical pipes, dye-core vortices extending halfway through the contracted section were much less frequent than 10 percent. With the vertical pipes and Pumps 11-13 operating, dye-core vortices extending halfway through the contracted section that formed downstream of the 6-in. pipes on the west wall occurred more than 10 percent of the time. It is recommended that the vertical wall pipes be moved upstream of the gates as far as possible from the entrance to the contracted section. Testing of alternate locations of the vertical pipes was not pursued because the keel coolers are proposed to be placed inside the Flowerpot Discharge Outlet. 


\section{Summary and Conclusions}

- The WCC pump station intake was evaluated for intake performance using a 1:20-scale model of the approach channel, intake bays, contracted section, FSI, and pump column. The pump station initially consisted of 16 pumps at $1250 \mathrm{cfs}$ per pump. The final design consisted of 11 pumps at 1,740 cfs per pump. The WCC pump station has a unique feature called a "contracted section" that is located immediately upstream of the FSI. An FSI improves pump intake conditions by gradually contracting the flow approaching the pump impeller. The contracted section is an additional contraction of the flow upstream of the FSI.

- Across the 11 different pump intakes, approach flow ranged from almost straight in to highly skewed. With all pumps operating, flow was almost straight in for pumps on the east side of the pump station and highly skewed for pumps near the west side. With less than all pumps operating, individual pumps had straight in approach flow for one pump operating condition and the same pump had highly skewed flow for a different set of pumps operating.

- The WCC had a flow divider wall between the pump station and the sector gates. The flow divider wall limited cross flow at the pump intakes when the sector gates are closed during storm surge conditions and limits cross flow that could adversely affect navigation when the sector gates are open under normal conditions. Testing showed that a flow divider wall was not needed on the east side of the pump station between the pump station and the sluice gates. A numerical model was used to evaluate different flow divider wall lengths between the sector gates and the pump station. Based on numerical model results, initial testing in the physical model was conducted with a 300-ft long flow divider wall. Testing in the physical model and a separate navigation model resulted in the elimination of the flow divider wall.

- The original design of the contracted section was shown to have unacceptable submerged vortices. A fillet (Figure 3) was added to eliminate a zone of low velocity and the submerged vortices were eliminated.

- Two lengths of the walls between the pump bays (referred to as dividing walls) were tested in the model and both met HI standards for 
swirl, vortices, and velocity distribution. The longer dividing walls were used to accommodate the selected trash rack cleaning rake.

- The recommended design consists of no flow divider wall, longer dividing walls, and contracted section with fillet added to low velocity zone. Tests were conducted with various pump operating combinations ranging from all pumps to single pumps to pumps on each end to odd versus even pumps. Tests were conducted for a range of approach flow skew ranging from large to straight in. Intake water level was varied from the minimum of EL 0 to the maximum of EL 7. Swirl in the pump intake was always less than the HI Standard of five degrees and was a maximum of three degrees when 50 percent of the trash rack on one side of the pump bay was completely blocked. Submerged vortices were acceptable with the fillet added to the contracted section. Time averaged velocity distribution in the pump throat met the HI Standard of \pm 10 percent for all conditions including tests with 50 percent of the trash rack blocked on one side of the pump bay. Most measured velocity distributions met and all but the trash rack blockage tests were within 1.0 percent of meeting the more stringent velocity distribution requirement of \pm five percent used in some pump intake studies. Testing showed that the combination of the contracted section and the FSI were effective in limiting swirl and producing an acceptable velocity for highly skewed approach flow conditions.

- Velocity fluctuations in the pump throat were measured with a Pitot tube connected to a differential pressure cell. No points of excessive velocity fluctuation were found at the 17 points measured in the pump intake. Although some dampening of velocity fluctuation was present, fluctuations equal to the standard deviation divided by the timeaveraged velocity were a maximum of 4.2 percent, which was less than one-half of the HI standard of 10 percent.

- Achieving acceptable surface vortices was one of the primary concerns of this study because past studies with only an FSI using relatively low submergence had resulted in surface vortices. Several past studies of large pumps with an FSI had shown the need for vortex suppressor beams just upstream of the entrance of the FSI. Based on HI standards, coherent dye-cores "entering the pump" are acceptable only if they occur less than 10 percent of the time. Unlike a pump fitted with a suction bell, the WCC pumps had an FSI and contracted section upstream of the pump impeller and "entering the pump" had to be defined. In this study, a coherent dye-core vortex was considered to have entered the pump if it made it halfway through the contracted 
section. For all combinations of pumps operating and various designs of flow divider wall length and dividing wall length, the following surface vortex trends were present:

o Coherent dye-cores formed just upstream of the contracted section. The total time the dye-core was present was almost always less than 10 percent of the total observation time. For some water levels and pump operating conditions, the coherent dye-cores never formed upstream of the contracted section.

- A small percentage of the coherent dye-cores upstream of the contracted section made it past the roof curve and into the contracted section. The percentage was much less than 10 percent.

o An even smaller percentage of the coherent dye-cores upstream of the contracted section made it to a point halfway through the contracted section. The percentage was much less than 10 percent.

o Only one test, with a flow divider wall on the east side of the pump station that was not recommended, resulted in a coherent dye-core extending to the 90 degree bend of the FSI.

o Based on these tests, an FSI with a contracted section resulted in acceptable surface vortices.

- Tests were conducted to evaluate radiator devices called keel coolers placed in the region between the trash rack and the bulkhead gates. Part of the keel cooler design included 6- or 8-inch diameter pipes running vertically against the dividing wall between the bulkhead gate and the contracted section. These pipes resulted in surface vortices that that were much greater than the surface vortex trends for all other tests. It was recommended that the pipes be moved upstream of the bulkhead gates to prevent unacceptable surface vortices. 


\section{References}

Fletcher, B.F. 1990. Yazoo Backwater Pumping Station Sump, West-Central Mississippi. US Army Corps of Engineers Waterways Experiment Station, Technical Report HL-90-8, Vicksburg, MS.

Fletcher, B.P. 1991. St. J ohns Bayou Pumping Station, Missouri. US Army Corps of Engineers Waterways Experiment Station, Technical Report HL-91-3, Vicksburg, MS.

Fletcher, B.P. 1994. Cypress Avenue Pumping Station. US Army Corps of Engineers Waterways Experiment Station, Technical Report HL-94-9, Vicksburg, MS.

Hydraulic Institute. 1998. American National Standard for Pump Intake Design. ANSI/HI 9.8-1998, NewJ ersey.

Kirkpatrick, T.L. and B.P. Fletcher. 1991. Alton Pumping Station, Alton, Illinois. US Army Corps of Engineers Waterways Experiment Station, Technical Report HL-91-9, Vicksburg, MS.

Leech, J.R. 1989. New Madrid Pumping Station, gravity flow conduit and confluence, New Madrid Floodway, Missouri. US Army Corps of Engineers Waterways Experiment Station, Technical Report HL-90-12, Vicksburg, MS.

Lehr, V., D.E. Werth, T.C. Demlow, R.E. Cornman. 1999. Optimizing the Design of a Formed Suction Intake for Large Flood Relief Pumps. 1999 International Water Resources Engineering Conference, EWRI.

Maynord, S.T. 2013. Physical Model Study of Flowerpot Discharge Outlet, West Closure Complex, New Orleans, LA. ERDC-CHL Technical Report_-_, Vicksburg, MS.

McCollum, R. (in prep). Navigation Model for West Closure Complex. US Army Engineer Research and Development Center, Vicksburg, MS.

Nakato, T. 2000. An Attempt to Clarify Acceptable Pump-Throat Velocity-Distribution Criteria in Pump-Intake Model Studies. ASCE 2000 J oint Conference on Water Resources Engineering and Water Resources Planning and Management, Minneapolis.

Papworth, M. 1972. The effects of screens on flow characteristics. BHRA TN 1198.

Sweeney, C.E. and G.E. Rockwell. 1982. Pump Sump Design Acceptance Through Hydraulic Model Testing. IAHR 11th Symposium on Operating Problems of Pump Stations and Powerplants, Amsterdam.

Werth, D.E. and T.C. Demlow. 1998.South Florida Water Management District Hydraulic Model Study. Conducted by ENSR Consulting and Engineering for IngersollDresser Pump Company. 
Werth, D.E. and T.C. Demlow. 1999. Station S-319 550 cfs \& 960 cfs Hydraulic Sump Modeling. Conducted by ENSR Consulting and Engineering for Ingersoll-Dresser Pump Company and US Army Corps of Engineers, J acksonville District.

Werth, D.E. and T.C. Demlow. 2000. Station S-362 550 cfs \& 960 cfs Hydraulic Sump Modeling. Conducted by ENSR Consulting and Engineering for Ingersoll-Dresser Pump Company and US Army Corps of Engineers, J acksonville District. 


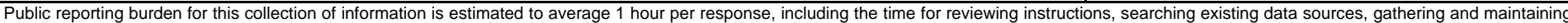

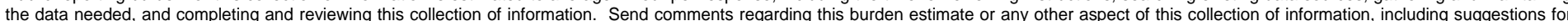

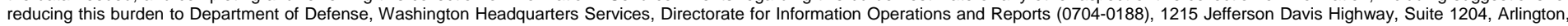

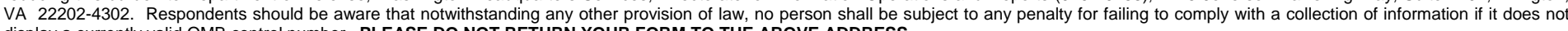
display a currently valid OMB control number. PLEASE DO NOT RETURN YOUR FORM TO THE ABOVE ADDRESS.
1. REPORT DATE (DD-MM-YYYY) 2. REPORT TYPE
February 2013 Final
3. DATES COVERED (From - To)

\section{TITLE AND SUBTITLE}

5a. CONTRACT NUMBER

West Closure Complex Pump Intake Model, New Orleans, Louisiana

5b. GRANT NUMBER

5c. PROGRAM ELEMENT NUMBER

\section{AUTHOR(S)}

Stephen T. Maynord

5d. PROJECT NUMBER

5e. TASK NUMBER

5f. WORK UNIT NUMBER

\section{PERFORMING ORGANIZATION NAME(S) AND ADDRESS(ES)}

\section{PERFORMING ORGANIZATION REPORT} NUMBER

Coastal and Hydraulics Laboratory

U.S. Army Engineer Research and Development Center

ERDC/EL TR-13-1

3909 Halls Ferry Road

Vicksburg, MS 39180-6199

\section{SPONSORING / MONITORING AGENCY NAME(S) AND ADDRESS(ES)}

10. SPONSOR/MONITOR'S ACRONYM(S)

\section{U.S. Army Corps of Engineers}

Washington, DC 20314-1000

11. SPONSOR/MONITOR'S REPORT NUMBER(S)

\section{DISTRIBUTION I AVAILABILITY STATEMENT}

Approved for public release; distribution is unlimited.

\section{SUPPLEMENTARY NOTES}

\section{ABSTRACT}

The WCC pump station intake was evaluated for intake performance using a 1:20-scale model of the approach channel, intake bays, contracted section, FSI, and pump column. Across the 11 different pump intakes, approach flow ranged from almost straight in to highly skewed. The original design of the contracted section was shown to have unacceptable submerged vortices. A fillet was added to eliminate a zone of low velocity and the submerged vortices were eliminated.

The recommended design consists of no flow divider wall, longer dividing walls, and contracted sections with fillet added to low velocity zone. Tests were conducted with various pump operating combinations ranging from all pumps to single pumps to pumps on each end to odd versus even pumps. Tests were conducted for a range of approach flow skew ranging from large to straight in. Intake water level was varied from the minimum of EL 0.0 to the maximum of EL 7.0. Swirl in the pump intake was always less than the HI Standard of five degrees and was a maximum of three degrees when 50 percent of the trash rack on one side of the pump bay was completely blocked. Submerged vortices were acceptable with the fillet added to the contracted section. Time averaged velocity distribution in the pump throat met the HI Standard of \pm 10 percent for all conditions including tests with 50 percent of the trash rack blocked on one side of the pump bay. Most measured velocity distributions met, and all but the trash rack blockage tests were within 1.0 percent of meeting, the more stringent velocity distribution requirement of \pm five percent used in some pump intake studies. Testing showed that the combination of the contracted section and the FSI were effective in limiting swirl and producing an acceptable velocity for highly skewed approach flow conditions.

\begin{tabular}{lll}
\hline 15. SUBJECT TERMS & Physical model & Pumping stations \\
Formed suction intake & Pump intake vortices & West Closure Complex
\end{tabular}

HI standards $\quad$ Pump performance

16. SECURITY CLASSIFICATION OF:

\begin{tabular}{|l|c|c|}
\hline a. REPORT & b. ABSTRACT & c. THIS PAGE \\
UNCLASSIFIED & UNCLASSIFIED & UNCLASSIFIED
\end{tabular}

17. LIMITATION OF ABSTRACT

18. NUMBER
OF PAGES
92

19a. NAME OF RESPONSIBLE PERSON

19b. TELEPHONE NUMBER (include area code) 